UNIVERSIDAD POLITÉCNICA DE VALENCIA DEPARTAMENTO DE BIOTECNOLOGIA INSTITUTO DE TECNOLOGÍA QUÍMICA (U.P.V.- C.S.I.C.)
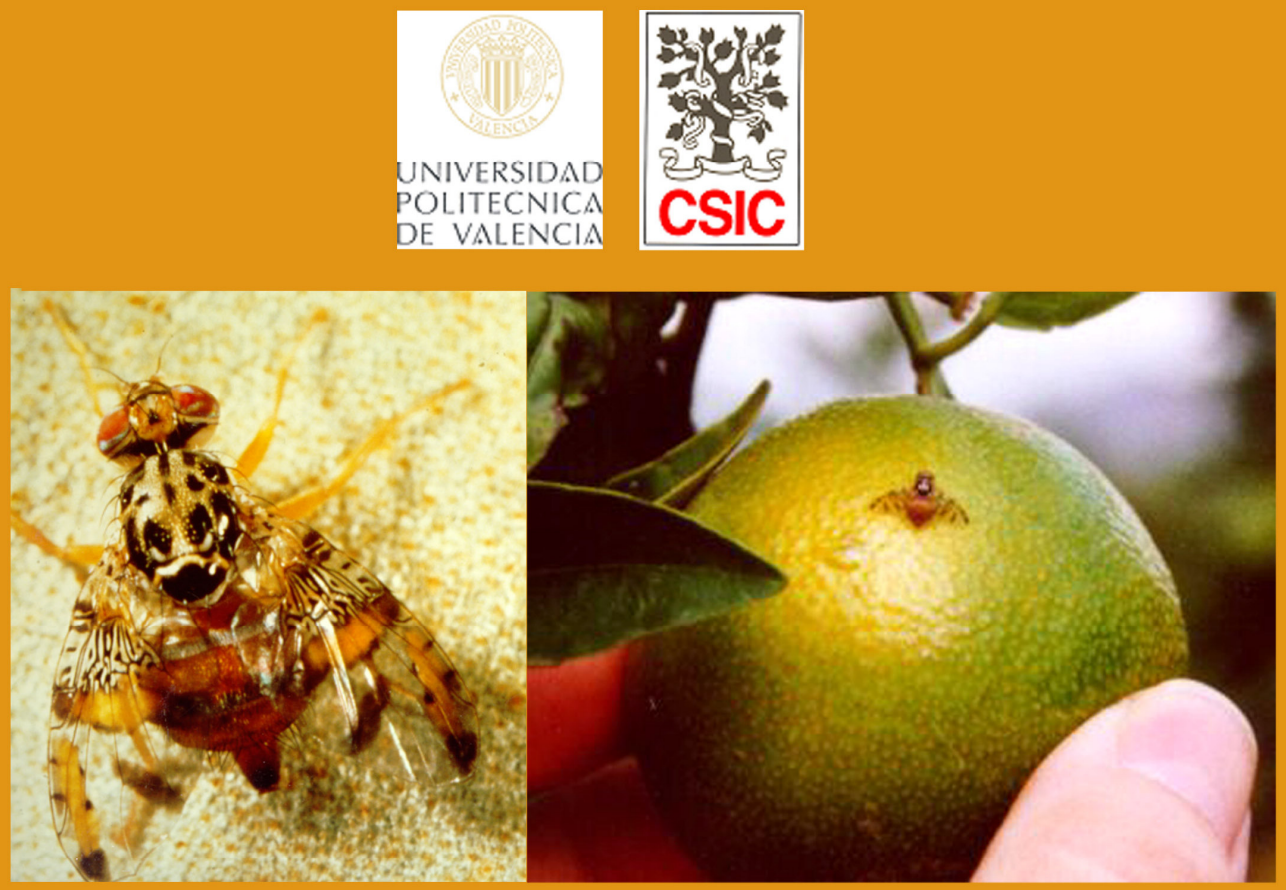

NUEVOS MÉTODOS DE LUCHA

CONTRA Ceratitis capitata (Wiedemann)

BASAdOS EN LA APLICACIÓN DE CEBOS ATRAYENTES COMBINADOS CON UN IGR ESTERILIZANTE

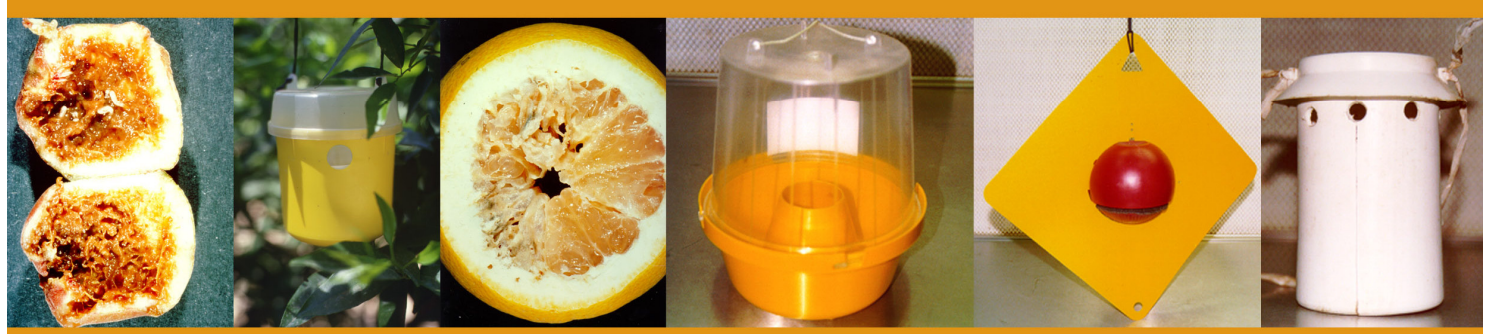

Presentada por: Vicente Navarro Llopis Dirigida por: Eduardo PrimoYúfera Valencia, diciembrede 2001 


\section{NUEVOS MÉTODOS DE LUCHA CONTRA Ceratitis capitata (WIEDEMANN) \\ BASADOS EN LA APLICACIÓN DE CEBOS ATRAYENTES COMBINADOS CON UN IGR ESTERILIZANTE}

\section{INTRODUCCIÓN GENERAL}

La mosca de la fruta Ceratitis capitata (Wiedemann) es una de las plagas que provoca mayores pérdidas económicas en la agricultura Mediterránea (Moner et al., 1988). A nivel mundial, se conocen más de 350 especies, pertenecientes a 67 familias diferentes, que se ven atacadas por ella (Liquido et al., 1991). Las zonas más afectadas por esta plaga se encuentran en latitudes templadas y tropicales, donde las temperaturas invernales, durante el día, raramente descienden de los $10^{\circ} \mathrm{C}$.

En el litoral levantino español se ha observado la presencia continua de mosca adulta durante todo el año, aunque las capturas durante los meses de enero y febrero son casi nulas. Cuando la temperatura durante el día supera los $14^{\circ} \mathrm{C}$ la actividad de las moscas aumenta y comienzan a buscar huéspedes donde depositar sus huevos. Las primeras generaciones de mosca, tras el invierno, ponen sus huevos en variedades tardías de cítricos como la variedad Valencia-Late. Los albaricoques, nísperos y primeros melocotones de la temporada dan la continuidad necesaria de huéspedes. El final de la primavera y comienzo del verano ofrecen a $C$. capitata una gran diversidad de frutos como ciruelos, higos, melocotones de temporada, peras, manzanas, etc. En el mes de agosto, la mosca de la fruta suele sufrir un descenso poblacional acusado provocado por los vientos cálidos y secos de poniente que alcanzan temperaturas de más de $34^{\circ} \mathrm{C}$. A final de agosto, los primeros cítricos, y en especial mandarinas tempranas como Marisol u Okitsu, comienzan a ser receptivas al ataque de la mosca de la fruta. A 
partir del mes de septiembre y hasta finales de noviembre, las clementinas y primeras variedades de naranjas como la Navelina son los últimos huéspedes de la mosca antes de comenzar un nuevo ciclo anual.

\section{Revisión histórica:}

La mosca del Mediterráneo fue descrita en 1824 por Wiedemann como Trypeta capitata. El nombre del género "Trypeta" derivaba de los hábitos de la mosca en la oviposición y la alimentación de las larvas, mientras que la especie se nombró "capitata" por las terminaciones en forma romboidal de las antenas de los machos, como menciona Wiedemann en 1830 "...fronte eminentis duabus setam apice lamella rhomboidali munitam gerentibus...". La mosca de la fruta recibió su actual nombre de género "Ceratitis" (del griego cuerno, antena) de Mac Leay (1829), basándose de nuevo en las llamativas proyecciones frontales del macho. Como conclusión, tanto el nombre del género (del griego), como el de la especie (del latín) se refieren a la misma característica externa del macho.

El método de lucha que se planteó a comienzos de siglo, para combatir la mosca de la fruta fue el control biológico clásico. En 1902, George Compere dirigió el primer programa de control biológico clásico para el gobierno de Australia Oeste, pero ninguna de las especies introducidas se estableció, provocando un fracaso rotundo. Fue Filippo Silvestri quien en 1913 crió 16 especies de parasitoides de Tephritidos, de los cuales se establecieron 3 en Hawaii también con poca repercusión. Un año más tarde David Fullaway introdujo dos nuevas especies en lo que se consideró el primer éxito relativo del control biológico en Ceratitis capitata. El éxito inicial de Psyttalia humilis (Silvestri) fue ensombrecido por los buenos resultados obtenidos por Diachasmimorpha tryoni (Cameron). 
A este éxito en Hawaii, le siguieron la introducción de siete parasitoides, en 15 países, en los siguientes 70 años. Los resultados de estas nuevas introducciones fueron negativos, ya que sólo se consiguió el establecimiento de Tetrastichus giffardianus Silvestri en Brasil, Fiji y España, con un pobre control de la plaga.

El comportamiento durante el cortejo de la mosca de la fruta fue descrito por Martelli en 1910, aunque fue en 1959 y 1962 cuando Féron lo describió con detalle. Prokopy y Hendrichs en 1979 dieron una explicación al comportamiento durante el cortejo de la mosca de la fruta (Wharton R.A., 1987).

\section{Biología:}

Ceratitis capitata (Wiedemann) se clasifica del siguiente modo (Chinery, 1988):

- CLASE: Insecta

- ORDEN :Diptera

- SUBORDEN: Cyclorrhapha

- SUPERFAMILIA: Schizophora

- SERIE: Acaliptrata

- FAMILIA: Tephritidae

- SUBFAMILIA: Trypetinae

- TRIBU: Trypetini

- GENERO: Ceratitis

- ESPECIE: capitata

C. capitata es un insecto holometábolo originario de Africa. Sus fases de desarrollo biológico son: huevo, larva, pupa y adulto.

La hembra adulta pone sus huevos en frutos maduros de donde, si las condiciones de temperatura son favorables (más de $10^{\circ} \mathrm{C}$ ), emergen las larvas en dos días. 
Las larvas recién emergidas son de color blanco de apenas $2 \mathrm{~mm}$ de longitud. Durante su desarrollo realizan tres mudas, durante las cuales van aumentando de tamaño hasta los $8 \mathrm{~mm}$. Las larvas son ápodas y tardan en alcanzar su madurez de 8 a 10 días según la temperatura, tras los cuales se abren camino hacia el exterior del fruto. Por lo general, los frutos picados sobremaduran y caen al suelo, lo que facilita a las larvas alcanzar su destino. Mediante movimientos vermiculares y saltos de hasta $15 \mathrm{~cm}$ de altura buscan con la cabeza un lugar en el suelo donde penetran y pupan.

La pupa, de forma elipsoidal y segmentada, tiene aproximadamente $5 \mathrm{~mm}$ de longitud. Es la forma más resistente de las diferentes fases de desarrollo de la mosca, por lo que pueden pasar los meses de invierno sin emerger hasta que las condiciones climáticas vuelven a ser adecuadas. La protección que le da el suelo a la pupa, amortiguando las temperaturas exteriores y protegiéndola de gran número de depredadores naturales, hace de éste el estadío más adecuado para permanecer latente hasta que las condiciones vuelvan a ser favorables.

Los adultos emergen de la pupa y tardan aproximadamente 3 días en ser activos sexualmente. Existe dimorfismo sexual, marcado por el oviscapto prominente de las hembras y la terminación romboidal de las antenas de los machos. Los machos alcanzan los $5 \mathrm{~mm}$ de longitud, aunque las hembras suelen ser ligeramente más grandes. Ambos poseen alas vistosas de tonos anaranjados que se insertan en un tórax oscuro punteado en negro. La terminación del abdomen de las hembras es puntiaguda, de donde extraen el oviscapto a modo de estilete para atravesar la piel de los frutos. La hembra se sitúa encima del fruto y pasea por encima de él y sirviéndose de su oviscapto busca un lugar, donde atravesar la piel, libre de glándulas o secreciones del fruto. Tras un movimiento en el que dobla el oviscapto, introduce un huevo. Este movimiento se repite cada vez como si de cargar una bala en el fusil se tratara. En cada puesta una hembra suele 
colocar 6 ó 7 huevos aunque se han observado puestas de más de 35 huevos. Finalizada la puesta, la hembra vuelve a pasear por el huésped y libera una sustancia que, en lo sucesivo, repelerá la puesta de otras moscas. Unicamente en el caso de que escaseen otros frutos en los que picar, se observan varias picadas en la misma pieza.

\section{Métodos de lucha}

\section{$\underline{\text { El control biológico }}$}

Los primeros métodos de lucha desarrollados para combatir la mosca de la fruta se basaban en el control biológico clásico. A lo largo de la historia se han descubierto multitud de especies que actúan como enemigos naturales, aunque sólo unos pocos llegaron a establecerse. Entre ellos encontramos a: Aceratoneuromyia indica (Silvestri), Biosteres arisanus (Sonan), Biosteres fullawayi (Silvestri), Biosteres vandenboschi (Fullaway), Diachasmimorpha longicaudata (Ashmead), Diachasmimorpha tryoni (Cameron), Dirhinus giffardii Silvestri, Pachycrepoideus vindemiae (Rondani), Psyttalia incisi (Silvestri), Spalangia endius Walker, Spalangia sp. y Tetrastichus giffardianus Silvestri. Pachycrepoideus vindemiae y Spalangia endius son polífagos parasitoides de pupas que sólo ocasionalmente atacan a tephritidos.

En todo caso, si bien el control biológico disminuye las poblaciones naturales de mosca, en ningún caso han sido capaces de mantener la población de Ceratitis capitata por debajo de los umbrales de daño tolerables. La contribución de los parásitos y depredadores al control de la mosca de la fruta es difícilmente valorable, aunque existen varias estimaciones de su capacidad en disminuir la población. Por ejemplo, se estima que, en Guatemala, un $25 \%$ de las larvas de mosca que caen al suelo son atacadas por Solenopsis germinata (hormiga de fuego) (Eskafi et al., 1990). 
Las pupas son susceptibles al ataque de otros insectos. En el caso de Guatemala, la acción depredadora la lleva a cabo el escarabajo Staphylinido (Eskafi et al., 1990), aunque su poca especificidad en la búsqueda de presas lo convierten en un depredador poco útil en el control biológico clásico (Clausen et al., 1965).

\section{Tratamientos Químicos}

Actualmente, sobretodo a nivel institucional, para mantener las poblaciones en niveles bajos se realizan tratamientos con malation acompañado de un cebo proteico en tratamientos aéreos y terrestres.

Los tratamientos aéreos se realizan mediante avionetas que sobrevuelan los campos cuando la población de mosca es alta y la fruta está receptiva. Estos tratamientos se repiten, de dos a cuatro veces, según campañas, aplicando malation $(50 \% \mathrm{p} / \mathrm{v})+$ cebo $(30 \%$ de proteínas hidrolizadas) $(1,5 \%: 1,5 \% \mathrm{p} / \mathrm{v})$ a ultrabaja dosis $(8$ 1. de caldo/Ha.) en bandas de 20 metros separadas 50 metros entre sí.

Los tratamientos terrestres se realizan por pulverización, con gota gruesa, en una superficie de 1 a 2 metros cuadrados en la cara sur de los árboles. Los tratamientos los realizan los propios agricultores, cuando la fruta comienza a estar receptiva, con productos subvencionados por la "Conselleria d'Agricultura, Pesca i Alimentació" de la Generalitat Valenciana. Los tratamientos se realizan cada 7-10 días, a partir del momento en que la fruta está receptiva hasta la recolección, lo que puede suponer de 3 a 6 tratamientos por campaña. El gasto por árbol es de 200 a $300 \mathrm{ml}$ dependiendo de su tamaño, lo que supone 75 litros de caldo por hectárea. En el caldo se incluye un cebo proteico al $1 \%$ y malation $(50 \% \mathrm{p} / \mathrm{v})$ al $0,5 \%$.

Ante niveles altos de población de mosca, cuando hay fruta receptiva, el único tratamiento que reduce el número de picadas es el de malation en árbol completo sin 
cebo, ya que la fruta supone una mayor atracción para la mosca que los cebos proteicos empleados en pulverización.

Los tratamientos químicos, utilizando organofosforados como el malation, tienen dos inconvenientes: por un lado la mala aceptación por la sociedad actual de la utilización de insecticidas organofosforados. Por otro lado, la aplicación de organofosforados de forma total $\mathrm{y}$ continua para proteger la fruta, provoca desequilibrios derivados de la muerte de depredadores y parásitos naturales.

\section{$\underline{\text { Trampeo masivo }}$}

Otra alternativa clásica para reducir la población es la colocación de trampas McPhail (Newell 1936; McPhail 1939) con atrayentes proteicos y azúcares fermentados (Gurney 1925). Este método ha evolucionado hacia la utilización de trampas más ligeras y manejables como son los actuales mosqueros McPhail de plástico, las trampas Nadel, las trampas cromáticas (Harris et al, 1971), la trampa Steiner, la trampa Jackson, las Tephri Trap ${ }^{\circledR}$, o las Frutec ${ }^{\circledR}$.

Las clásicas trampas McPhail son mosqueros de cristal de planta circular, invaginados en su parte inferior, en los que se coloca un atrayente líquido para atraer a las moscas. El atrayente utilizado suele ser de naturaleza proteica aunque también se utilizan sales amoniacales, urea o residuos animales. Estos mosqueros resultaban pesados y difíciles de manejar por la fragilidad del cristal, aunque tenían como ventaja el ser reciclables, limpios e inertes.

Los actuales mosqueros McPhail se componen de dos partes, una base de color amarillo de plástico opaco y una tapa trasparente. Suelen ser de mayor tamaño que los 
mosqueros de cristal lo que resulta de gran utilidad cuando las capturas son elevadas. Son ligeros, fácilmente transportables y, al ser desmontables, de fácil limpieza y colocación. Actualmente también se utilizan con paraferomonas e insecticidas en pastillas, en lo que se ha dado a conocer como "trampas secas", de más fácil manejo y limpieza. Foto 1.

Las trampas Nadel son mosqueros de forma cilíndrica con una tapa en forma de tejadillo. En la parte superior del cilindro, protegidas por el tejadillo, se encuentran 8 aperturas de $1 \mathrm{~cm}$. de diámetro por donde entran las moscas. En el interior de la trampa se coloca un atrayente y DDVP que mata a las moscas atraídas. Son mosqueros de plástico de fácil manejo y bajo costo que resultan eficaces en las redes de vigilancia y control de población. Foto 2.

Las trampas cromáticas son láminas de plástico de forma rectangular a las que se les impregna un adhesivo. Las moscas se ven atraídas por el color de la trampa (amarilla) y se posan sobre ella quedando atrapadas por el pegamento. En algunas ocasiones, en la base de la placa se coloca un atrayente alimentario o una paraferomona que aumente la atracción. Estas trampas resultan baratas y vistosas a los ojos de los agricultores, pero a la vez son engorrosas en su manejo y reposición. Otro inconveniente es que no son prácticas cuando la población de mosca es elevada, ya que la placa se llena de moscas y deja de capturar.

Las trampas Jackson (o trampas delta) también son adhesivas, pero en este caso la placa adhesiva se introduce en una trampa triangular en el que la base es una lámina pegajosa. Los dos catetos del triángulo constituyen una protección a modo de tejado que 
evita que la superficie adherente se moje y se ensucie. En estas trampas se suele utilizar una paraferomona como atrayente aunque realmente funciona con todo tipo de atrayentes.

La trampa Jackson, al igual que las cromáticas tienen el problema de saturarse de moscas si la población es muy alta, aunque resultan más manejables. Foto 3.
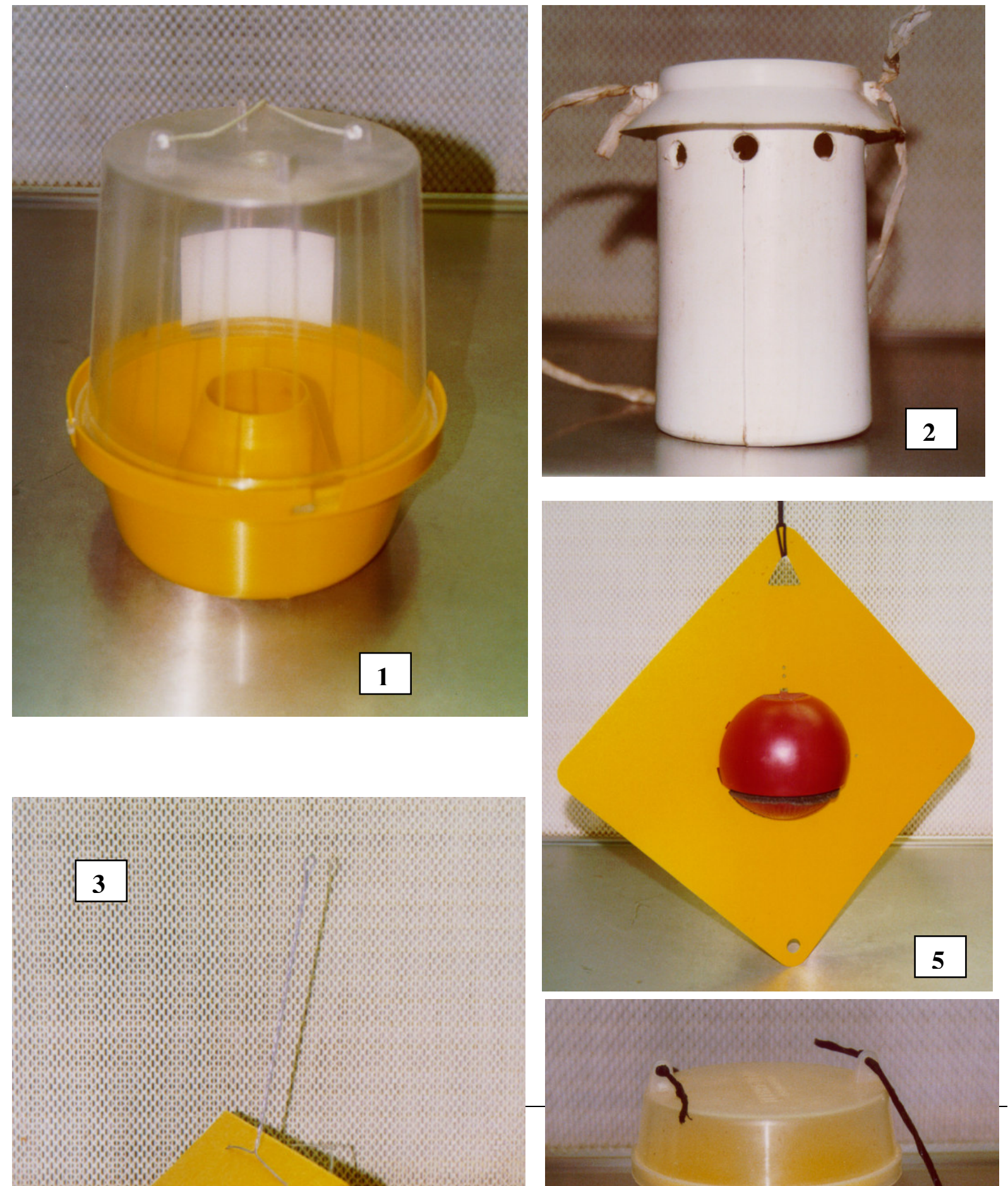
Los mosqueros Tephri-Trap son en realidad mosqueros McPhail modificados en los que se ha practicado cuatro agujeros de $2 \mathrm{~cm}$ de diámetro en la parte superior del cilindro que forma el cuerpo de la trampa, pero que también conservan la invaginación inferior del cilindro. Es decir, son una combinación de mosqueros McPhail y mosqueros Nadel. La tapa de estos mosqueros es traslúcida, lo que favorece que las moscas permanezcan en el interior de la trampa el tiempo necesario para que el DDVP produzca su efecto letal. En estas trampas se suele utilizar una mezcla de tres atrayentes sintéticos en emisores de membrana: trimetilamina, putrescina y acetato amónico (BioLure, Consep, Bend, OR, EEUU) y una pastilla de DDVP para matar a las moscas que entren en la trampa. Foto 4.

Esta trampa resulta muy fácil de manejar y limpiar, además de capturar un número elevado de hembras. El inconveniente de la misma es el alto coste de los atrayentes a utilizar, ya que si bien los productos químicos de base son baratos, los emisores comerciales que hay disponibles tienen precios abusivos.

Las trampas Frutec $^{\circledR}$ están formadas por un difusor que contiene un hidrolizado de proteínas que se incrusta en el centro de una placa adhesiva de color amarillo. El difusor es una esfera de unos $8 \mathrm{~cm}$ de diámetro en la que se introduce un hidrolizado de proteínas. A través de una membrana que recorre el ecuador de la esfera se emiten los aromas atrayentes. En una parte de las trampas (en el 20\%) se coloca un difusor con trimedlure (Beroza et al, 1961) para aumentar la captura de machos. Foto 5.

Como en las trampas cromáticas, su manejo es engorroso, y el número de capturas está limitado por la superficie de la placa. 
La densidad de trampas Tephri-Trap ${ }^{\circledR}$ y Frutec $^{\circledR}$ a colocar oscila de 40 a 50 trampas por hectárea, lo que supone, actualmente un gasto mínimo de 420 euros por hectárea.

Las capturas masivas de mosca mediante trampas con atrayentes, si bien, en algunos casos, reducen la población por debajo del umbral de tratamiento, tienen una eficacia muy limitada en áreas con poblaciones naturales de mosca medias y elevadas.

En cualquier caso, la mayoría de los fabricantes de estas trampas recomiendan la aplicación de organofosforados para proteger la fruta cuando está receptiva.

\section{Búsqueda de un nuevo método de lucha}

Ante esta situación, surge la necesidad de desarrollar nuevos métodos para controlar la mosca de la fruta de forma más eficaz, económica y ecológica que las alternativas existentes. En este proyecto se exponen los primeros ensayos para buscar un nuevo método de control, basado en la autoesterilización de la mosca de la fruta mediante un inhibidor del desarrollo de los insectos (IGR).

Anteriormente, se había observado que el diflubenzuron, añadido a la dieta de las moscas en un $0,3 \%$ p/p, provocaba malformaciones e inhibía la oviposición de Ceratitis capitata (Sarasua y Santiago, 1983). También se observó que, cuando se añadía ciromazina al agua de bebida de las moscas criadas en insectario durante 12 días, a una concentración del $1 \%$ p/v, se reducía la producción de huevos y la fertilidad de los mismos (Budia y Viñuela, 1996; Jiménez-Peydro et al, 1995).

Sobre otros Tephritidos como Batrocera oleae Gmelin (Fytizas, 1976) o Rhagoletis pomonella Walsh (Duan et al., 1995) también se ha comprobado que algunos 
IGRs disminuyen el porcentaje de eclosión y la producción de huevos (Langley and Hall, 1986).

El IGR: (RS) - 1 - [ 2, 5 - dicloro - 4 - (1,1,2,3,3,3-hexafluoropropoxi) fenil - 3 - ( 2, 6 -difluorobenzoil) urea, (lufenuron), cuando se añade a la dieta de Ceratitis capitata, a una concentración del 0,5\%, impide la eclosión de los huevos que pone (Casaña et al, 1999). La esterilización es efectiva tanto en machos como en hembras, aunque no de forma permanente en los machos.

Figura 1. Estructura química del lufenuron.<smiles>CC(F)(F)C#COc1cc(Cl)c(NC(=O)NC(=O)c2c(F)cccc2F)cc1Cl</smiles>

Con este último descubrimiento se plantea una estrategia de lucha que, basada en los nuevos atrayentes y la actividad del lufenuron, sea capaz de controlar esta plaga tan devastadora. 


\section{OBJETIVOS Y PLAN DE TRABAJO.}

La presente Tesis Doctoral se compone de tres partes:

En la Parte I se desarrolla una formulación adecuada del IGR con poder fagoestimulante. Esta formulación debe cumplir una serie de propiedades como son: alto poder de atracción, permanecer activo en el campo durante un largo período, tanto en su poder atrayente como en la actividad esterilizante y que sea fácil de manejar o aplicar.

En el laboratorio y en ensayos de campo, se realizan experiencias para encontrar la dosis efectiva de lufenuron y la duración de cada una de las formulaciones.

La Parte II trata de encontrar la mejor forma de aplicación en campo del lufenuron y hacer una estimación inicial de la eficacia del método. En esta parte se realizan ensayos de campo en pequeña escala y se establece una metodología de los ensayos. En estos ensayos se estudió la mejor forma de aplicar el producto y se eligieron los atrayentes adecuados para aumentar su eficacia.

La Parte III tiene como objetivo estimar la verdadera eficacia del método mediante un ensayo de campo en gran escala. En esta parte se estudian las dinámicas de población de mosca, el efecto de las aplicaciones, la influencia de factores climáticos y los distintos sistemas de trampeo y captura. 


\section{PARTE I}

ENSAYOS LABORATORIO. 


\section{I.1.- INTRODUCCIÓN}

El lufenuron es una fenilbenzoil urea inhibidora de la síntesis de quitina. Su efecto se produce por contacto, y, en mucho mayor grado, por ingestión. De aquí nace la necesidad de encontrar un cebo que, además de atraer a las moscas, resulte fagoestimulante. La opción más clara, en la búsqueda de este atrayente fagoestimulante, son los cebos proteicos ya que $C$. capitata precisa ingerir hidratos de carbono y proteínas durante su fase adulta. Además, se ha observado que las hembras de $C$. capitata aumentan su fertilidad y fecundidad con la ingesta de proteínas (Cangussu, J.A. and Zucoloto, F.S., 1995).

En esta primera parte de esta tesis doctoral, se han estudiado las diferentes formulaciones posibles del cebo, así como su forma de aplicación en campo. En primer lugar se estudió la formulación del cebo para su aplicación por pulverización, observando la duración del efecto esterilizante de las aplicaciones, la dosis óptima de lufenuron a emplear y la atracción de las moscas por el cebo. Los ensayos se realizaron aplicando gotas del producto sobre placas en laboratorio y posteriormente, en el campo, por pulverización sobre hojas de naranjo.

En segundo lugar se han desarrollado varios geles sólidos atrayentes. En estos geles se ha estudiado las concentraciones de gelificante, humectante y atrayente, adecuadas para conseguir un gel con las propiedades fisico-químicas óptimas. Una vez obtenido el gel se ha estudiado la disminución del efecto esterilizante con el envejecimiento, en laboratorio, en condiciones de campo. 


\section{I.2.- MATERIALES Y MÉTODOS, GENERALES.}

Las moscas, "Ceratitis capitata" (Wiedemann), se criaron en nuestro laboratorio con un fotoperíodo 16:8 (luz:oscuridad), a $28^{\circ} \mathrm{C}$ y $50 \%$ de H.R. Las moscas adultas se alimentaron con una mezcla de autolisado de levaduras y sacarosa en proporción 1:4 (p/p). Las larvas se alimentaron con una mezcla de salvado de trigo, levadura de cerveza, sacarosa, nipagín, nipasol, agua y ácido clorhídrico (20:5:1:0,5:0,5:10:0,1) en peso.

Los productos químicos utilizados en esta experiencia son: Corn Steep Liquor de Dadelos S.L. (Valencia, España), Jarabe de glucosa de Roquette Laisa España S.A. (Valencia, España), Sorbitol 70\% de Guinama (Valencia, España), Lufenuron Tech. $(99,1 \%)$ de Novartis (Basilea, Suiza), Match de Novartis (Barcelona, España), Emulsogen y FSCa de Agrevo España (Valencia, España), Aralure de Aragonesas Agro S.A. (España), Buminal de Bayer (Andernach, Alemania). La trimetilamina, putrescina y acetato amónico en emisores de BioLure Consep, (Bend, OR, EEUU). A la mezcla de acetato amónico (Panreac), trimetilamina añadida como cloruro de trimetilamonio (Acros) y putrescina (Aldrich) en proporción (10:10:1) la denominamos ATP. El trimedlure de AgriSense (Reino Unido).

\section{Composición base del cebo atrayente.}

El cebo base que utilizamos para la ingestión del lufenuron tiene la siguiente composición:

- Corn Steep Liquor (CSL) $60 \%$

- Meliosa 30\%

- Sorbitol $10 \%$ 
El CSL (Dadelos, Valencia, España) es un subproducto de la fabricación del almidón del maíz y constituye la fuente de proteínas del cebo (Hull et al, 1996). La meliosa (RoquetteLaisa, Valencia, España) es un jarabe de glucosa-fructosa (39\%:21\%) con un 76\% de materia seca, que aumenta la ingestión del cebo por las moscas. El Sorbitol (70\%, no cristalizable, Guinama, Valencia, España) tiene como finalidad mantener la humedad de los cebos sólidos y de ese modo mantenerlos apetecibles para las moscas. 


\section{I.3.- ENSAYOS CON CEBOS EN GOTAS.}

\section{I.3.1.- Introducción.}

Para poder aprovechar la capacidad quimioesterilizante del lufenuron, debemos desarrollar un método de aplicación barato y sencillo que a la vez atraiga y estimule la ingestión por las moscas. La alternativa más sencilla, para conseguir estos objetivos, es la pulverización de un cebo atrayente fagoestimulante, de naturaleza proteica, que lleve incorporado el lufenuron.

Para desarrollar estos atrayentes debemos encontrar una formulación adecuada para pulverización que nos dé la máxima atracción y sea activa durante el mayor tiempo posible. Para ello se realizan ensayos con gotas, sobre placas petri y sobre hojas, en los que se mide la esterilidad producida en las moscas en función de dos variables: la concentración de lufenuron y el tiempo de envejecimiento de los cebos.

Una vez conocida la concentración de lufenuron óptima según los ensayos de laboratorio, se realizan los ensayos de pérdida de actividad con el envejecimiento, en condiciones reales de campo, pulverizando el cebo sobre hojas de naranjo.

\section{I.3.2.- Materiales y métodos.}

Los componentes del cebo son los siguientes:

- Cebo completo

- Corn Steep Liquor (CSL) 60\%

- Meliosa $30 \%$

- Sorbitol $10 \%$

- Lufenuron

- Fenilsulfonato cálcico y Emulsogen (6:4)

- Agua 


\section{I.3.A.- Ensayos de laboratorio con gotas de cebo sobre placas. Envejecimiento.}

\section{I.3.A.1.- Materiales y métodos.}

El cebo, diluido en agua 1:30 (v:v), se pone en placas petri de $5 \mathrm{~cm}$ de diámetro en forma de gotas (150 gotas de $1 \mathrm{~mm}$ de diámetro sobre cada placa). Al cebo se le incorpora el lufenuron como Match (50 g de lufenuron/litro) al 0,5 , 0,75 y 1\% (peso lufenuron / volumen de cebo). El Match se refuerza con un emulgente para evitar los problemas de separación del lufenuron de la mezcla. El emulgente utilizado ha sido el fenilsulfonato cálcico más emulsogen EL (6:4) a razón de 50 g de emulgente por litro de Match.

Las placas se colocan a $30^{\circ} \mathrm{C}$ y $20 \%$ de $\mathrm{HR}$ y luz ambiente, y se recogen a los $0,6,12$ y 24 días.

Las placas con cebo se introducen en jaulas de metacrilato de 10x10x10 cm. con 5 hembras copuladas, y se mantienen durante tres horas con acceso al cebo tratado. Las moscas que se ensayan tienen 5 días de edad y han permanecido en ayunas durante 24 horas previas al ensayo.

A partir de las 24 horas de la ingestión y durante 1 día, se recogen los huevos que ponen las moscas en cubetas con agua. De estos huevos, 50 se siembran sobre gel de agar al $0,3 \%$ en peso. A los 3 días de la siembra se observa el porcentaje de emergencia de los huevos con ayuda de un binocular. Este proceso se repite a los 2, 4, 6, 8, 10 y 12 días de la ingestión.

Para cada tiempo de envejecimiento y cada concentración se realizan 3 ensayos, con moscas de generaciones diferentes. De cada ensayo se realizan 3 repeticiones en 3 jaulas independientes y se compara la eclosión frente a un blanco en el que la comida de las moscas no contiene lufenuron. 


\section{I.3.A.2.- Resultados y discusión.}

Con este ensayo se trata de observar cuanto dura la actividad atrayente-esterilizante del cebo aplicado por pulverización sobre placas. Los resultados de las experiencias se pueden observar en la Tabla I.1:

Tabla I.1.- Porcentaje de eclosión de huevos de moscas tratadas con cebos, en gotas sobre placas, envejecidos a diferentes tiempos, y con distintas concentraciones de lufenuron.

\begin{tabular}{|c|c|c|c|}
\hline \multicolumn{4}{|c|}{ \% de eclosión \pm E.S. } \\
\hline $\begin{array}{c}\text { Concentración de } \\
\text { lufenuron }\end{array}$ & \multicolumn{3}{|c|}{ Tiempo de envejecimiento del cebo en días } \\
\cline { 2 - 4 } & $\mathbf{0}$ & $\mathbf{1 2}$ & $\mathbf{2 4}$ \\
\hline $\mathbf{0 , 5} \%$ & $5,20^{\mathrm{a}} \pm 0,77$ & $11,94^{\mathrm{a}} \pm 1,34$ & $10,12^{\mathrm{a}} \pm 1,69$ \\
\hline $\mathbf{0 , 7 5} \%$ & $4,60^{\mathrm{a}} \pm 0,65$ & $10,30^{\mathrm{a}} \pm 1,31$ & $7,13^{\mathrm{a}} \pm 0,71$ \\
\hline $\mathbf{1 \%}$ & $4,61^{\mathrm{a}} \pm 0,73$ & $4,61^{\mathrm{b}} \pm 0,59$ & $3,47^{\mathrm{b}} \pm 0,58$ \\
\hline
\end{tabular}

Multiple Range Test con intervalos LSD al 90\%.

El análisis estadístico se ha realizado utilizando la transformación $\mathrm{X}=\operatorname{arcsen}(\operatorname{raiz}(\mathrm{x}))$

Huevos recogidos, durante 24 horas, a partir de las 48 horas de la ingestión de los cebos.

Cebo ofrecido a las moscas durante 3 horas.

Lectura de la eclosión de los huevos a las 72 horas de la siembra.

Figura I.1.- Evolución del porcentaje de eclosión de huevos de moscas tratadas con cebos en gotas sobre placa, envejecidos a diferentes tiempos y con distintas concentraciones de lufenuron. 


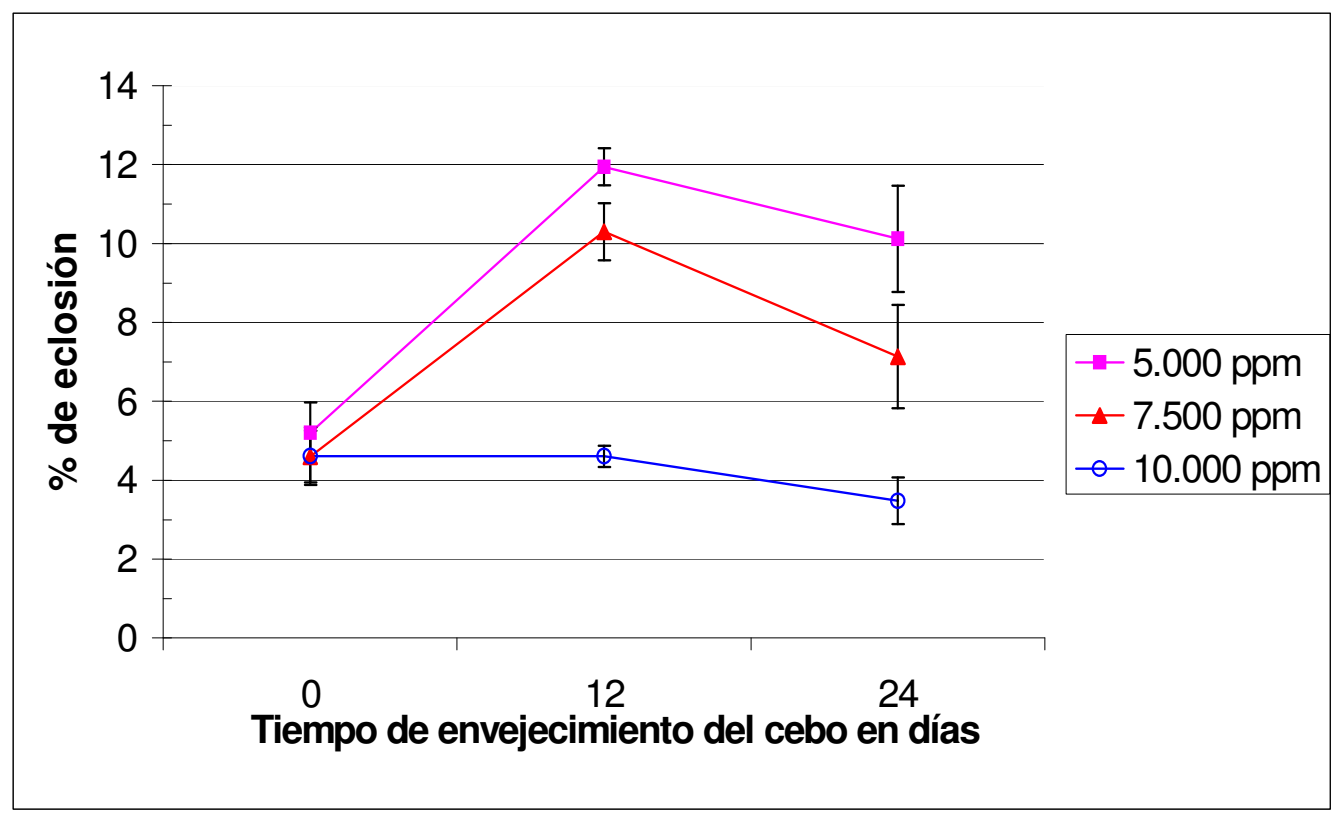

Huevos recogidos a partir de las 48 horas de la ingestión de los cebos durante 24 horas.

Lectura de la eclosión de los huevos a las 72 horas de la siembra.

Cebo ofrecido a las moscas durante 3 horas

Si tenemos en cuenta la eclosión de huevos en los testigos y aplicamos la transformación de Abbott (Abbott W.E, 1925), se pueden dar los resultados como eficacia esterilizante en tanto por cien como se muestra en la Tabla I.2 y en Figura I.2.

Tabla I.2.- Porcentaje de la eficacia esterilizante de cebos en gotas sobre placas, envejecidos a diferentes tiempos y con distintas concentraciones de lufenuron.

\begin{tabular}{|c|c|c|c|}
\hline & \multicolumn{3}{|c|}{ Tiempo de envejecimiento en días } \\
\hline & $\mathbf{0}$ & $\mathbf{1 2}$ & $\mathbf{2 4}$ \\
\hline $\mathbf{5 . 0 0 0} \mathbf{~ p p m}$ & 94,20 & 85,58 & 88,68 \\
\hline $\mathbf{7 . 5 0 0} \mathbf{~ p p m}$ & 94,86 & 86,85 & 92,32 \\
\hline $\mathbf{1 0 . 0 0 0} \mathbf{~ p p m}$ & 94,85 & 94,44 & 96,11 \\
\hline
\end{tabular}

Eficacia esterilizante en tanto por cien.

huevos.

Datos obtenidos por medio de la transformación de Abbott de la eclosión de

Figura I.2.- Evolución del porcentaje de la eficacia esterilizante de cebos en gotas sobre placas, envejecidos a diferentes tiempos y distintas concentraciones de lufenuron. 


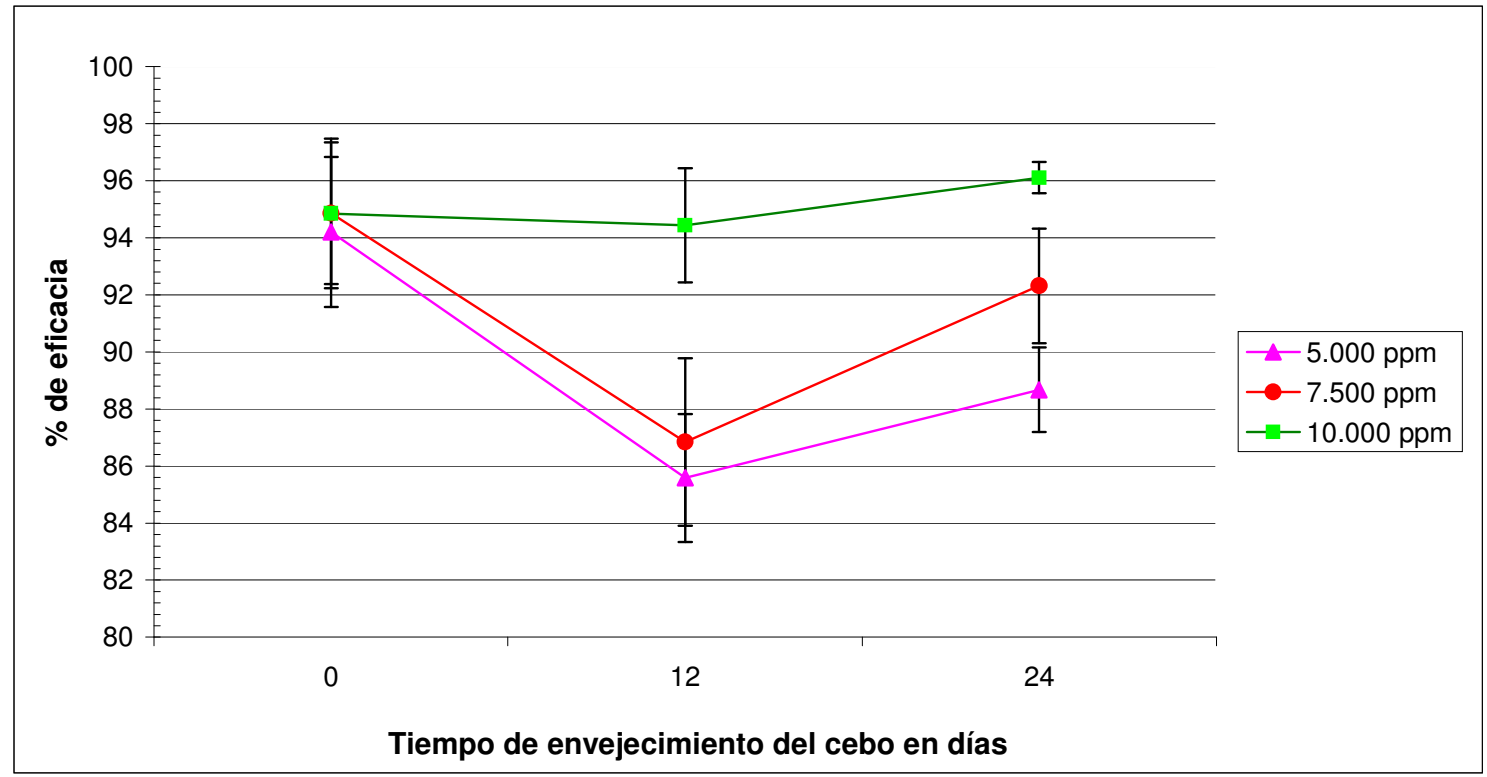

Eficacia esterilizante en tanto por cien.

Datos obtenidos por medio de la transformación de Abbott de la eclosión de huevos.

Como se puede observar en las tablas y gráficas precedentes, la actividad esterilizante de cebos con $0,5 \%$ y $0,75 \%$ en peso de lufenuron, disminuye con el envejecimiento de los cebos. Con concentraciones de lufenuron del 1\% no se produce una disminución significativa en la eficacia esterilizante en 24 días. 


\section{I.3.B.- Ensayos con gotas de cebo sobre hojas de naranjo.}

\section{I.3.B.1.- Materiales y métodos.}

Para cuantificar la duración del efecto esterilizante, en condiciones reales, realizamos una pulverización sobre naranjos del mismo caldo utilizado en la pulverización sobre placas. Las hojas se pulverizaron mediante mochila manual con boquilla troncocónica de $8 \mathrm{~mm}$ y también manualmente depositando gotas de aproximadamente $1 \mathrm{~mm}$ de diámetro mediante ayuda de un capilar. Las hojas marcadas se llevaron al laboratorio el mismo día de la pulverización, y a los 7 y 14 días de la misma.

Las hojas tratadas se introducen, a los 0,7 y 14 días, en 3 jaulas de metacrilato de 10x10x10 cm, donde se dejan, durante 3 horas, para que las moscas puedan ingerir el cebo. En cada jaula se ponen 5 hembras adultas copuladas que hayan permanecido en ayunas durante 24 horas, y dos hojas tratadas, y se recogen los huevos que ponen a los 2 días de la ingestión. Estos huevos, al igual que en el ensayo de envejecimiento sobre placas, se siembran sobre gel de agar al 0,3\% y se observa su eclosión a los 3 días.

El ensayo se repite 3 veces en jaulas independientes.

También se pulverizaron hojas de naranjo con cebo sin Match, para tener un blanco en cuanto a la eclosión.

\section{I.3.B.2.- Resultados y discusión.}

Con este ensayo se pretende conocer la duración de la actividad esterilizante de los cebos pulverizados sobre naranjos.

Los resultados se ven en la Tabla I.3 y Figura I.3. 
Tabla I.3.- Porcentaje de eclosión de los huevos procedentes de moscas que han ingerido el cebo, de hojas de naranjo a diferentes tiempos después de la pulverización.

\begin{tabular}{|l|c|c|c|}
\hline \multirow{2}{*}{} & \multicolumn{3}{|c|}{ Días de envejecimiento } \\
\cline { 2 - 4 } & $\mathbf{0}$ & $\mathbf{7}$ & $\mathbf{1 4}$ \\
\hline Tratado & $6,65^{\mathrm{a}} \pm 0,88$ & $54,48^{\mathrm{a}} \pm 2,73$ & $67,34 \pm 10,11^{\mathrm{a}}$ \\
\hline Blanco & $94,21^{\mathrm{b}} \pm 3,91$ & $98,36^{\mathrm{b}} \pm 1,12$ & $85,56 \pm 9,71^{\mathrm{a}}$ \\
\hline
\end{tabular}

${ }^{\mathrm{a}, \mathrm{b}}$ Los porcentajes de eclosión con la misma letra, para el mismo tiempo de envejecimiento, no difieren significativamente en el análisis tStudent $(\mathrm{P}>0,05)$

El análisis estadístico se ha realizado utilizando la transformación $\mathrm{X}=\operatorname{arcsen}(\operatorname{raiz}(\mathrm{x}))$

Huevos recogidos, durante 24 horas, a partir de las 48 horas de la ingestión de los cebos.

Lectura de la eclosión de los huevos a las 72 horas de la siembra.

Cebo ofrecido a las moscas durante 3 horas.

Como se puede observar en la Tabla I.3 y la Figura I.3 posterior, cuando los cebos pulverizados envejecen en el campo, la capacidad esterilizante disminuye rápidamente. A partir de los 14 días se pierde el efecto esterilizante.

Figura I.3.- Porcentaje de eclosión de huevos de moscas que han ingerido cebos, pulverizados y envejecidos a diferentes tiempos, sobre hojas de naranjo.

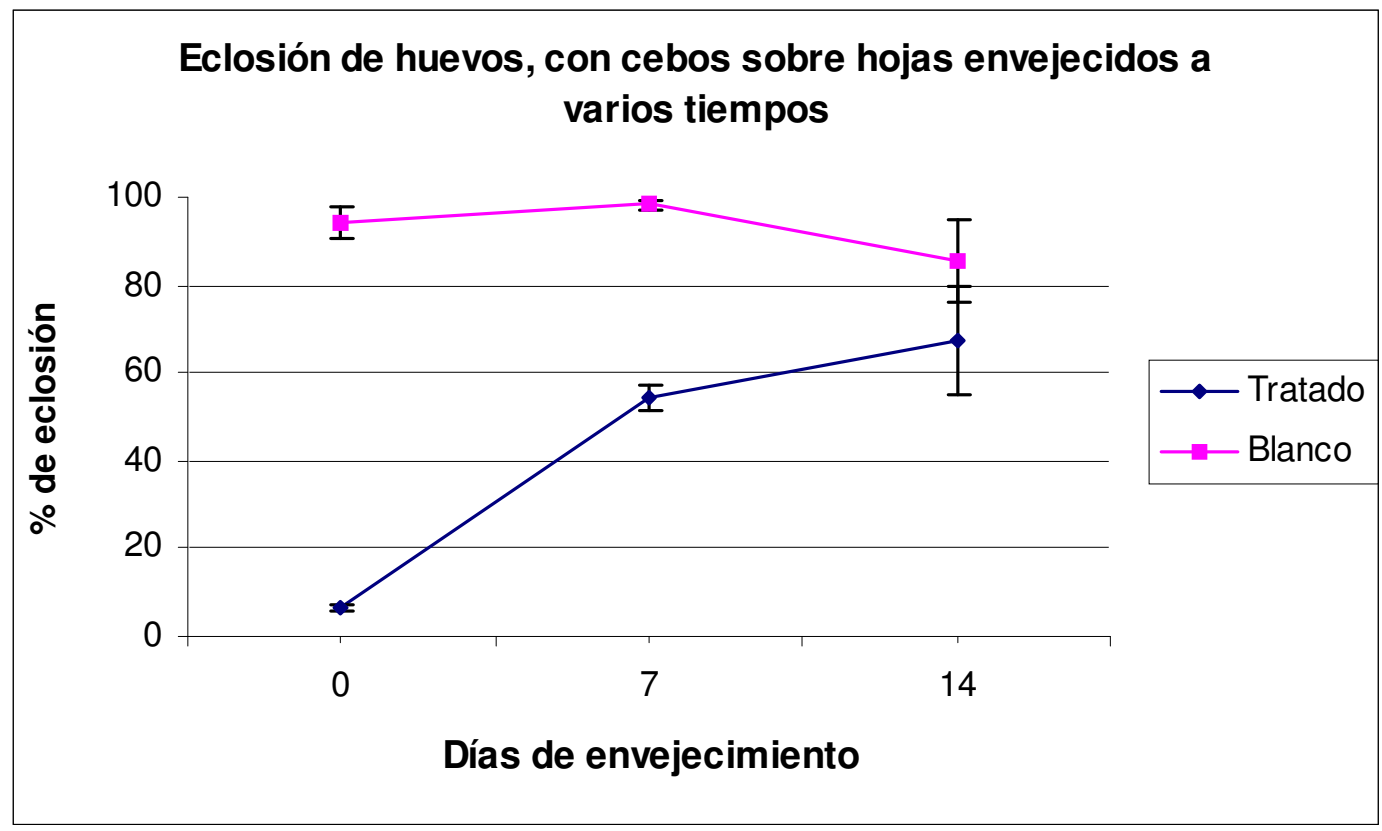

Huevos recogidos, durante 24 horas, a partir de las 48 horas de la ingestión de los cebos.

Lectura de la eclosión de los huevos a las 72 horas de la siembra. 
Cebo ofrecido a las moscas durante 3 horas.

Si tenemos en cuenta que los métodos de esterilización deben actuar durante largos períodos, para afectar a las sucesivas generaciones, es obvio que esta forma de aplicación no es adecuada. La necesidad de realizar tratamientos quincenales para que el efecto esterilizante en el campo sea continuado no es favorable económicamente, por lo que se ha de pensar en otra forma de aplicación. 


\section{I.4.- PREPARACIÓN DE GELES SÓLIDOS.}

\section{I.4.1.- Introducción.}

En los resultados de longevidad de los cebos aplicados por pulverización se observa que dejan de ser atrayentes/esterilizantes en menos de dos semanas. Si bien el resultado no puede considerarse malo, en comparación con las aplicaciones de organofosforados normales (a lo sumo 10 días de actividad), para un método de quimioesterilización en que los cebos deben ser activos durante largos períodos no es una duración suficiente. Sólo dos semanas de duración implicaría la repetición continua de tratamientos y el consiguiente encarecimiento del método.

Para poder aumentar la duración de las aplicaciones se decidió realizar ensayos con cebos sólidos gelificados. Estos cebos sólidos deben tener una duración mucho mayor, y ser atrayentes muy efectivos, para que las moscas acudan a comer de ellos. Los geles deben permanecer activos durante al menos 45 días para que el método resulte viable.

Para obtener los geles adecuados se han ensayado diferentes proporciones de cebo, gelificantes y humectantes, y se han realizado ensayos de envejecimiento a distintas concentraciones de lufenuron para poder estimar su duración efectiva.

\section{I.4.2.- Materiales y métodos.}

El gel sólido tiene la siguiente composición:

- Cebo completo $80 \%$

- Corn Steep Liquor (CSL) 60\%

- Meliosa $30 \%$

- Sorbitol $10 \%$

- Gelificante (1-8\%) 
- $\quad$ ATP $2,1 \%$

- Acetato amónico $1 \%$

- Trimetilamina $1 \%$

- Putrescina $0,1 \%$

- Lufenuron (1-5\%)

- Fenilsulfonato Cálcico y Emulsogen EL(6:4) 1\%

- Agua hasta alcanzar el $100 \%$.

Se ensayan 3 dosis de lufenuron: 1,2 y $5 \%$ en peso, respecto al total del gel de la placa.

A la base proteica de los cebos sólidos, se han añadido dos tipos de atrayentes: alimenticios para incrementar la atracción sobre hembras, y sexuales para aumentar la atracción sobre machos. Los atrayentes alimenticios, además del propio cebo, son el acetato amónico, la trimetilamina y la putrescina (ATP) $(1: 1: 0,1)(\mathrm{p} / \mathrm{p})$ sobre cebo. Esta mezcla ha demostrado, en ensayos realizados por otros grupos de investigación (Katsoyannos et al., 1999), (Robacker, 1995), tener poder atrayente sobre hembras de Ceratitis capitata. Además, se han utilizado emisores de trimedlure (TML), los cuales, aunque sólo son eficaces con machos, tienen un poder atrayente mayor y más específico que el de los atrayentes alimentarios. El TML se coloca sobre los cebos en forma de comprimidos de materiales microporosos que liberan lenta y continuamente el TML durante al menos 3 meses.

Entre los gelificantes que se plantearon para la elaboración de geles sólidos, se eligieron la Carboximetil-celulosa (CMC) (Aldrich), el agar-agar (Panreac) y alginatos (Sigma).

El gel de agar (Panreac) se prepara del siguiente modo: se calienta agua con agar y se hierve durante 1 minuto. Una vez hervido, se deja enfriar hasta $55^{\circ} \mathrm{C}$, y se le añade, gota a gota, el lufenuron emulsionado en agua mediante fenilsulfonato cálcico y emulsogen (6:4). Después se añade la mezcla de ATP y se vierte sobre placas. El gel se deja secar al aire durante 2 días para que se seque ligeramente. 
Se han ensayado 2 tipos de CMC, uno de baja (20-40 cps al $2 \%$ en agua y $25^{\circ} \mathrm{C}$ ) y otro de ultra baja densidad (10-55 cps al $4 \%$ en agua y $\left.25^{\circ} \mathrm{C}\right)$ y tres tipos de alginatos (densidad baja $\left(250 \mathrm{cps}\right.$ al $2 \%$ en agua a $\left.25^{\circ} \mathrm{C}\right)$, media $\left(3.500 \mathrm{cps}, 2 \%\right.$ y $\left.25^{\circ} \mathrm{C}\right)$ y alta $(14.000 \mathrm{cps}, 2 \%$ y $\left.25^{\circ} \mathrm{C}\right)$. De todos ellos se probaron distintas concentraciones para conseguir un gel con la solidez suficiente para que las moscas no se quedasen pegadas cuando se posaban sobre él, pero que no resultase demasiado seco con el fin de que las moscas pudiesen ingerir el cebo. Con cada tipo de gel se ha ensayado la concentración de humectante (Sorbitol no cristalizable) que evitase la excesiva desecación de los cebos. Se han estudiado 3 concentraciones de gelificante y, con la concentración más adecuada, se ha buscado la concentración de Sorbitol que retenga la humedad de forma conveniente.

Para preparar el gel de CMC se coloca el cebo completo en un vaso de precipitados y se le va añadiendo la CMC en polvo, poco a poco y con agitación constante. Después se le añade la emulsión de lufenuron en agua sin cesar la agitación. Una vez homogeneizado, se vierte en placas para que pierda humedad hasta alcanzar la textura y viscosidad buscadas.

El gel de alginatos se fabrica añadiendo, al cebo, los distintos alginatos en polvo, poco a poco, con agitación continua mediante un agitador de palas.

\subsection{3.- Resultados y discusión.}

De los tres gelificantes ensayados (CMC, agar-agar y alginatos) los alginatos han sido descartados por no proporcionar un gel con la solidez suficiente.

La CMC, de baja viscosidad, al $4 \%$ y el agar al $1 \%$ proporcionan una solidez adecuada para que las moscas ingieran el cebo sin que queden adheridas a la placa. Concentraciones superiores de estos gelificantes hacen que el gel resulte demasiado sólido, mientras que 
concentraciones inferiores provocan que el gel quede fluido y resulte demasiado adherente para nuestro propósito.

Además se ensayaron tres concentraciones de humectante (Sorbitol): 5, 10 y 20\%. Si bien concentraciones de humectante mayores provocaban una retención mayor de agua, los geles quedaban viscosos y fluidos, por lo que se desecharon esas concentraciones.

Definitivamente se seleccionaron las siguientes condiciones:

- $80 \%$ Cebo completo

- $4 \%(\mathrm{p} / \mathrm{v})$ CMC baja viscosidad o agar al $1 \%(\mathrm{p} / \mathrm{v})$

- 1 a $3 \%$ lufenuron

- 1 a 3\% emulgente (fenilsulfonato cálcico+emulsogen EL, 6:4)

- $2,1 \%$ de la mezcla ATP

- Agua hasta el $100 \%$ 


\section{I.5.- ENSAYO DE ENVEJECIMIENTO DE LOS CEBOS, EN CAMPO.}

\subsubsection{Materiales y métodos.}

Se han ensayado los dos geles que resultaron más adecuados por sus características físicas, según el apartado 1.4.3 de la presente Tesis Doctoral: CMC (baja viscosidad) 4\% y agar $1 \%$.

Los geles se colocan en trampas delta para evitar que se mojen y se ensucien y se cuelgan en árboles del campo para que envejezcan. Las trampas se cuelgan de 1 a 1,5 metros de altura, prefiriendo una zona cubierta del árbol para evitar las insolaciones excesivas de la placa.

Desde el momento en que se cuelgan, y cada 15 días, los geles se llevan al laboratorio donde se ensaya su actividad esterilizante. El ensayo se realiza en jaulas metálicas de 30x30x30 cm con paredes laterales de malla de $2 \mathrm{~mm}$, base continua y tapa de metacrilato (Foto 6). Con estas jaulas se persigue que no se sature el ambiente gracias a las caras laterales del cubo y poder observar el comportamiento de las moscas a través de la cara transparente superior.

Dentro de cada jaula se colocan 60 moscas (30 machos y 30 hembras) de 5 días (adultas y copuladas), que hayan permanecido en ayunas durante 24 horas. En el interior de la jaula se coloca un bebedero con agua que consiste en un frasco de $100 \mathrm{ml}$, en el que se coloca una tira de bayeta a modo de mecha para que las moscas puedan beber sin ahogarse. Durante 3 horas se coloca la placa con gel en el interior de la jaula y se deja que las moscas ingieran el cebo. Una vez transcurridas las tres horas, se saca el cebo y se cazan 15 hembras que se llevan de 5 en 5 a 3 jaulas de metacrilato de 10x10x10 cm, donde se les pone comida normal y agua (Fotos 7 y 8). Estas jaulas más pequeñas disponen, en una de sus caras, de una tela fina donde las moscas clavan su oviscapto y dejan caer sus huevos. Los huevos caen en un recipiente con 
agua colocado bajo la tela, de donde se recogen mediante una pipeta Pasteur y se siembran sobre gel de agar al 0,3\% p/v. A los tres días de la siembra se comprueba, mediante una lupa binocular, la emergencia de las larvas.

\section{Foto 6.}

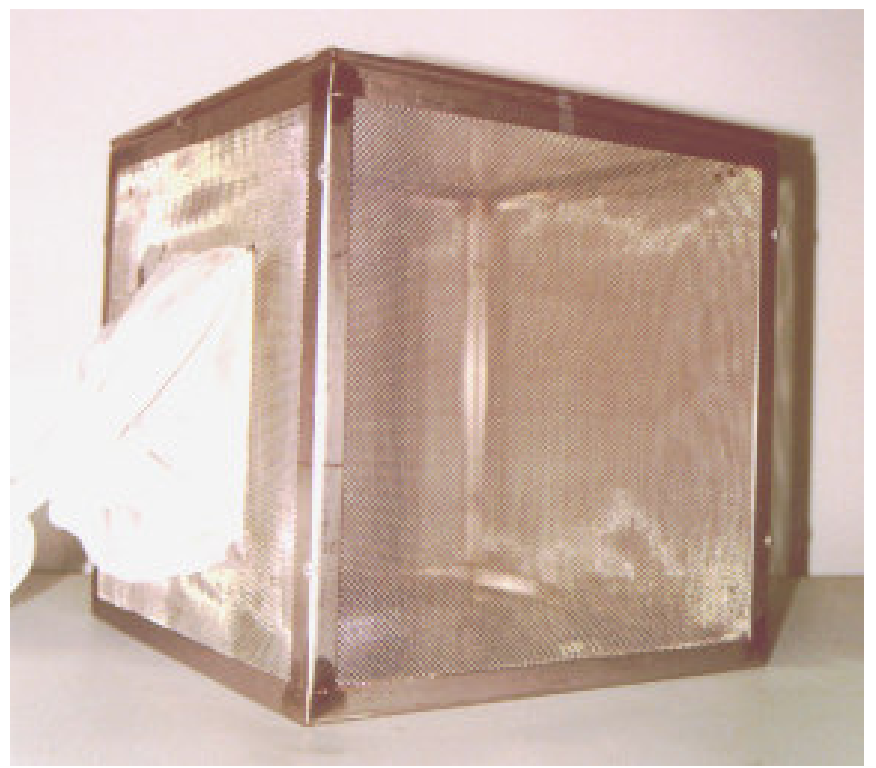

Foto 7

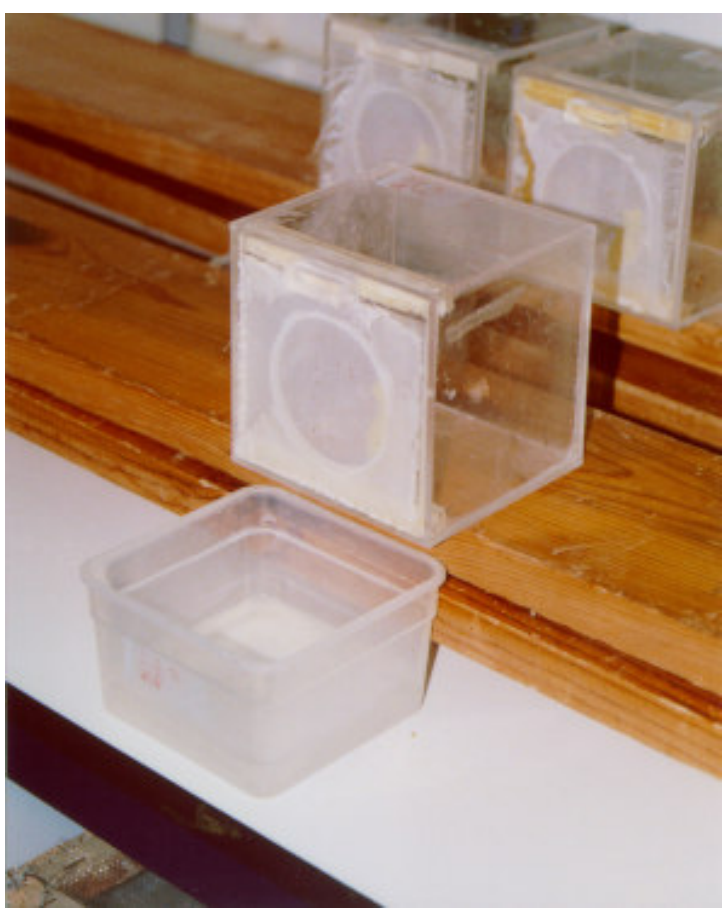

Foto 8.

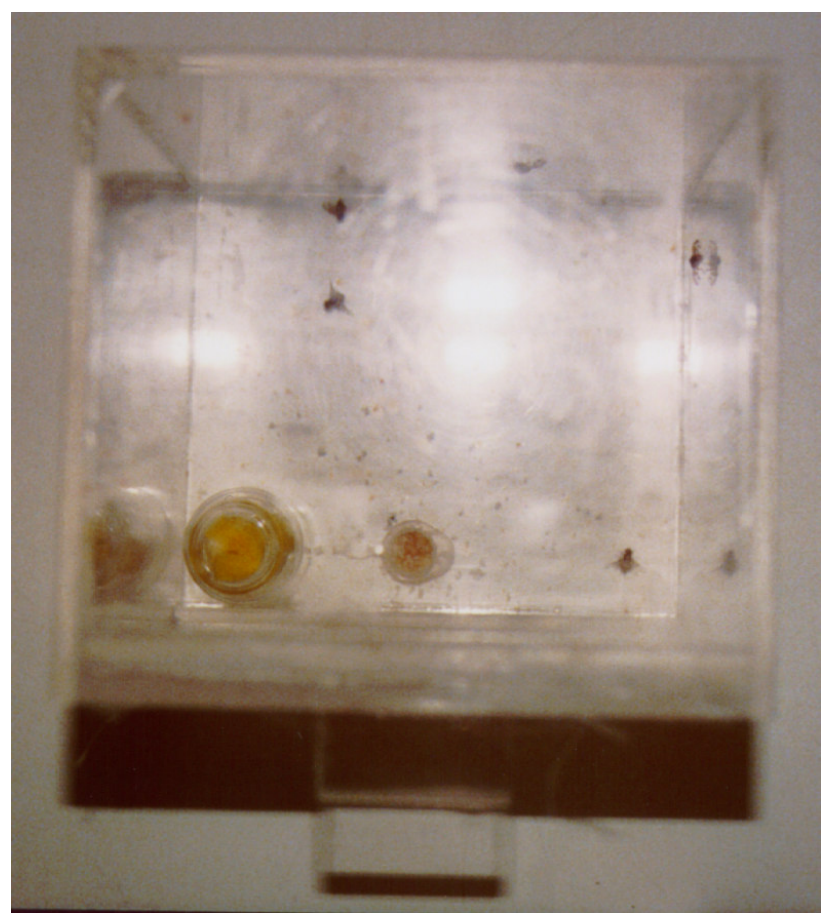




\subsection{2.- Resultados y discusión.}

\section{GELES DE AGAR:}

En las Figuras I.4 y I.5 se dan los resultados de la pérdida de actividad esterilizante, con el envejecimiento en el campo, de los cebos gelificados con agar con un $2 \%$ de lufenuron (peso/volumen total del gel). La Figura I.4a muestra el porcentaje de huevos eclosionados y la Figura I.4b muestra el porcentaje de eficacia del tratamiento según la transformación de Abbott para tener en cuenta la eclosión de huevos en el testigo. En la Experiencia 1, el envejecimiento de las placas que se muestra en las Figuras I.4a y I.4b se realizó de abril a julio en el interior de trampas delta colgadas a la intemperie en Valencia. En la Experiencia 2, el envejecimiento de las placas, que se muestra en las Figuras I.5a y I.5b, se realizó de julio a septiembre, en un campo de cítricos de Sagunto. 


\section{Experiencia 1. Abril-junio}

Figura I.4a. Porcentaje de huevos eclosionados en función del tiempo de envejecimiento, en el campo, del cebo con agar que han ingerido las moscas, (abril a junio).

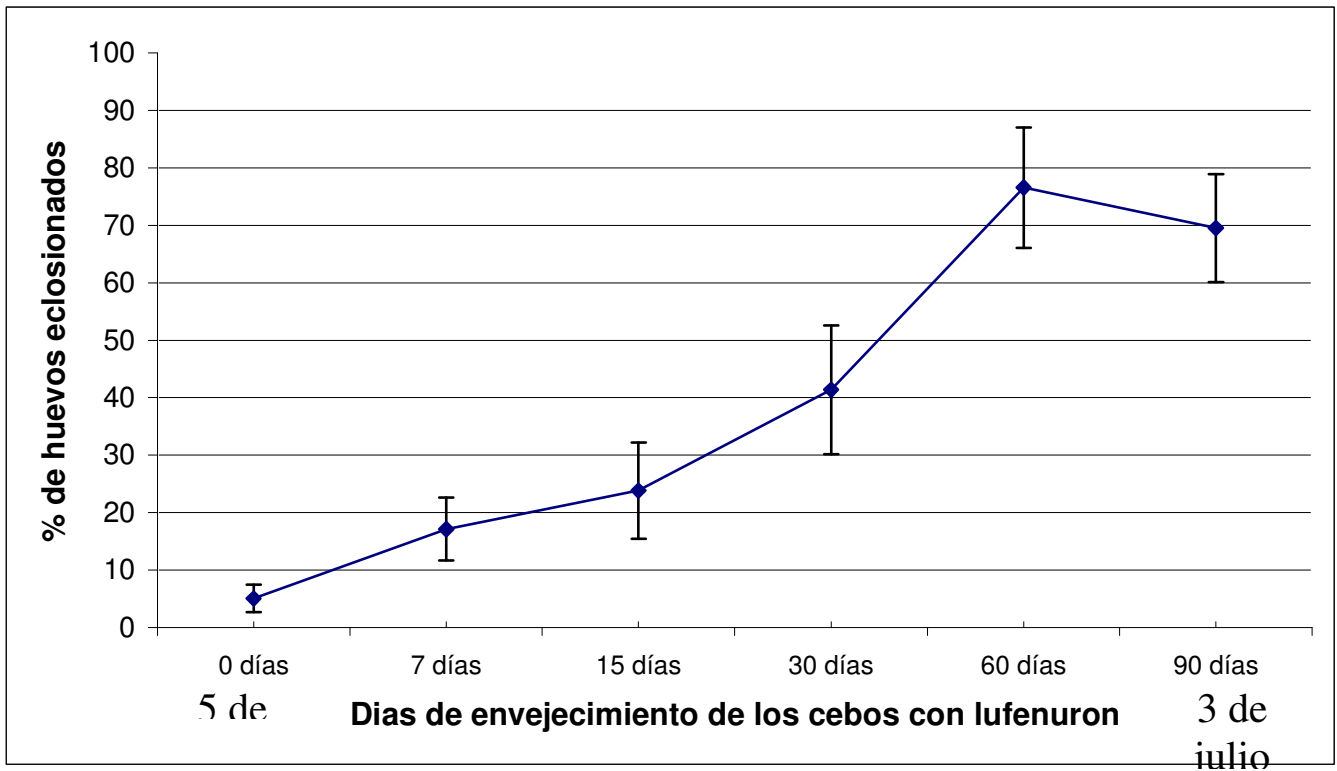

De los huevos puestos por las moscas, durante 24 horas, a partir de las 48 horas de ingerir el cebo.

Cebo ofrecido a las moscas durante 3 horas.

Eclosión de huevos medida a las 72 horas de la siembra.

Cebos con agar $1 \%$ y lufenuron al $2 \%$ (peso / volumen total del gel)

Figura I.4b. Eficacia esterilizante de los cebos, en tanto por cien, en función de su envejecimiento, (abril a junio)

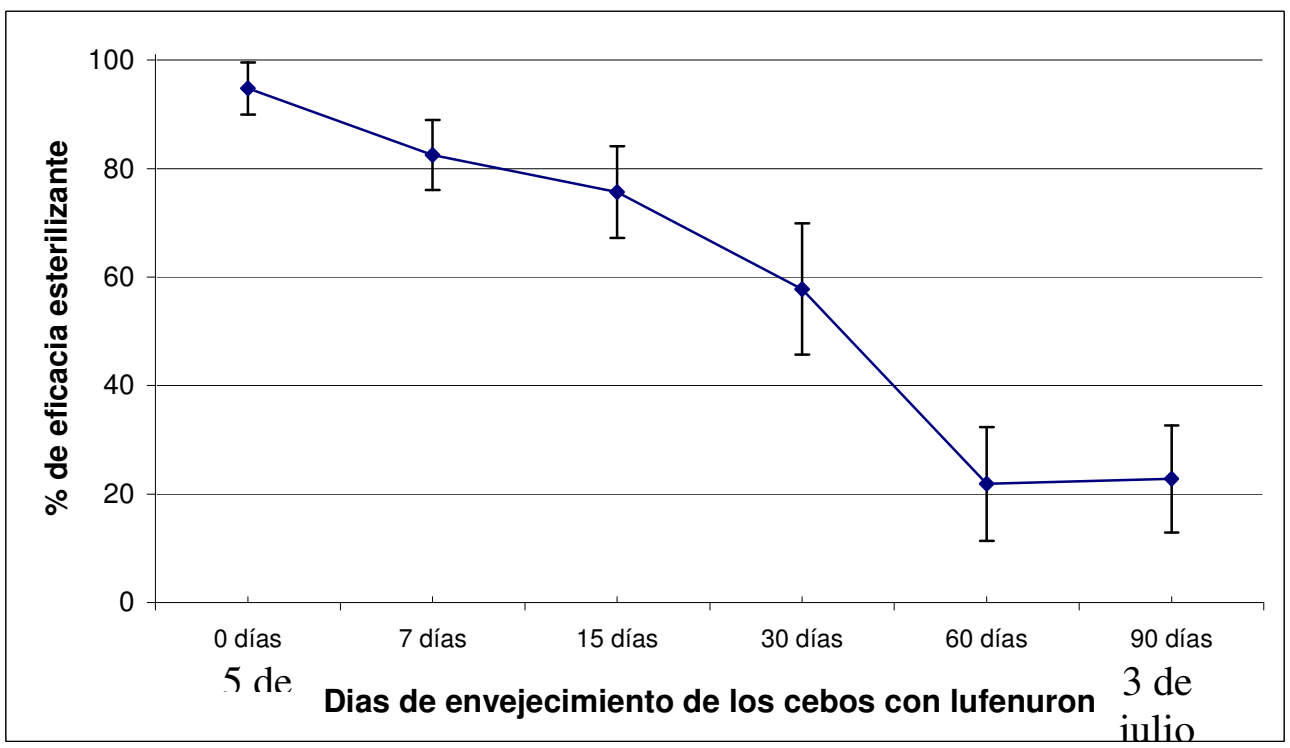

De los huevos puestos por las moscas, durante 24 horas, a partir de las 48 horas de ingerir el cebo.

Cebo ofrecido a las moscas durante 3 horas. 
Eclosión de huevos medida a las 72 horas de la siembra.

Eficacia obtenida según la transformación de Abbott.

Cebos con agar $1 \%$ y lufenuron al $2 \%$ (peso / volumen total del gel)

\section{Experiencia 2. Julio-septiembre}

El envejecimiento de las placas de cebo con lufenuron se realizó de julio a septiembre (Figuras I.5a y I.5b), situando las placas en el interior de trampas delta y colgándolas en el campo de ensayo. En esta segunda experiencia, para tratar de aumentar la vida útil, los geles se voltearon en las placas a los 45 días, ofreciendo la cara inferior no desecada.

Figura I.5a. Porcentaje de huevos eclosionados en función del tiempo de envejecimiento, en el campo, del cebo con agar que han ingerido las moscas, (julio a septiembre).

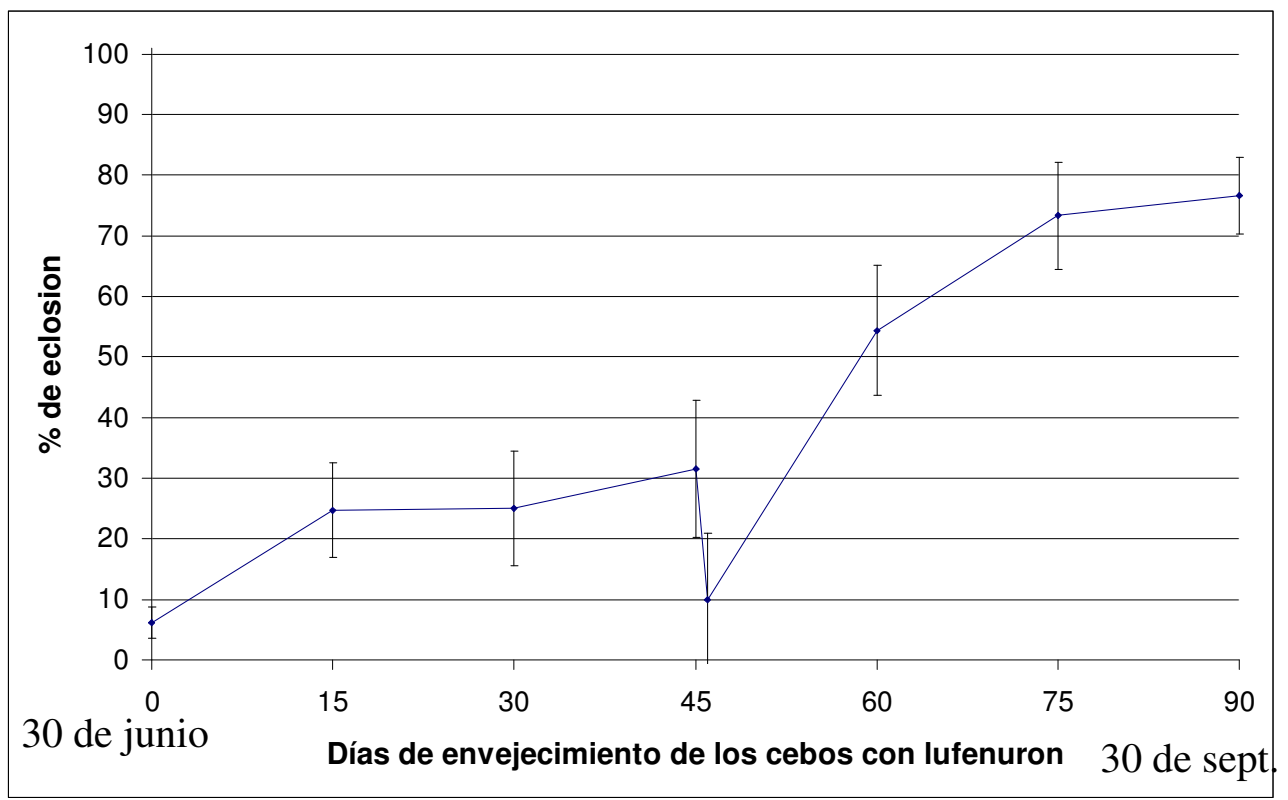

De los huevos puestos por las moscas, durante 24 horas, a partir de las 48 horas de ingerir el cebo.

Cebo ofrecido a las moscas durante 3 horas.

Eclosión de huevos medida a las 72 horas de la siembra.

Los cebos se voltearon a los 45 días de envejecimiento.

Cebos con agar $1 \%$ y lufenuron al $2 \%$ (peso / volumen total del gel) 
Figura I.5b. Eficacia esterilizante, en tanto por cien, de los cebos con agar dependiendo de su envejecimiento, (julio a septiembre).

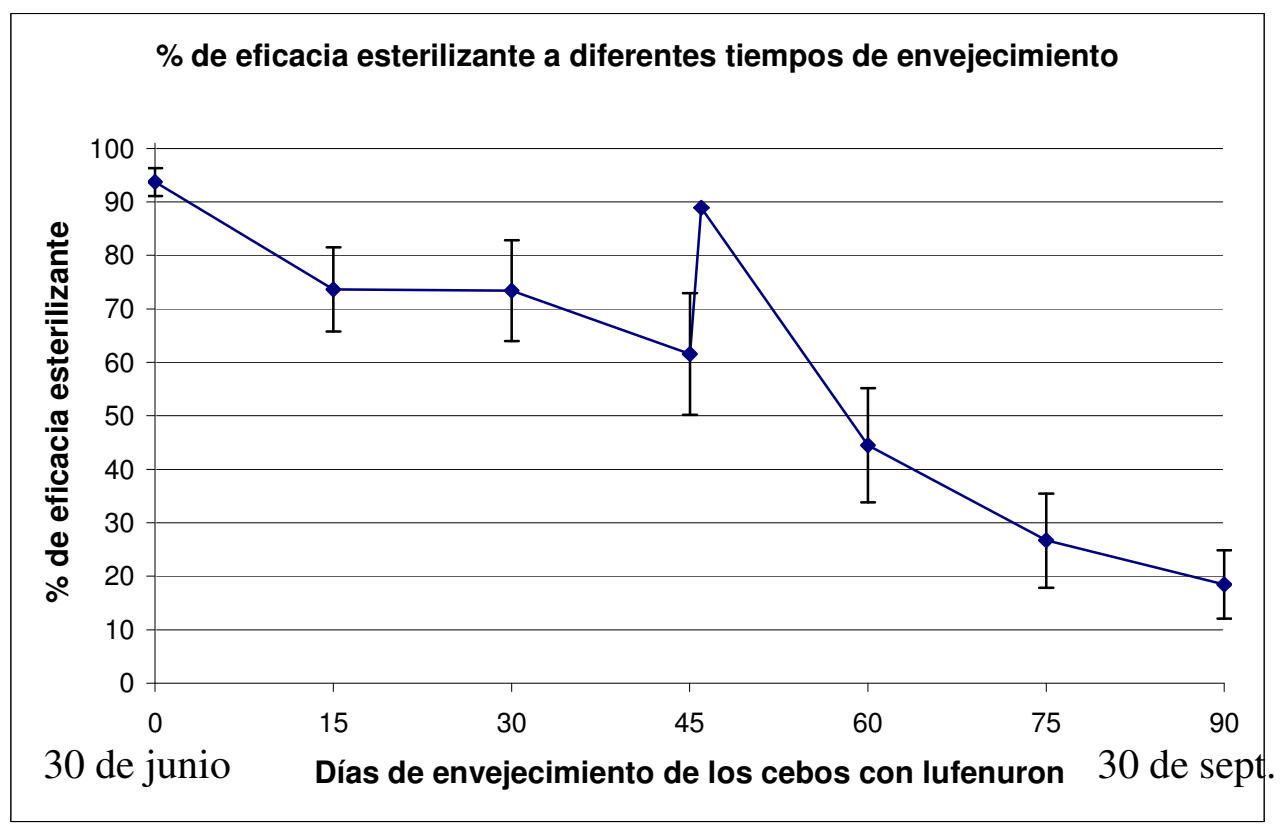
ingerir el cebo.

De los huevos puestos por las moscas, durante 24 horas, a partir de las 48 horas de

Cebo ofrecido a las moscas durante 3 horas.

Eclosión de huevos medida a las 72 horas de la siembra.

Eficacia obtenida según la transformación de Abbott.

Cebos con lufenuron gelificados; se voltearon a los 45 días de envejecimiento.

Cebos con agar $1 \%$ y lufenuron al 2\% (peso / volumen total del gel)

En el envejecimiento de las placas de cebo con agar y lufenuron, se observa una menor afluencia de las moscas al cebo en las jaulas. Realmente estamos midiendo el poder atrayente, ya que, en experiencias posteriores, se ha demostrado que el lufenuron no pierde su actividad.

En verano, las placas permanecieron en un nivel de eclosión por debajo del $35 \%$ hasta los 45 días (Figura I.5a). La disminución de la eclosión que se observa a los 45 días se debe a que se les dio la vuelta a los geles de cebo con lufenuron, para observar si la cara interior conservaba la actividad que la cara expuesta al aire, durante mes y medio, había perdido por desecación; sin embargo, este efecto dura muy pocos días.

En efecto, durante el ensayo, se observa que las placas envejecidas más de 30 días tienen una película muy fina, en su parte superior, producida por la desecación superficial del 
gel y que disminuye su capacidad esterilizante, bien sea por la menor emisión de los atrayentes a través de esta película o por dificultad para ingerir el cebo. Ante esta observación se decidió dar la vuelta al gel para observar si el resto seguía siendo activo. Como se muestra en la Figura I.5b, al dar la vuelta a la placa, a los 45 días de envejecimiento, el cebo recupera capacidad esterilizante (10\% de eclosión), aunque la actividad vuelve a disminuir y a los 60 días la eclosión es del 55\%.

Al ensayar el envejecimiento con diferentes concentraciones de lufenuron, en los geles de agar, obtenemos la Figura I.6. En esta figura, se puede observar que la duración de la actividad esterilizante depende de la concentración de lufenuron. Con geles de agar al 1\%, las placas con concentraciones del 5\% de lufenuron no pierden actividad en 45 días de envejecimiento. También se observa que el incremento del 1 al 2\% de lufenuron alarga mucho el período de actividad esterilizante.

Figura I.6. Pérdida de la actividad esterilizante, con el envejecimiento, de cebos de agar con tres concentraciones diferentes de lufenuron.

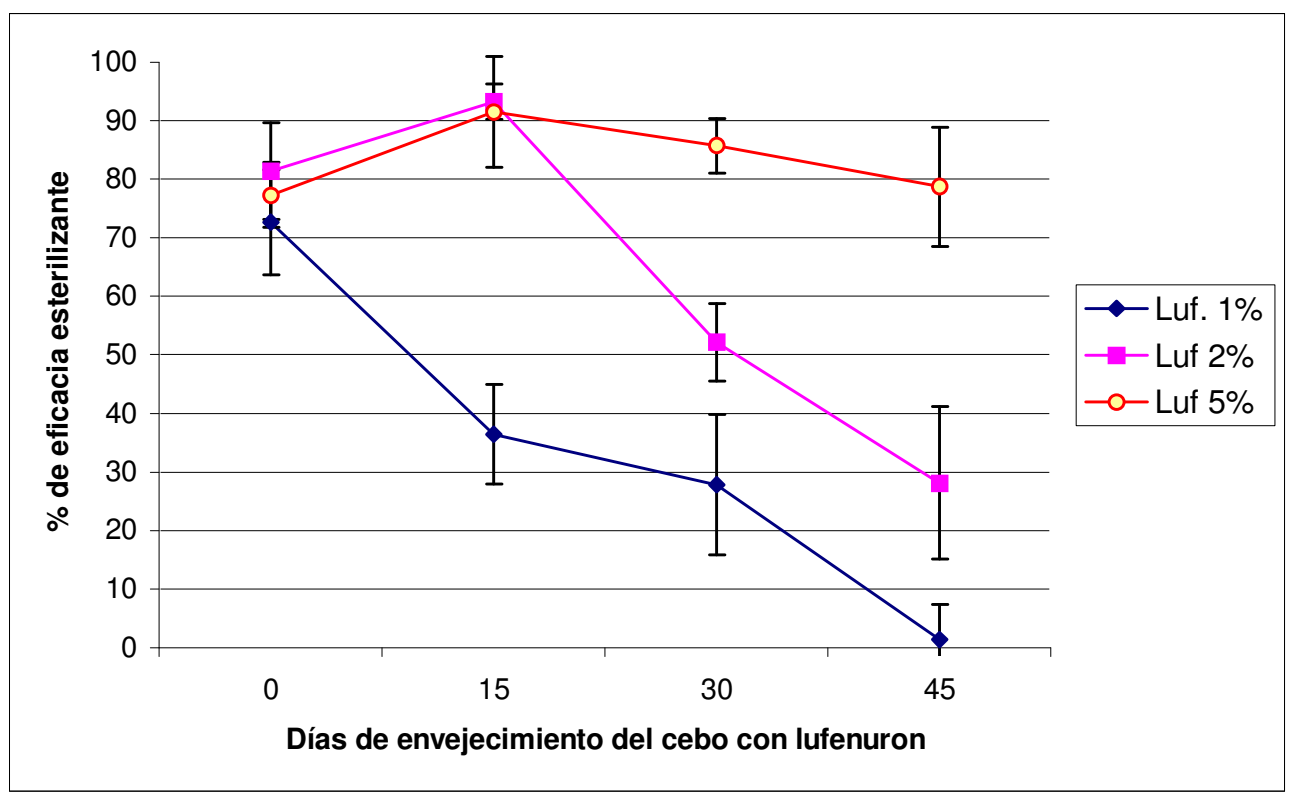
el cebo.

Huevos puestos por las moscas, durante 24 horas, a partir de las 48 horas de ingerir Cebo ofrecido a las moscas durante 3 horas. 
Eclosión de huevos medida a las 72 horas de la siembra.

Concentraciones de lufenuron en peso respecto al volumen total del gel.

\section{GELES DE CMC:}

Estos geles resultaron más efectivos que los de agar, ya que conservan su actividad esterilizante por más tiempo. En este caso, la actividad esterilizante de los geles se midió a los $0,15,30,60,90$ y 120 días.

En la Figura I.7 se da la evolución de la actividad esterilizante de estos cebos, con el envejecimiento. Los cebos tratados contienen lufenuron al 3\%, mientras que los blancos son geles sin lufenuron.

Figura I.7. Porcentaje de eclosión de huevos de moscas, que han ingerido un cebo de CMC tratado con lufenuron o un cebo sin tratar (blanco), en función del envejecimiento.

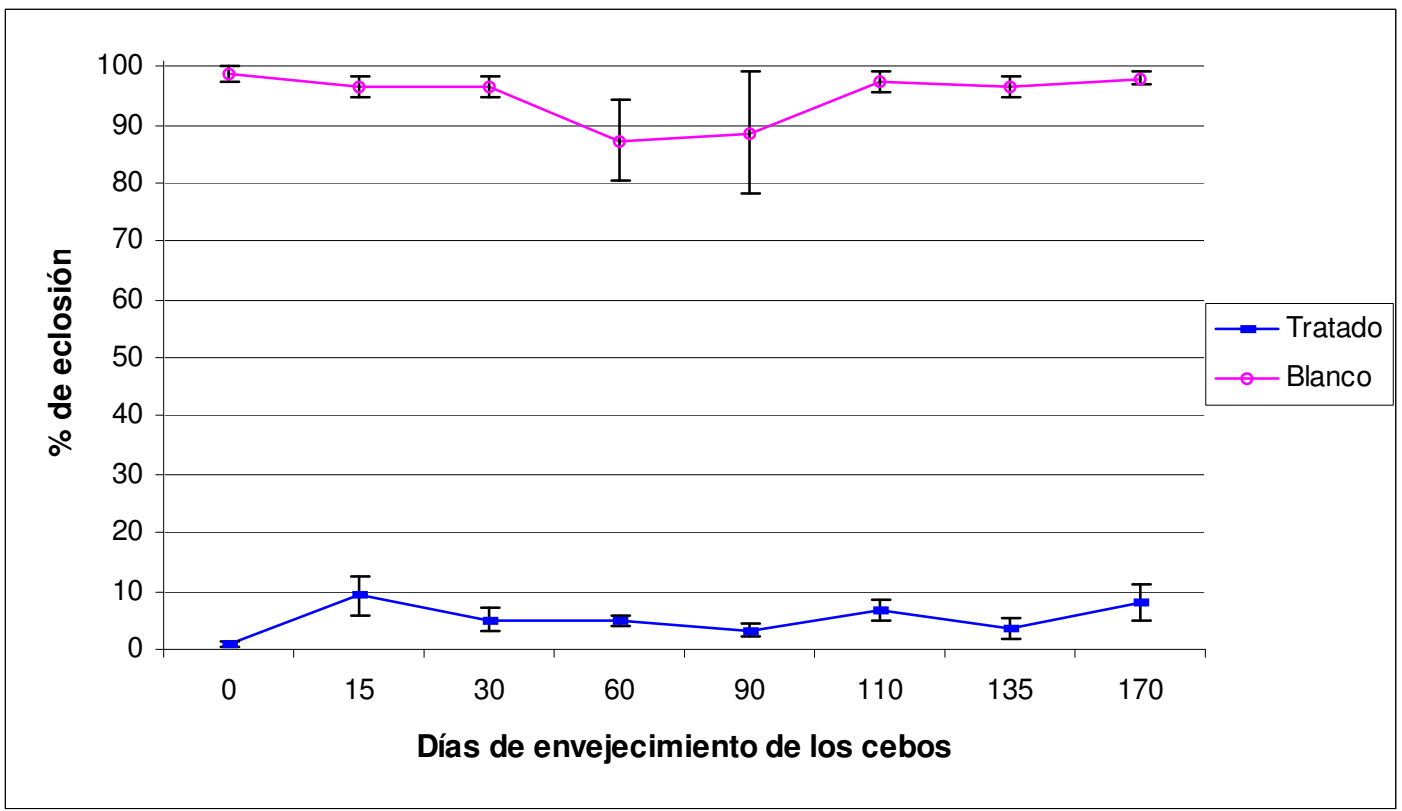
cebo.

Huevos puestos por las moscas, durante 24 horas, a partir de las 48 horas de ingerir el

Cebo ofrecido a las moscas durante 3 horas.

Eclosión de huevos medida a las 72 horas de la siembra.

Cebos gelificados con CMC 4\% y lufenuron al 3\% (peso / volumen total del gel) 
Como se puede observar en la gráfica anterior, no se aprecia pérdida de actividad de los cebos con tiempos de envejecimiento de 170 días.

Con este resultado se puede decir que hemos obtenido geles con más de cinco meses de duración efectiva. Este logro significa que los geles se pueden colocar a principio de campaña y permanecer activos, en el campo, hasta el final de la misma sin necesidad de ser sustituidos, lo que abarata mucho el coste de los tratamientos.

Estos geles se han seleccionado para los ensayos en campo a gran escala que se desarrollan en la Parte III de la presente Tesis Doctoral. 


\section{I.6.- CONCLUSIONES.}

Con los ensayos realizados durante esta primera parte de la Tesis, se abre un nuevo camino para la lucha contra la mosca de la fruta, de una forma más específica y por lo tanto más respetuosa con el medio.

La consecución de una duración esterilizante efectiva de los geles, por encima de los 4 meses, disminuye eficazmente la mano de obra necesaria para cambiar las placas y convierte a este método en una alternativa comercialmente viable.

En la parte siguiente de esta Tesis Doctoral se realizan ensayos de campo que determinan su eficacia en el control de la mosca. 


\section{PARTE II.}

ENSAYOS EN CAMPO DE LOS GELES DESARROLLADOS.

PARCELAS DE TAMAÑO MEDIO O PEQUEÑO. 


\section{II.1.- INTRODUCCIÓN.}

Estas experiencias tenían como objeto obtener los primeros datos sobre la efectividad de los distintos cebos desarrollados y de su modo de aplicación. En el cuadro siguiente se resume las cuatro experiencias realizadas.

\begin{tabular}{|l|c|c|l|c|c|c|}
\hline Finca & Fecha & Ubicación & Variedad & Extensión & Tratamiento & Blanco \\
\hline HiperRiego & $\begin{array}{c}\text { Abr-Oct } \\
1999\end{array}$ & $\begin{array}{c}\text { Turís } \\
\text { (Valencia) }\end{array}$ & Marisol & 4 & $\begin{array}{c}\text { Parcheo con } \\
\text { Match }^{\circledR}\end{array}$ & $\begin{array}{c}\text { Sin } \\
\text { tratamiento }\end{array}$ \\
\hline José Soler & $\begin{array}{c}\text { Feb-Jun } \\
2000\end{array}$ & $\begin{array}{c}\text { Denia } \\
\text { (Alicante) }\end{array}$ & Valencia & 5 & $\begin{array}{c}\text { Geles con ATP } \\
+ \text { lufenuron }\end{array}$ & $\begin{array}{c}\text { Sin } \\
\text { tratamiento }\end{array}$ \\
\hline Gausa & $\begin{array}{c}\text { Jun-Sep } \\
2000\end{array}$ & $\begin{array}{c}\text { Gandía } \\
\text { (Valencia) }\end{array}$ & Marisol & 1 & $\begin{array}{c}\text { Geles con } \\
\text { ATP+TML } \\
+ \text { lufenuron }\end{array}$ & Frutec $^{\circledR}$ \\
\hline San Jaime & $\begin{array}{c}\text { May-Oct } \\
2000\end{array}$ & $\begin{array}{c}\text { Sagunto } \\
\text { (Valencia) }\end{array}$ & New-Hall & 2,7 & $\begin{array}{c}\text { Geles con } \\
\text { ATP+TML } \\
\text { +lufenuron }\end{array}$ & $\begin{array}{c}\text { Parcheo con } \\
\text { malation }\end{array}$ \\
\hline
\end{tabular}

Parcheo: pulverización de 1-1,5 $\mathrm{m}^{2}$ de superficie en la cara sur del árbol con cebo $(3,33 \%)$ +lufenuron $0,033 \%$ m.a. en el caldo pulverizado

ATP (Acetato amónico, trimetilamina y putrescina, 1:1:0,1\% en cebo)

TML (Pastilla de $5 \mathrm{~g}$ de sepiolita y poliestireno (70:30) con $1 \mathrm{~g}$ de trimedlure)

Frutec: Captura masiva con trampas Frutec (42 trampas/Ha).

En el cuadro anterior se puede observar que las experiencias se realizaron en campos de al menos 1 Ha y que se tomó en cada ensayo un campo de referencia. Los campos de referencia permanecieron sin tratar en los ensayos de Turís y Denia. En el campo de Sagunto, se tomó como referencia una parcela que se trató con malation por parcheo. En el campo de Gandía la parcela de referencia estaba protegida con trampas Frutec ${ }^{\circledR}$.

EL seguimiento de la población de mosca se realiza mediante capturas con mosqueros y atrayentes. El atrayente utilizado en estas pruebas es el TML, ya que permite detectar, pequeños cambios de población de mosca. 
La densidad de trampa varía en cada ensayo según las características de la parcela tal como se muestra en el siguiente cuadro.

\begin{tabular}{|c|c|c|c|}
\hline Parcela & Trampa utilizada & Emisor & $\begin{array}{c}\text { Densidad } \\
\text { Trampas/Ha }\end{array}$ \\
\hline Turís & Cromática adhesiva & Aralure (Aragonesas Agro) & 3 \\
\hline Denia & $\begin{array}{c}\text { Cromática adhesiva } \\
\text { y Nadel }\end{array}$ & Aralure y Bote difusor & 6,5 \\
\hline Gandía & Nadel & Bote difusor & 12 \\
\hline Sagunto & Nadel & Bote difusor & 9 \\
\hline
\end{tabular}

Bote difusor: contiene $1 \mathrm{ml}$ de TML líquido y 0,5 $\mathrm{ml}$ de DDVP.

Denia: $50 \%$ de trampas cromáticas y $50 \%$ de trampas Nadel colocadas alternativamente.

Emisores Aralure: se sutituyen a los 2 meses

Bote difusor: se sustituye mensualmente.

Todos los campos de ensayos se seleccionaron para que estuvieran lo más aislados posible o al menos poco influenciados por los campos vecinos, para que no hubiera invasión de moscas fértiles. 


\section{II.2.- Ensayo de cebos quimioesterilizantes pulverizados, en Turís (variedad} Marisol).

\section{II.2.1- Introducción.}

En Turís se realizó el primer ensayo de eficacia del método de quimioesterilización. La aplicación del cebo+lufenuron se realizó, mediante pulverización, de forma similar a los actuales tratamientos por parcheo con organofosforados.

En esta experiencia, se ha realizado un seguimiento de la población de mosca de la fruta, y también recuentos de fruta picada.

\section{III.2.2.- Materiales y métodos.}

La mezcla de cebo+lufenuron se pulverizó por parcheo, sobre una superficie de 1-1,5 $\mathrm{m}^{2}$ en la cara sur del árbol, mediante mochila manual, con boquilla troncocónica de $8 \mathrm{~mm}$ y difusor hueco, cada 15 días. Se han realizado un total de 12 aplicaciones desde el 3 de mayo hasta el 4 de octubre.

El lufenuron se aplicó como Match (50 g de lufenuron/l) a una dosis de 6,67 $\mathrm{ml}$ de Match por litro de caldo a pulverizar. Cada litro de caldo a pulverizar contiene, además, $33 \mathrm{ml}$ de cebo proteico (Corn Steep Liquor : Meliosa: Sorbitol, en proporción 6:3:1 v/v), y como atrayente, el 0,033\% de lufenuron (m.a) en el caldo (p/v).

Las trampas que se utilizaron durante los ensayos, para seguir la evolución de la población de mosca, son trampas cromáticas adhesivas amarillas de 20 x $20 \mathrm{~cm}$ de Econex 
(España). En el extremo superior de estas placas se inserta un emisor "Aralure" (Aragonesas Agro, España) que lleva una carga de $1 \mathrm{~g}$ de TML.

Para tener una estimación de la población de mosca sin provocar un descenso significativo, como sucedería si se dejasen las trampas permanentemente en el campo, éstas se colocan y se retiran al día siguiente. Quincenalmente en el primer período del ensayo y semanalmente a partir del mes de agosto, se cuentan las moscas atrapadas durante un día, y se retiran de las trampas cromáticas, que se limpian y se les renueva el adhesivo; los emisores de TML se sustituyen cada dos meses. En el campo de ensayo se colocaron 12 trampas a razón de 3 trampas/Ha, mientras que en el campo sin tratar, de menores dimensiones, se colocaron 4 trampas con la misma densidad.

Los recuentos de fruta picada se realizaron sobre una muestra constituida por toda la fruta del $1 \%$ de los árboles tratados. En total se muestrearon 26 árboles completos de tres zonas diferentes. 


\section{II.2.3.- Resultados y discusión.}

Figura II.1: Evolución de las capturas de $C$. capitata en el campo de ensayo tratado con lufenuron por parcheo y en un campo blanco de referencia sin tratamiento. (Variedad Marisol)

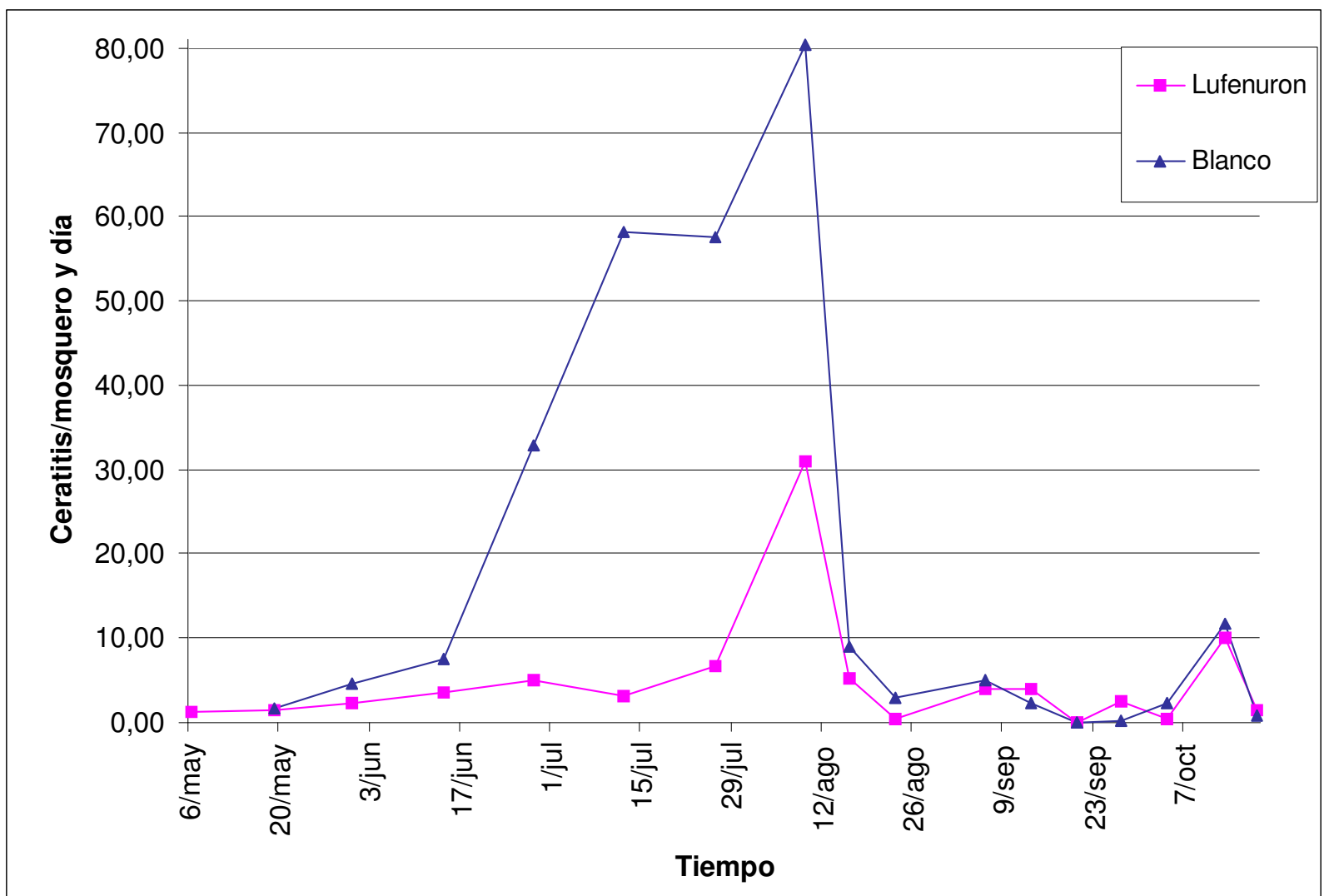

Tratamiento quincenal con lufenuron $(0,033 \%$ peso luf. / volumen de caldo)

Cebo proteico ( $1 \%$ volumen de cebo / volumen de caldo aplicado)

Aplicaciones quincenales desde el 3 de mayo al 4 de octubre.

Capturas realizadas con trampas cromáticas (amarillas) adhesivas, de 20x20 cm, con un emisor Aralure (TML).

Según se puede observar en el Figura II.1, la pauta de la evolución de la plaga es muy similar en los dos campos, pero la población del campo tratado es mucho menor que la del campo no tratado, hasta finales de agosto. En estas fechas, se produce una bajada espontánea de la población en la zona no tratada, y en septiembre no hay diferencia significativa entre ambas zonas. Esto se debe a que el campo blanco fue recolectado por su dueño precozmente.

Para estimar la influencia sobre las capturas de las poblaciones de mosca de los campos vecinos, hemos diferenciado dos poblaciones dentro del campo de ensayo. La 
población de la zona externa se recuenta con las trampas de 1, 2, 3, 5, 6 y 7 (situadas a menos de 100 metros de los campos vecinos) y la población interna se recuenta con las trampas 9, 10 y 12 (situadas a más de 100 metros de los campos vecinos). Las trampas 4, 8 y 11 se encuentran a una distancia aproximada de 100 metros por lo que se consideran como incluidas en una zona intermedia. Las medias totales y por períodos, de cada zona, se dan en la Tabla

\section{II.1.}

Tabla II.1: Media de capturas de mosca por zonas. (Campo de variedad Marisol).

\begin{tabular}{|c|c|c|c|c|}
\hline $\begin{array}{c}\text { Promedio de } \\
\text { capturas por } \\
\text { trampa y día. }\end{array}$ & $\begin{array}{c}\text { Del 4-5-99 al } \\
\mathbf{1 4 - 6 - 9 9} .\end{array}$ & $\begin{array}{c}\text { Del 15-6-99 } \\
\text { al 15-8-99 }\end{array}$ & $\begin{array}{c}\text { Del 16-8-99 } \\
\text { al 4-10-99 }\end{array}$ & Media anual \\
\hline Exterior (1) & $3,33 \pm 1,21 \mathrm{a}$ & $15,00 \pm 1,59 \mathrm{a}$ & $2,95 \pm 0,38 \mathrm{a}$ & $6.27 \pm 0.71 \mathrm{a}$ \\
\hline Media & $1,33 \pm 0,79 \mathrm{a}$ & $8,67 \pm 2,21 \mathrm{~b}$ & $2,14 \pm 0,73 \mathrm{a}$ & $3.67 \pm 0.53 \mathrm{~b}$ \\
\hline Interior (2) & $0,50 \pm 0,14 \mathrm{~b}$ & $7,08 \pm 0,55 \mathrm{~b}$ & $1,33 \pm 0,70 \mathrm{a}$ & $2,64 \pm 0.40 \mathrm{~b}$ \\
\hline Blanco & $4,63 \pm 0,83 \mathrm{a}$ & $\begin{array}{c}66,75 \pm 10,64 \mathrm{c} \\
* *\end{array}$ & $3,20 \pm 0,83 \mathrm{a}$ & $\begin{array}{c}18,05 \pm 1,63 \mathrm{c} * \\
*\end{array}$ \\
\hline
\end{tabular}

${ }^{a}$ las capturas que tienen la misma letra no difieren significativamente en el test tstudent con $\mathrm{P} \leq 0.05$.

** Denota diferencia significativa en el test $\mathrm{t}$-student con $\mathrm{P} \leq 0.01$.

Tratamiento con lufenuron ( $0,033 \%$ peso m.a. / volumen de caldo)

Aplicación por parcheo con cebo proteico $(3,33 \% \mathrm{v} / \mathrm{v})$ en las zonas exterior, media e interior. Aplicaciones quincenales desde el 3 de mayo al 4 de octubre.

(1) Zona lindante con los campos vecinos.

(2) Zona situada a más de 100 metros de los campos vecinos.

El análisis estadístico realizado, cuyos resultados se pueden observar en la Tabla II.1, denota una diferencia significativa $(\mathrm{P} \leq 0,01)$ entre la población media anual de mosca del campo sin tratar y las de cualquier zona del campo tratado. Esta diferencia es debida, principalmente, al período incluido entre el 15-6-99 y el 15-8-99. Como se puede observar en la Figura II.1, las capturas realizadas en este período son muy altas, influyendo decisivamente sobre las medias anuales. En los períodos previo (del 4 de mayo al 14 de junio) y posterior (del 16 de agosto al 4 de octubre) las diferencias de población son mínimas, apreciándose únicamente una diferencia significativa entre la población del campo sin tratar y la zona interior, en los meses iniciales del ensayo (Tabla II.1). 
En la Tabla II.2 se muestra el resumen de picadas y agusanadas, en las zonas interiores y exteriores.

Tabla II.2.- Promedio del porcentaje de fruta picada y agusanada frente a fruta muestreada, de las distintas zonas del campo tratado con lufenuron.

\begin{tabular}{|c|c|c|}
\hline Zonas & $\%$ (picadas/muestreadas) & $\begin{array}{c}\text { \% (agusanadas / } \\
\text { muestreadas) }\end{array}$ \\
\hline Exteriores & $0.99 \pm 0.22^{\mathrm{a}}$ & $0.32 \pm 0.14^{\mathrm{a}}$ \\
\hline Media & $1.00 \pm 0.16^{\mathrm{a}}$ & $0.08 \pm 0.03^{\mathrm{a}}$ \\
\hline Interiores & $0.33 \pm 0.08^{\mathrm{b}} *$ & $0.07 \pm 0.05^{\mathrm{b}} *$ \\
\hline
\end{tabular}

*** Denota diferencia significativa en el t-student con $\mathrm{P} \leq 0.01$.

${ }^{*}$ Denota diferencia significativa en el t-student con $\mathrm{P} \leq 0.1$.

${ }^{\mathrm{a}, \mathrm{b}}$ Porcentajes con la misma letra no difieren significativamente en el test t-student.

Muestreo de toda la fruta, del $1 \%$ de los árboles del campo tratado.

Tratamiento con lufenuron ( $0,033 \%$ peso m.a. / volumen de caldo)

Aplicación por parcheo con cebo proteico $(3,33 \% \mathrm{v} / \mathrm{v})$ en las zonas exterior, media e interior.

Aplicaciones quincenales desde el 3 de mayo al 4 de octubre.

Como se puede observar en la Tabla II.2, el porcentaje de frutas picadas en la zona interior es significativamente menor que en las zonas más cercanas a campos vecinos. De igual manera, el porcentaje de fruta agusanada respecto al de picadas es significativamente inferior en la zona interior. La baja proporción de naranjas en las que se han desarrollado larvas en su interior, respecto a la de naranjas picadas, confirma el efecto esterilizante del tratamiento. 


\section{II.3.- Ensayo de cebos quimioesterilizantes sólidos en Denia (variedad Valencia} Late); (cebos con lufenuron y ATP).

\section{II.3.1.- Introducción.}

Esta experiencia se realizó en un campo de naranjas (variedad Valencia Late) de 5 Ha de extensión. En este caso, el cebo quimioesterilizante se dispuso en forma sólida, en placas que se introducen en trampas delta. Las moscas son atraídas por las placas fagoestimulantes para su esterilización. Estas placas contienen ATP para atraer a hembras.

La eficacia del tratamiento se comprueba mediante el seguimiento de la población de mosca y por recuentos de fruta picada.

\section{II.3.2.- Materiales y métodos.}

El cebo se elabora en el laboratorio, con el lufenuron, emulgentes, atrayentes de hembras y un gelificante, como se describe en el punto I.4.2 de la Parte I de esta Tesis Doctoral, con la siguiente composición:

- Cebo completo $80 \%$

- Corn Steep Liquor $60 \%$

- Meliosa $30 \%$

- Sorbitol $10 \%$

- Agar 1\%

- $\quad$ ATP $2,1 \%$

- Lufenuron $1 \%$

- Fenilsulfonato cálcico + Emulsogen EL (6:4) 1\%

- Agua 14,9\% 
La mezcla se vierte en placas de $15 \times 12 \mathrm{~cm}$ de base y $1 \mathrm{~cm}$ de altura, colocando en cada placa $100 \mathrm{ml}$ de gel. A las placas con el cebo y el lufenuron les denominaremos, en adelante, "placas esterilizantes".

Las placas esterilizantes se colocaron en el interior de trampas delta y se colgaron en los árboles a razón de una cada 9 árboles (40 placas esterilizantes por Ha), de forma que ningún punto del campo estuviese a más de 10 metros de alguna placa esterilizante.

Las placas esterilizantes se colocaron en el campo durante la primera semana de marzo y se sustituyeron el 22 de abril. Durante la tercera semana de mayo se recogió la fruta del campo tratado con lufenuron.

Para valorar la eficacia de este método de aplicación se realizaron dos tipos de medidas: seguimiento de la población mediante capturas ("monitoring") de machos, y recuento de fruta picada.

En esta experiencia se utilizaron dos tipos de trampas de captura para seguir la evolución de la población de mosca: trampas cromáticas y trampas Nadel. Las trampas cromáticas son láminas de color amarillo, de 20 x $20 \mathrm{~cm}$, cubiertas por adhesivo de Econex (España). En el extremo superior de estas placas se insertó un emisor "Aralure" (Aragonesas Agro, España) que llevaba una carga de $1 \mathrm{~g}$ de TML.

Las trampas Nadel, descritas en la introducción de la presente Tesis Doctoral, llevaban en su interior un bote difusor que contiene $1 \mathrm{ml}$ de TML y $0,5 \mathrm{ml}$ de diclorvos (DDVP) para matar a las moscas que entren en la trampa.

Los recuentos de capturas y la limpieza de las trampas se hacía semanalmente. Las trampas permanecieron en el campo durante todo el ensayo, ya que las capturas durante los meses de marzo y abril son demasiado bajas para estimar la población en un solo día; el recuento semanal de capturas se inició el 2 de marzo. Los emisores de TML (Aralure) de las 
trampas cromáticas se sustituyen cada dos meses. Dado que este ensayo se desarrolla en invierno y primavera, y los botes difusores de TML+DDVP de las trampas Nadel no sufren temperaturas tan elevadas como en verano, en vez de cambiarlos cada 30 días se sustituyeron cada 45 días.

En el campo de ensayo se colocaron 36 trampas de conteo de capturas (18 Nadel y 18 cromáticas), con una densidad de 6,5 trampas/Ha, mientras que en el campo sin tratar, con la misma densidad se colocaron 5 trampas. En adelante, a las trampas utilizadas para tener un índice de población las denominaremos "trampas de captura".

Para realizar el recuento de picadas, la fruta se dejó sobremadurar en 6 árboles. Durante la segunda semana de mayo, se recogió toda la fruta del campo exceptuando la de estos 6 árboles marcados. La fruta permaneció en el campo hasta la segunda semana de junio, en que se realizó el recuento de fruta picada, en los árboles señalados, observando todos los frutos. Los árboles de muestreo se dejaron sin recolectar en un blanco vecino y en la zona central de la finca tratada, donde las placas esterilizantes permanecieron hasta el conteo de fruta picada. La zona central coincide con el centro geográfico de la finca, en un área alejada más de 50 metros de los campos sin tratamiento. 


\section{II.3.3.- Resultados y discusión.}

Hemos visto que el efecto de los cebos+lufenuron está muy influenciado por los campos vecinos $\mathrm{y}$, en particular, por los campos que tienen frutales de primavera. Como hemos visto, en este ensayo, para tener en cuenta el efecto de estos campos, hemos separado las capturas en tres poblaciones. Población del campo blanco, población de las zonas exteriores y población de las zonas interiores.

Las capturas de cada una de las parcelas se dan en la Figura II.2.

Figura II.2. Evolución de las capturas en las parcelas interiores, exteriores y blanco (ATP+lufenuron).

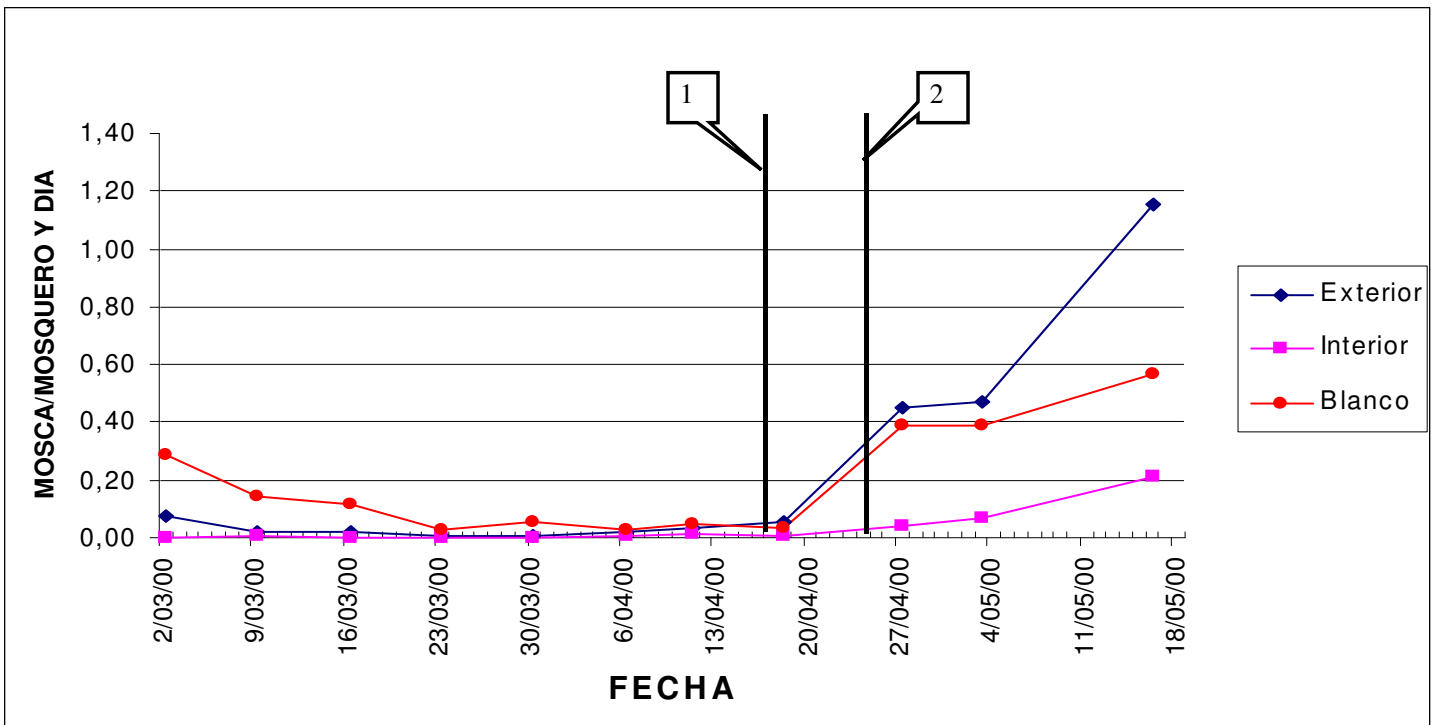

1.- Naranja recolectada el 15 de abril en el campo blanco (sin tratamiento).

Naranja recolectada el 20 de mayo en el campo tratado.

2.- Cambio de las placas atrayentes-esterilizantes.

Capturas de mosca con trampas cromáticas y trampas Nadel, ambas con TML.

Placas esterilizantes en las zonas interior y exterior desde la primera semana de marzo hasta el 15 de junio (40 placas esterilizantes / Ha.)

Como se puede observar en la gráfica, la población de mosca se mantiene a niveles bajos hasta mediados de abril. Es a partir de la segunda quincena de abril cuando la población aumenta rápidamente en las zonas exteriores y en el campo blanco, pero la zona interior tiene 
un aumento mucho menor. La naranja se recogió el 15 de abril, por su dueño, en el campo blanco, mientras que en los campos con placas esterilizantes (tanto interior como exterior) la naranja se recogió el 15 de mayo, lo que explica que la población de mosca aumente más lentamente en el campo blanco que en las zonas exteriores. A pesar de que la naranja se recogió un mes antes en el campo blanco, éste siguió teniendo capturas superiores al de la parcela interior.

A continuación se da una tabla con las capturas que se han realizado a lo largo del año repartidas en dos períodos. Un período inicial, en que las poblaciones son muy similares, y un período final que coincide con el aumento de las temperaturas y por lo tanto con el aumento generalizado de la población de Ceratitis capitata.

Tabla II.3- Resumen de capturas (ATP+lufenuron).

\begin{tabular}{|c|c|c|c|}
\hline $\begin{array}{c}\text { Promedio de } \\
\text { capturas por } \\
\text { trampa y día }\end{array}$ & $\begin{array}{c}\text { Del 2-3-00 al 18-4- } \\
\text { 00 }\end{array}$ & $\begin{array}{c}\text { Del 19-4-00 al 16- } \\
\mathbf{5 - 0 0}\end{array}$ & Media anual \\
\hline Exterior & $0,028 \pm 0,010^{\mathrm{a} 1}$ & $0,488 \pm 0,120^{\mathrm{a} 1}$ & $0,194 \pm 0,047^{\mathrm{a} 1}$ \\
\hline Interior & $0,006 \pm 0,003^{\mathrm{a} 1}$ & $0,084 \pm 0,025^{\mathrm{b} 2}$ & $0,034 \pm 0,009^{\mathrm{b} 2}$ \\
\hline Blanco & $0,161 \pm 0,063^{\mathrm{b} 3}$ & $0,339 \pm 0,133^{\mathrm{ab} 1} *$ & $0,161 \pm 0,063^{\mathrm{ab} 1}$ \\
\hline
\end{tabular}

, $\mathrm{b}$ las capturas que tienen la misma letra no difieren significativamente en el Multiple Range Test, con intervalos LSD, al 95\%.

1,2 las capturas que tienen el mismo número no difieren significativamente en el Multiple Range Test, con intervalos LSD, al 90\%.

* Naranja recolectada el 15 de abril en el campo blanco.

Capturas de mosca con trampas cromáticas y trampas Nadel, ambas con TML.

Como se puede observar en la Tabla II.3, no existe diferencia en las capturas entre la parte exterior del campo y la interior, a principios de ensayo, aunque sí existe diferencia significativa cuando la población de mosca empieza a crecer. A partir de mediados del mes de abril, la población comienza un crecimiento rápido en las parcelas exteriores; en cambio, en las parcelas interiores este crecimiento es mucho menor, ya no se ve tan invadida de moscas vecinas, y por lo tanto, el efecto esterilizante es más notable. La media de capturas es 
significativamente superior en el campo blanco que en la zona interior en el análisis estadístico con intervalos LSD al 90\%.

\section{Recuento de naranjas picadas.}

La fruta que se dejó sin recolectar estuvo muy expuesta a las picadas porque era la única que sobremaduró en el campo y supuso una gran atracción sobre la población de toda la zona.

El 16 de junio se realiza un conteo de fruta picada en los árboles sin recolectar. Los resultados se muestran en la Tabla II.4.

Tabla II.4.- Recuento de naranjas picadas en 6 árboles.

\begin{tabular}{|c|c|c|c|c|}
\hline Arbol & $\begin{array}{l}\text { Naranjas } \\
\text { revisadas }\end{array}$ & $\begin{array}{l}\text { Naranjas } \\
\text { picadas }\end{array}$ & $\begin{array}{c}\% \text { de } \\
\text { picadas }\end{array}$ & Promedio \\
\hline Blanco 1 & 100 & 99 & 99,00 & \multirow{3}{*}{$99,67^{\mathrm{a}} \pm 0,33$} \\
\hline Blanco 2 & 45 & 45 & 100,00 & \\
\hline Blanco 3 & 50 & 50 & 100 & \\
\hline Central 1 & 161 & 59 & 36,34 & \multirow{3}{*}{$35,25^{\mathrm{b}} \pm 1,75$} \\
\hline Central 2 & 110 & 35 & 31,82 & \\
\hline Central 3 & 157 & 59 & 37,58 & \\
\hline
\end{tabular}

a,b, c - Promedios con letras diferentes difieren significativamente según t student con $\mathrm{P}<0,05$.

Conteo de picadas el 16 de junio.

Blanco: Campo sin tratamientos.

Central: Zona interior tratada hasta el final del ensayo, no lindante con la zona sin tratamientos.

Como se puede observar en la tabla anterior el porcentaje de picadas es muy alto en la zona del blanco y mucho menor en la zona interior. El elevado número de picadas que se registró es justificado, ya que no se realizó ningún tratamiento insecticida y la única fruta receptiva que quedaba en las cercanías eran los 6 árboles reservados.

Otra observación remarcable es que, mientras en los árboles de la zona lindante el 70\% de la fruta estaba colgando del árbol, en las parcelas exteriores el 100\% de la fruta había caído al suelo. Mientras la fruta de la zona lindante tenía un elevado número de picadas pero con ausencia de larvas (picadas no efectivas o con huevos estériles), todas las frutas que se 
inspeccionaron en las parcelas exteriores (no tratadas) tenían en su interior larvas o se les podía apreciar un orificio por donde éstas habían salido. 


\section{II.4.- Ensayo de cebos quimioesterilizantes sólidos en Gandía; (cebos con lufenuron+ATP+TML).}

\section{II.4.1.- Introducción.}

Esta experiencia se realizó en Gandía en un campo de clementinas (variedad Marisol) de 1 Ha de extensión. El cebo quimioesterilizante se dispuso, en forma sólida, en placas petri de $9 \mathrm{~cm}$ de diámetro. Estas placas de cebo se ponen en el interior de trampas delta y se cuelgan de los árboles. Las moscas acudían a las trampas donde ingerían el cebo+lufenuron quedando esterilizadas.

En esta experiencia se ha realizado un seguimiento de la población de mosca y recuentos de fruta picada.

\section{II.4.2.- Materiales y métodos.}

El cebo se elaboró en laboratorio, añadiéndole el lufenuron, emulgentes, atrayentes y un gelificante tal y como se describe en el apartado I.4.2 de la presente Tesis doctoral. La composición del gel es:

- Cebo completo $80 \%$

- Corn Steep Liquor $60 \%$

- Meliosa $30 \%$

- Sorbitol $10 \%$

- Agar $1 \%$

- $\quad$ ATP $2,1 \%$

- Lufenuron $2 \%$

- Fenilsulfonato cálcico + Emulsogen EL (6:4) 2\%

- Agua 12,9\%

La mezcla se vierte en placas petri de $9 \mathrm{~cm}$ de diámetro, colocando en cada placa $60 \mathrm{ml}$ de gel. 
La parcela del campo tratada se encuentra relativamente aislada de otros campos de cítricos, ya que tiene el lado oeste y el lado norte cubiertos por una ladera de montaña sin cultivar. El lado sur enfrenta a una extensión de más de 300 metros de longitud de plantones que no han entrado en producción y la cara este enfrenta un campo de variedad Navelate (que no están receptivas durante el ensayo) y un campo de clementinas más tardías que la Marisol.

Por la ausencia de frutales y de variedades más precoces de cítricos en las proximidades, esta parcela es adecuada para estos ensayos.

En el campo tratado con lufenuron se colocaron, durante la primera semana de julio, 33 trampas/Ha con placas esterilizantes, que permanecieron en el campo hasta el mes de octubre. El gel contiene, además de cebo proteico y lufenuron, trimetilamina, acetato amónico y putrescina como atrayente de hembras, y en una de cada cinco placas una pastilla de sepiolita con trimedlure como atrayente de machos. Se ha dispuesto 1 placa esterilizante con atrayente de hembras cada 9 árboles (33 en el total del campo) y, en siete de estas placas, una pastilla de TML (una pastilla cada 36 árboles). Las placas se introducían en el interior de trampas delta que se colgaban de los árboles.

Para tener un término de comparación en el número de capturas se tomó un campo tratado con trampas de captura masiva, situado a 400 m en dirección norte, de la misma variedad de cítricos. En este campo, para combatir la mosca de la fruta, se realizaba un tratamiento recomendado de "captura masiva" mediante trampas comerciales (trampas Frutec $^{\circledR}$ ). Las trampas Frutec ${ }^{\circledR}$ se colocaron a mediados de julio y permanecieron en el campo hasta la recolección de la fruta, con una densidad de 42 trampas/Ha. Estas trampas se colocan a mediados de julio para disminuir progresivamente la población hasta niveles bajos. Con este 
método se pretende que cuando la fruta comience a estar receptiva, el nivel de población esté por debajo del umbral de tratamiento.

Para valorar la eficacia de este método de aplicación se realizaron dos tipos de medidas: seguimiento de la población mediante capturas ("monitoring") y recuento de picadas cuando la fruta iba a ser recolectada.

Para seguir la evolución de la población de mosca, en esta experiencia, se utilizaron trampas Nadel, y como atrayente-tóxico se utilizó un "bote difusor" que contenía $1 \mathrm{ml}$ de TML y $0,5 \mathrm{ml}$ de diclorvos (DDVP).

Las trampas de conteo, (trampas Nadel), permanecían en el campo un día a la semana. De este modo se pretendía tener una estimación de la población de mosca, sin provocar un descenso significativo de la población. Las capturas se contaron, semanalmente, a partir de la primera semana de junio. Los difusores de TML+DDVP se cambiaron cada 6 semanas. En el campo de ensayo se colocaron 12 trampas de conteo (a razón de 12 trampas/Ha), mientras que en el campo sin tratar se colocaron 5 trampas de conteo (con la misma densidad) para seguir la evolución de la población del blanco.

Para realizar el recuento de fruta picada se cogieron, en la segunda semana de septiembre, 100 frutos de 10 árboles en las parcelas tratadas y 100 frutos de 7 árboles en la parcela testigo. 


\section{II.4.3.- Resultados y discusión.}

La evolución de las poblaciones en el campo tratado con placas con lufenuron y las del campo tratado con trampas Frutec se puede observar en la Figura II.3:

Figura II.3: Evolución de las capturas de mosca en el campo tratado con placas con lufenuron $y$ en el campo tratado con trampas Frutec $^{\circledR}$. (Campos de variedad Marisol).

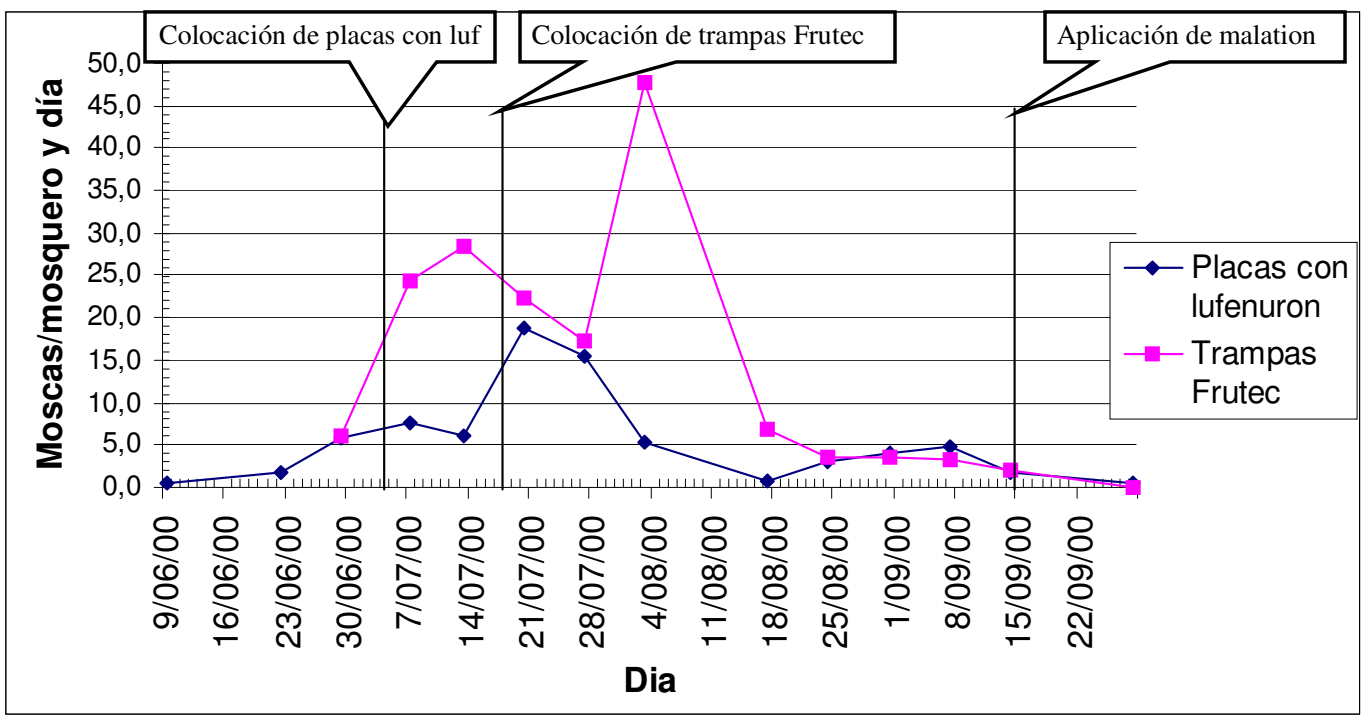

Capturas con trampas de tipo Nadel con TML (12 trampas /Ha).

Trampas Frutec colocadas el 18 de julio.

Placas con lufenuron colocadas el 4 de julio.

La línea vertical que se indica en la gráfica, a fecha 4 de julio, indica la colocación de cebos esterilizantes en el campo tratado con lufenuron, y la del 18 de julio indica la colocación de las trampas Frutec ${ }^{\circledR}$ en el campo tratado por capturas masivas. A mediados de julio, la población de mosca tenía niveles similares pero, mientras en el campo tratado con cebos esterilizantes se registró una población descendente, en las parcelas con las trampas Frutec $^{\circledR}$ se produjo un pico poblacional elevado (47 moscas/mosquero y día). Desde primeros de agosto, se observa el fuerte descenso de población que es usual para C. capitata. A partir del 25 de agosto no hay diferencias significativas entre los dos tratamientos, con niveles insuficientes de eficacia. Estadísticamente, la población de mosca del campo de referencia 
(tratado con trampas Frutec $^{\circledR}$ ) es, en toda la temporada, significativamente mayor que la población de mosca en el campo con cebos esterilizantes. En la segunda quincena de septiembre y para asegurar cualquier posible riesgo de perder parte de la cosecha, por la picada de mosca, se realizaron dos tratamientos con malation, ya que el campo era de propiedad privada, cedido amablemente para la experiencia.

\section{Conteo de fruta picada:}

A continuación se da el cuadro de porcentaje de clementinas picadas en los dos campos, cuyo conteo se realizó el 16 de septiembre.

Tabla II.5: Media del porcentaje de clementinas picadas en el campo tratado con cebos esterilizantes (lufenuron) y en el campo tratado con trampas Frutec. (Campos de variedad Marisol)

\begin{tabular}{|l|c|c|}
\hline \multirow{2}{*}{} & \multicolumn{2}{|c|}{ Media del tanto por cien de clementinas picadas \pm E.S. } \\
\cline { 2 - 3 } & $\begin{array}{c}\text { Campo con cebos } \\
\text { esterilizantes }\end{array}$ & $\begin{array}{c}\text { Campo con trampas } \\
\text { Frutec }\end{array}$ \\
\hline$\%$ de picadas & $1,70^{\mathrm{a}} \pm 0,49$ & $1,71^{\mathrm{a}} \pm 0,72$ \\
\hline
\end{tabular}

$\mathrm{P}<0,05$

${ }^{a}$ Promedios con letras iguales no difieren significativamente según t student con

Porcentaje de picadas antes de la realización de tratamientos con malation.

Las placas esterilizantes permanecen en el campo tratado con lufenuron, desde la primera semana de julio hasta la recolección de la fruta.

Las trampas Frutec permanecen en el campo del 18 de julio hasta la recolección de la fruta.

En las dos parcelas se aplicó un tratamiento con malation, a todo el árbol, el 16 de septiembre, por lo que a partir de esa fecha no se realizaron más conteos de fruta picada. Como se puede observar en el cuadro anterior, no hay diferencias entre las picadas de el campo tratado con lufenuron y el campo tratado con trampas Frutec ${ }^{\circledR}$. 


\section{II.5.- Ensayo con geles quimioesterilizantes en Sagunto (variedad New-Hall).}

\section{II.5.1.- Introducción.}

En esta experiencia se compara la eficacia de los tratamientos con placas esterilizantes frente a los habituales con malation.

Por razones poco claras, la población de mosca ha sido muy elevada en todas las parcelas, lo que condiciona los resultados finales del ensayo. Sin embargo, la experiencia nos da información de la evolución de las capturas con los dos tipos de tratamientos, aunque sean altas.

\section{II.5.2.- Materiales y métodos.}

El ensayo se realizó, entre los meses de junio y octubre, en una finca de cítricos de 2,7 Ha situada en el término municipal de Sagunto (Valencia). La variedad cultivada es NewHall, teniendo la finca en estudio 930 árboles.

La finca se encuentra rodeada de montañas al oeste, norte y sur, siendo el este el único lado que comunica con más cultivos de cítricos. Para evitar el contacto directo de la finca tratada con lufenuron con otros campos sin tratar, se coloca, en una franja de 100 metros en el linde este de la finca, una barrera de mosqueros Nadel y Tephri-trap para captura masiva. De esta forma se pretende disminuir la entrada de moscas fértiles en la finca de ensayos.

En la finca en estudio se colocaron 80 placas de $9 \mathrm{~cm}$ de diámetro de cebo gelificado que llevaba incorporado el lufenuron. Las placas iban introducidas en trampas delta de color amarillo de PVC y se dispusieron con una densidad de 1 cada 9 árboles. Las placas se colocaron el 30 de junio y permanecieron en el campo hasta el 30 de septiembre.

Los tratamientos con malation, en la parcela exterior, comenzaron el 2 de agosto y se han continuado semanalmente hasta el 18 de octubre. Los primeros tratamientos se realizaron 
por parcheo pero, a partir del 18 de septiembre, se realizaron mojando el árbol completo y sin cebo.

Las placas con gel contenían cebo proteico y atrayente para hembras (trimetilamina, acetato amónico y putrescina, tal y como se describe en el apartado I.4.2 de esta Tesis Doctoral) o atrayente para machos (emisor de TML), además del lufenuron. La composición del cebo, que es la misma que se utilizó en el ensayo de Gandía, se indica en el apartado II.4.2. Se ha dispuesto 1 placa con atrayentes de hembras cada nueve árboles y una placa con atrayentes de machos cada 36 árboles.

La población de moscas se siguió mediante capturas en trampas Nadel con difusores de TML (1ml) y DDVP (0,5 ml). Estas trampas se colocaron semanalmente, desde el 15 de junio al 15 de octubre. Las trampas se colocaban entre las 9 y 10 de la mañana y se retiraban entre las 11 y las 12 horas del día siguiente. De cada trampa se anotó el número total de capturas. 


\section{II.5.3.- Resultados y discusión.}

Figura II.4: Comparación de la evolución de las poblaciones de $C$. capitata en un campo tratado con lufenuron y en un campo tratado con malation. (Variedad New-Hall).

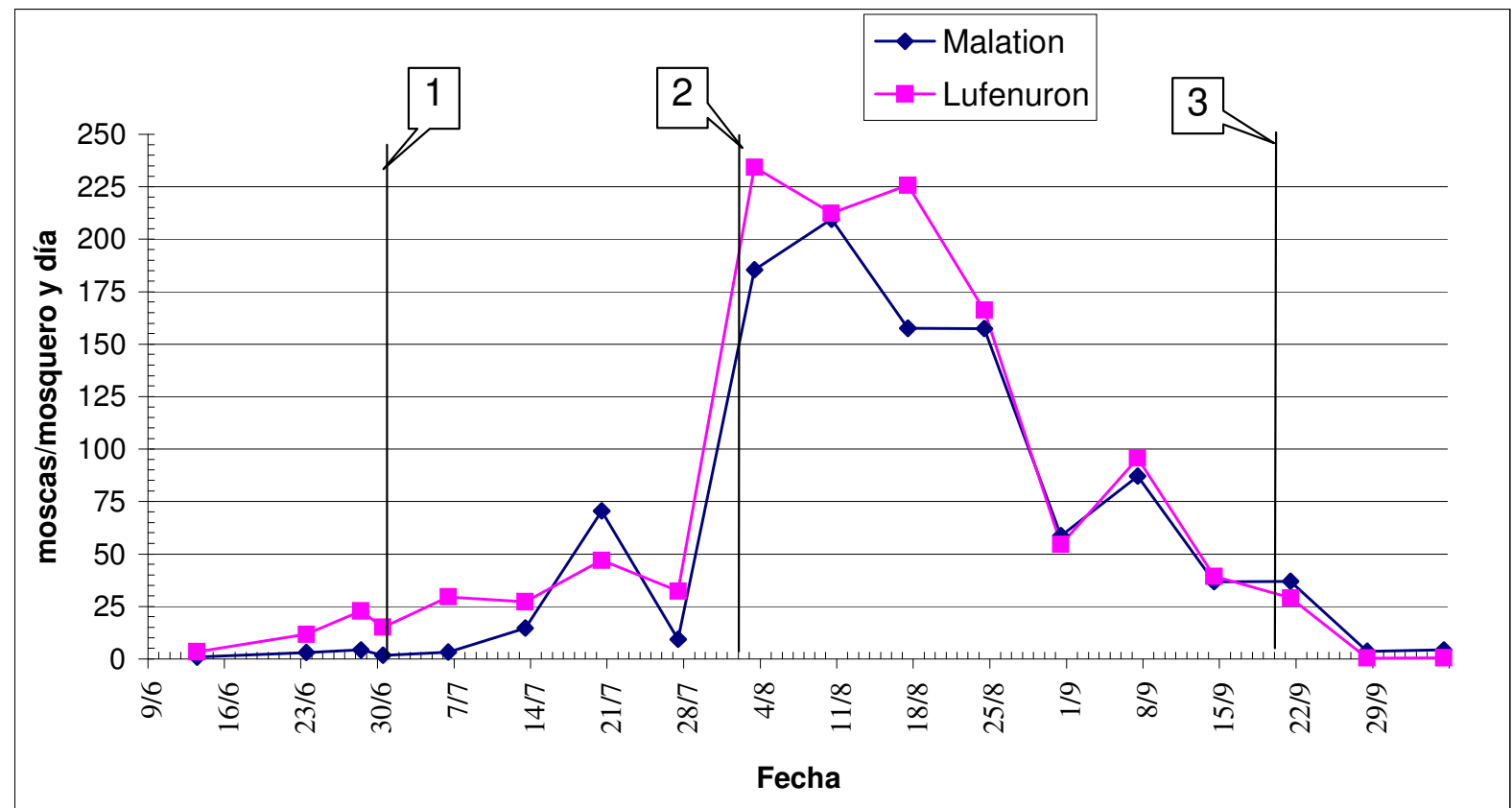

1 Colocación de placas esterilizantes.

2 Comienzo de los tratamientos semanales por parcheo con malation.

3 Comienzo de los tratamientos semanales a todo el árbol con malation. $\mathrm{ml})$.

Capturas realizadas con trampas Nadel (con un bote emisor de TML $1 \mathrm{ml}$ y DDVP 0,5

Las capturas que se observan en la Figura II.4 alcanzan valores de 200 moscas/mosquero y día, lo que supone un índice muy elevado. También se puede observar la pauta de la evolución de la plaga es muy similar en los campos con distintos tratamientos, aunque las capturas en el campo tratado con lufenuron nunca superan las del campo tratado con malation.

En la Figura II.4 hay que considerar 2 períodos importantes. Un primer período que va desde el 30 de junio al 1 de agosto, en que las parcelas no se tratan con malation. El segundo período va desde el 2 de agosto, fecha en que se realizó el primer tratamiento semanal por parcheo con malation en las parcelas de referencia, y el 18 de septiembre, en que se realizó el primero de los dos tratamientos totales con malation. 
En la Tabla II.6 se muestran las capturas realizadas en este campo de Sagunto durante los 2 períodos considerados.

Para disminuir la diferencia de variabilidad en las capturas y poder realizar el análisis estadístico hemos utilizado la transformación $\mathrm{X}=(\mathrm{x})^{1 / 2}$, siendo $\mathrm{x}$ la media de las capturas en las zonas en los períodos citados. Las medias con las transformaciones se dan en la Tabla

II.7.

Tabla II.6.- Comparación de medias de capturas en los campos de ensayo con diferentes tratamientos.

\begin{tabular}{|c|c|c|}
\hline & \multicolumn{2}{|c|}{ Media de capturas \pm E.S. } \\
\hline $\begin{array}{l}\text { Promedio de } \\
\text { capturas por } \\
\text { trampa y día }\end{array}$ & Del 30-6-00 al 1-8-00 & Del 2-8-00 al 22-9-00 \\
\hline Malation & $19,83 \pm 12,9$ & $116.16 \pm 24,52$ \\
\hline Lufenuron & $16,45 \pm 4,40$ & $91,53 \pm 21,83$ \\
\hline
\end{tabular}

Capturas realizadas con mosqueros Nadel con bote emisor de TML y DDVP

30 de junio: colocación de la placas con lufenuron en el campo de ensayo.

2 de agosto: comienzo de los tratamientos con malation en el campo de referencia.

Tabla II.7.- Comparación de la media de la raíz de las capturas en los campos de ensayo con diferentes tratamientos.

\begin{tabular}{|c|c|c|}
\hline & \multicolumn{2}{|c|}{ Media de capturas \pm E.S. } \\
\hline $\begin{array}{l}\text { Promedio de } \\
\text { capturas por } \\
\text { trampa y día }\end{array}$ & Del 30-6-00 al 1-8-00 & Del 2-8-00 al 22-9-00 \\
\hline Malation & $3,03 \pm 0,54^{\mathrm{a}}$ & $10,17 \pm 0,45^{\mathrm{a}}$ \\
\hline Lufenuron & $3,20 \pm 0,40^{\mathrm{a}}$ & $8,36 \pm 0,60^{\mathrm{b}}$ \\
\hline
\end{tabular}

${ }^{\mathrm{a}, \mathrm{b}}$ Las capturas que tienen la misma letra no difieren significativamente en el test $\mathrm{t}$ student con $\mathrm{P} \leq 0.05$.

Capturas realizadas con mosqueros Nadel con bote emisor de TML y DDVP 30 de junio: colocación de la placas con lufenuron en el campo de ensayo.

2 de agosto: comienzo de los tratamientos con malation en el campo de referencia.

Como se puede observar en la Tabla II.7, no existen diferencias entre las capturas de ambos campos en el primer período. En el segundo período sí que existen diferencias 
significativas, ya que aunque en los dos campos las capturas hayan sido elevadas, en el campo tratado con lufenuron son siempre menores.

En este ensayo no se pudo realizar un recuento fiable de picadas porque la fruta se recolectó la primera quincena del mes de octubre, cuando aún no estaba receptiva. En la única prospección que se realizó, antes de la recolección de la fruta, no se encontró ninguna naranja picada. 


\section{II.6.- CONCLUSIONES DE LOS ENSAYOS DE CAMPO.}

La complejidad de esta plaga provoca que los resultados obtenidos varíen según las experiencias si bien, en todas ellas, los mejores se han conseguido con las placas esterilizantes. La gran movilidad que presenta esta plaga en busca de fruta donde poner sus huevos, hace que los tratamientos localizados en pequeñas extensiones con cebos autoesterilizantes estén afectados por esta circunstancia.

Las aplicaciones han conseguido disminuir las poblaciones de mosca en todos los ensayos, si bien han necesitado el apoyo de aplicaciones insecticidas para proteger la fruta cuando el nivel de plaga es elevado.

Este método, al igual que los de captura masiva y confusión sexual, precisaría estudios mucho más extensos en cuanto a superficie y durante un período de tiempo no inferior a 3 años, para obtener resultados definitivos. Con el aumento de la superficie evitaríamos la gran influencia de las invasiones que se producen en los ensayos realizados, y con la prolongación de la duración de los ensayos, se confirmaría una disminución progresiva de la población por la esterilización de sucesivas generaciones y, a medio plazo, una reducción por debajo de los umbrales de tratamiento.

Este método también podría suponer un refuerzo muy efectivo de los medios de lucha que se basan en la suelta de machos estériles. La esterilización en campo, mediante quimioesterilizantes, supondría un aumento enorme de la eficacia de las sueltas, ya que, actuando sobre la población salvaje, disminuiría mucho la proporción "machos fértiles/machos estériles".

La mejora de los atrayentes es el mejor medio para incrementar la eficacia de este método y, con su perfeccionamiento, se puede conseguir aumentar las distancias de atracción y, por lo tanto, reducir la densidad de trampas necesarias para un tratamiento efectivo. 
Con la colocación de placas con geles sólidos se ha aumentado la duración del efecto esterilizante, lo que resulta esencial para este tipo de tratamientos. De esta forma las aplicaciones quincenales se ven sustituidas por la colocación de trampas al principio de la campaña, resultando más cómodo y económico.

En la Parte III de esta Tesis se trata de aumentar la duración esterilizante de los geles y reducir la densidad de trampas necesarias conservando la eficacia.

\section{PARTE III.}


ENSAYOS EN CAMPO DE LOS GELES DESARROLLADOS.

PARCELAS DE GRAN EXTENSIÓN. 


\section{III.1- INTRODUCCIÓN.}

Las técnicas de esterilización en la lucha contra insectos, suponen la posibilidad de reducir las plagas a niveles tolerables. Mientras las aplicaciones de insecticidas químicos consiguen un control puntual de las plagas, los tratamientos basados en la esterilización pueden reducir la población, situándola por debajo de los umbrales deseados e incluso acabar con una plaga endémica (Borkovec, 1966).

La suelta de machos estériles es una modalidad de esta forma de lucha, pero los éxitos obtenidos, hasta ahora con este método, han sido puntuales y en zonas localizadas (Katsoyannos et al, 1999b); (Wong et al., 1992). La utilización de machos estériles de Ceratitis capitata en España se desarrolló entre los años 74 a 77 en la isla de Hierro y Tenerife y Murcia (Ros, J.P., 1977). Tras un trabajo de tres años en la isla de Hierro, si bien se alcanzó un nivel de protección de la fruta aceptable (1\% de fruta picada), no se consiguió erradicar la plaga. A lo largo de los tres años de tratamiento, se soltaron, en una superficie de $1500 \mathrm{Ha}$, cerca de 100 millones de pupas.

Otra forma de lucha, enmarcada en las técnicas de esterilización, es la aplicación de quimioesterilizantes. Por las distancias a las que se puede desplazar la mosca de la fruta, estos ensayos deben realizarse en campos aislados y de gran extensión, en los que los efectos de poblaciones vecinas se vean atenuados, y mejor si están protegidos por barreras naturales o artificiales que impidan la entrada de moscas fértiles. En esta parte de la Tesis, se describen las experiencias que tratan de cumplir estas condiciones. 
El principal objetivo de este ensayo en gran escala es estudiar la disminución de la población de mosca, en relación con los campos de referencia.

Otros objetivos son: estudiar la distribución de mosca dentro del campo de ensayo y su dinámica poblacional en función de variables climatológicas y orográficas. También se estudia el efecto que tiene la presencia de frutales de verano en la población de mosca y su influencia como reservorio, así como la eficacia de distintos tipos de trampas y atrayentes, para machos y hembras. Finalmente, se hace una estimación del valor umbral de tratamiento para $C$. capitata, expresado como moscas /mosqueros y día, por encima del cual se observan daños económicos importantes en los cultivos.

Puesto que se experimenta con campos de propiedad privada, amablemente cedidos, se ha cuidado el evitar posibles daños sobre la fruta, cuando está receptiva, realizando tratamientos con malation cuando las circunstancias lo requerían.

En esta parte de la Tesis Doctoral se detallan los ensayos realizados, durante un primer año de experiencias, en campos de gran extensión. 


\section{III.2.- MATERIALES Y MÉTODOS.}

El campo de ensayos se encuentra en el término municipal de Alzira, concretamente en el interior del Valle de la Casella. Este valle se encuentra cerrado al norte por la "Serra de Murta" y al sur por la "Serra de les Agulles". En dirección este, el valle se cierra con una pequeña elevación montañosa de varios km de longitud que separa el Valle de la Casella de los campos de cultivo del municipio de Tavernes de la Valldigna. Por el oeste, el valle se abre hacia la población de Alzira, siendo el único extremo del campo de ensayo que linda con otros cultivos de cítricos.

La zona de experiencias se sitúa en un valle orientado este-oeste que tiene una extensión de $80 \mathrm{Ha}$, y linda al este con una zona utilizada para el ensayo de placas infectivas con un hongo entomopatógeno, y al oeste con campos de cultivo de cítricos donde se realizaron tratamientos convencionales. A 300 metros al oeste de la zona de experiencias se eligió un campo de 5 Ha que se tomó como blanco para comparar sus capturas con el campo tratado con quimioesterilizantes.

Para evitar en lo posible, que las moscas de huertos vecinos invadiesen el campo tratado con placas quimioesterilizantes, se han empleado dos tratamientos: el primero, mediante una barrera de captura masiva, colocando trampas con atrayentes e insecticida, a lo largo de la frontera entre el campo tratado con quimioesterilizantes y el resto de los campos; además se reforzó la barrera mediante tratamientos convencionales con malation y cebo proteico. Para la captura masiva se emplearon trampas McPhail modificadas, con emisor de TML (Econex), cada 40 metros $\left(6,25\right.$ trampas/Ha), y trampas Tephri-Trap cebadas con Tri-pack de Consep ${ }^{\circledR}$ cada 20 metros (25 trampas/Ha). La barrera de trampas se colocó en el límite oeste de la zona de ensayo, en una banda de 100 metros de ancho. Las aplicaciones se realizaron en tierra, por los propios agricultores, aplicando malation con pistola, y por aire mediante una avioneta de 
tipo Brave. El tratamiento aéreo se realizó el 28 de agosto sobre los 500 metros de ancho del valle, y a lo largo de $2 \mathrm{~km}$., con un tratamiento total de la superficie y un gasto de 20 litros por Ha de caldo (malation $0,75 \%$ m.a.: concentrado de proteínas hidrolizadas 1,2\% (con una riqueza proteica del $30 \% \mathrm{p} / \mathrm{v}))$.
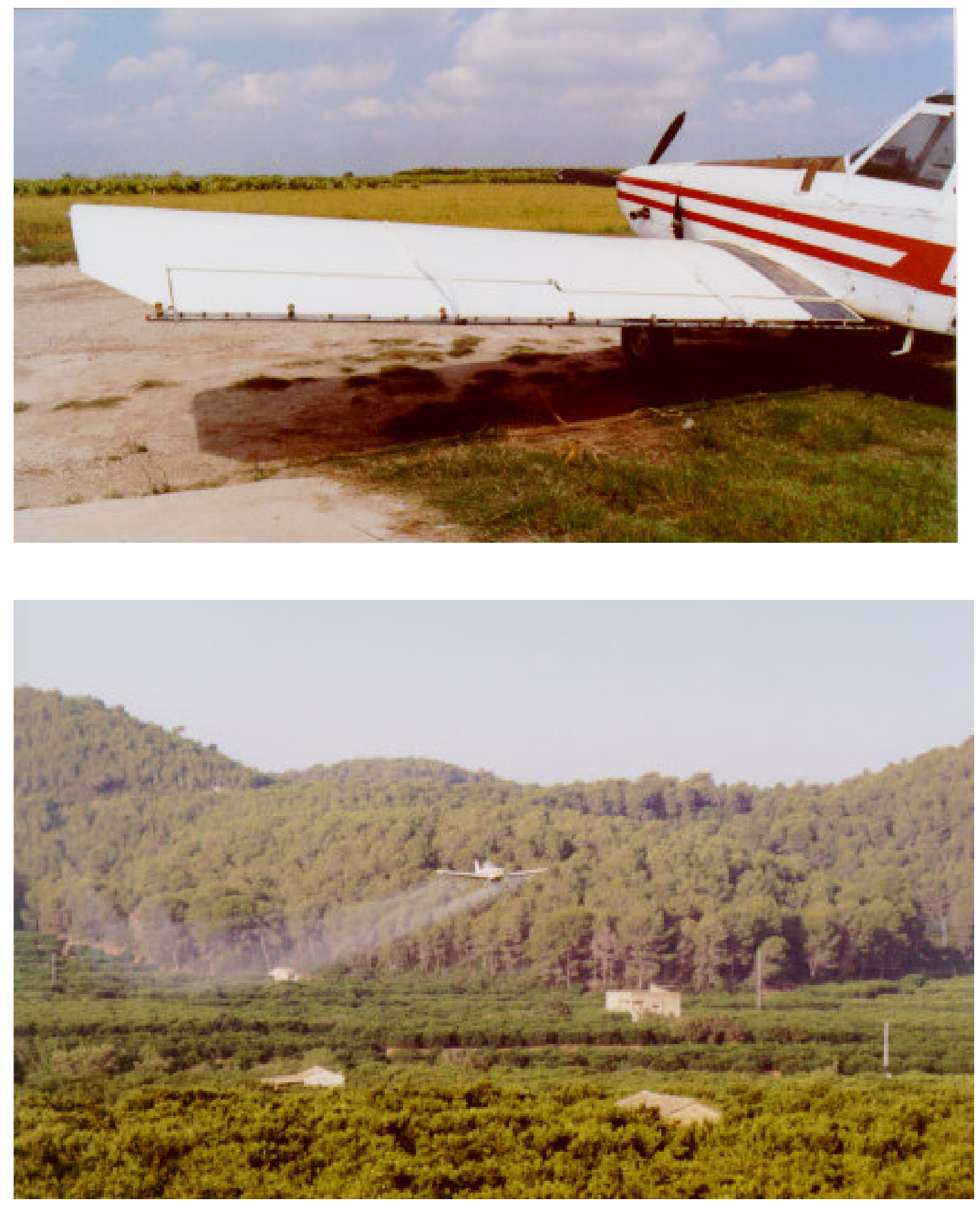
Con estos tratamientos se perseguían dos objetivos: disminuir la entrada de mosca por el lado oeste de la zona de estudio y proteger la fruta del campo tomado como blanco. Esto hace que el campo blanco sólo pueda servir de referencia de la población natural hasta el 28 de agosto, lo cual ha sido necesario para no arriesgar la cosecha de los campos cedidos para el ensayo. Por lo tanto, a partir del 28 de agosto la comparación de la eficacia del campo tratado con lufenuron se realizará frente a un campo tratado con malation, lo que nos informa de la eficacia de los tratamientos quimioesterilizantes frente a los tratamientos convencionales.

El campo de ensayo es una plantación donde predominan especies del género Citrus, siendo las variedades cultivadas: Okitsu, Marisol, Satsuma, Clementina fina, Clementina Córcega, Clemen Nules, Navelina, Washington Navel, Navelate, Sanguinelli y Valencia. También hay varias líneas de frutales o algún frutal aislado que, aunque no supongan una gran influencia sobre los resultados totales, si pueden alterar la población en algunas parcelas del área en estudio. Los frutales presentes en la zona son: nísperos, melocotoneros, ciruelos, higueras y caquis.

Las placas atrayentes con lufenuron se fabrican como se explica en la Parte I de esta Tesis Doctoral, siendo su composición final:

- Cebo completo $80 \%$

- Corn Steep Liquor (CSL) $60 \%$

- Meliosa $30 \%$

- Sorbitol $10 \%$

- Carboximetil celulosa $4 \%$

- Lufenuron $3 \%$

- Fenil Sulfonato Cálcico y Emulsogen EL(6:4) 3\%

- Agua $10 \%$ 
Cada placa petri de $9 \mathrm{~cm}$ de diámetro contiene $70 \mathrm{ml}$ del gel descrito, formando lo que en adelante denominamos placas de lufenuron. Estas se introdujeron en trampas delta y se colgaron de los árboles a una altura de 1,5 m. En el campo se pusieron 26 trampas delta por hectárea a tresbolillo, de forma que cada trampa tuviera un radio de influencia de 11 metros. En total se colocaron 1.800 trampas, lo que suponía 70 Ha de tratamiento tras descontar barrancos y caminos no tratados.

En cada trampa delta, además de la placa de lufenuron, se introdujeron, adheridos a su pared, tres sobres de Tri-pack de Consep ${ }^{\circledR}$ (trimetilamina, acetato amónico y putrescina) con los que se pretendía aumentar la atracción de hembras sobre la que supone el cebo. En una de cada tres trampas delta con Tripack, se introdujo un emisor de TML (Econex) para la atracción sobre machos. En este caso, la distancia entre emisores de TML es tres veces mayor que la distancia entre emisores Tripack.

Las trampas delta con placas de lufenuron se colocaron entre el 24 de abril y el 10 de mayo y no se han sustituido hasta el mes de octubre, lo que supone más de 150 días de actividad contrastada mediante ensayos en laboratorio cada 20 días. La metodología de los ensayos se describe en la Parte I de la presente Tesis Doctoral (apartado 1.5.1).

Para realizar el seguimiento de la población, se colocaron 65 mosqueros McPhail para machos y 19 mosqueros Tephri-Trap para machos y hembras. Ambos tipos son mosqueros de plástico, invaginados y con tapa transparente, pero cada uno llevaba un tipo de atrayente. El mosquero McPhail no tiene aperturas laterales y llevaba en su interior un emisor de TML $\left(\right.$ Econex $\left.^{\circledR}\right)$ y una pastilla de DDVP. Los mosqueros Tephri-Trap llevan en su interior los 3 emisores de membrana que forman el Tripack $\left(\right.$ Consep $\left.^{\circledR}\right)$ y una pastilla de DDVP.

Los mosqueros McPhail, con emisores de TML, se colocan a 100 metros uno de otro, formando una cuadrícula sobre el campo de ensayo, en que cada mosquero nos da el índice de 
población de una hectárea. Para tener una estimación de la población de hembras se colocaron mosqueros Tephri-Trap con atrayentes Tri-pack cada 200 metros, en el centro geográfico de cada cuadrado formado por los mosqueros McPhail, es decir, un mosquero cada 4 hectáreas.

Los mosqueros se revisan semanalmente desde el mes de abril hasta la primera quincena de agosto y dos veces por semana de la segunda quincena de agosto hasta el 7 de octubre. De esta forma se pretende tener un índice de población fiable, durante todo el año, con un seguimiento más preciso en el período en que la fruta está receptiva.

Tanto los emisores de los mosqueros de barrera, como los de lo mosqueros de seguimiento de la población se fueron reemplazando a lo largo de la experiencia. Los emisores Tripack se sustituyeron cada 45 días (3 sustituciones a lo largo del ensayo), mientras que los emisores de TML permanecieron en el campo durante 90 días (una sola sustitución). Las pastillas de DDVP se renovaron cada 90 días.

El muestreo de picadas se realizó semanalmente a partir del 20 de agosto en las variedades que comenzaban a estar receptivas en este orden: Okitsus, Marisol y Navelinas. El conteo de picadas se realizó sobre uno de cada 20 árboles y 40 frutos en cada árbol, 10 en cada orientación, hasta que apareció la primera fruta picada. Una vez se observó la primera picada el muestreo se realizó sobre uno de cada 10 árboles y 40 frutos por árbol repartidos de la misma forma.

En el campo de ensayos se han realizado dos pulverizaciones puntuales mediante un turbo con malation $50 \%$ p/v al 0,15\% de concentración de m.a.. La primera se realizó el 23 de agosto sobre una higuera cuyos efectos podían alterar el ensayo. La segunda, llevada a cabo el 31 de agosto se realizó sobre la misma higuera y 3 caquis que comenzaban a madurar con el mismo producto. 
El 25 de septiembre, 2 de octubre y 8 de octubre se realizaron tratamientos en una subparcela de variedad Marisol con orientación sur para evitar la pérdida de parte de la cosecha. El tratamiento se realizó con turbo aplicando malation $50 \%$ p/v, al 0,15\% m.a. sobre árbol completo. La primera semana de octubre también se realizó una aplicación de malation con mochila (malation $50 \%$ al $0,5 \%$ m.a. y cebo proteico $30 \%$ al $0,5 \%$ ) en una parcela donde se cultivan clementinas var. Marisol dobladas de melocotoneros.

Para la medida de la población de referencia (sin tratamiento quimioesterilizante) se colocaron seis mosqueros McPhail en una banda de $100 \mathrm{~m}$ situada a $500 \mathrm{~m}$ al oeste de la zona de ensayos. En esta zona no se realizaron tratamientos para la mosca hasta el 28 de agosto, en que se realizó una pulverización aérea. Esta pulverización tuvo por objeto prevenir las pérdidas de cosecha en los campos amablemente cedidos y, por otra parte, reforzaba la barrera contra la invasión de mosca. Con la aplicación de malation perdemos una referencia de un campo sin tratar, pero lo aprovechamos como una referencia de campo con tratamientos insecticidas clásicos. Los mosqueros se colocaron con la misma densidad que en la zona tratada, abarcando de norte a sur todo el ancho del valle. Además se colocaron 5 mosqueros McPhail en una finca "ecológica", situada a $3 \mathrm{~km}$ en dirección oeste, para tener un segundo campo de referencia sin ningún tratamiento químico. En este "blanco ecológico" sólo se cultivan variedades tardías de cítricos.

Para ver diferencias de población entre las distintas zonas tratadas se utiliza un test de datos apareados, para eliminar la variabilidad diaria propia de la dinámica de población de mosca. Mediante este análisis se comparan las poblaciones, día a día, de las distintas zonas en estudio, de forma que la media de las diferencias dividida por el error estándar se compara con los valores de una distribución t de Student con n-1 grados de libertad, siendo n el número de recuentos dentro de un mismo período.

Los datos se analizan mediante el paquete estadístico Statgraphics 5.0. 
PARTE III 


\section{III.3.- RESULTADOS.}

A continuación se exponen los resultados del seguimiento de la población, mediante mosqueros McPhail de plástico, utilizando trimedlure (TML) como atrayente. Los resultados del seguimiento de la población se muestran en la Figura III.1 y III.2:

Figura III.1- Comparación de la evolución de las capturas del 17 de abril al 27 de agosto entre un blanco ecológico y un campo tratado con lufenuron.

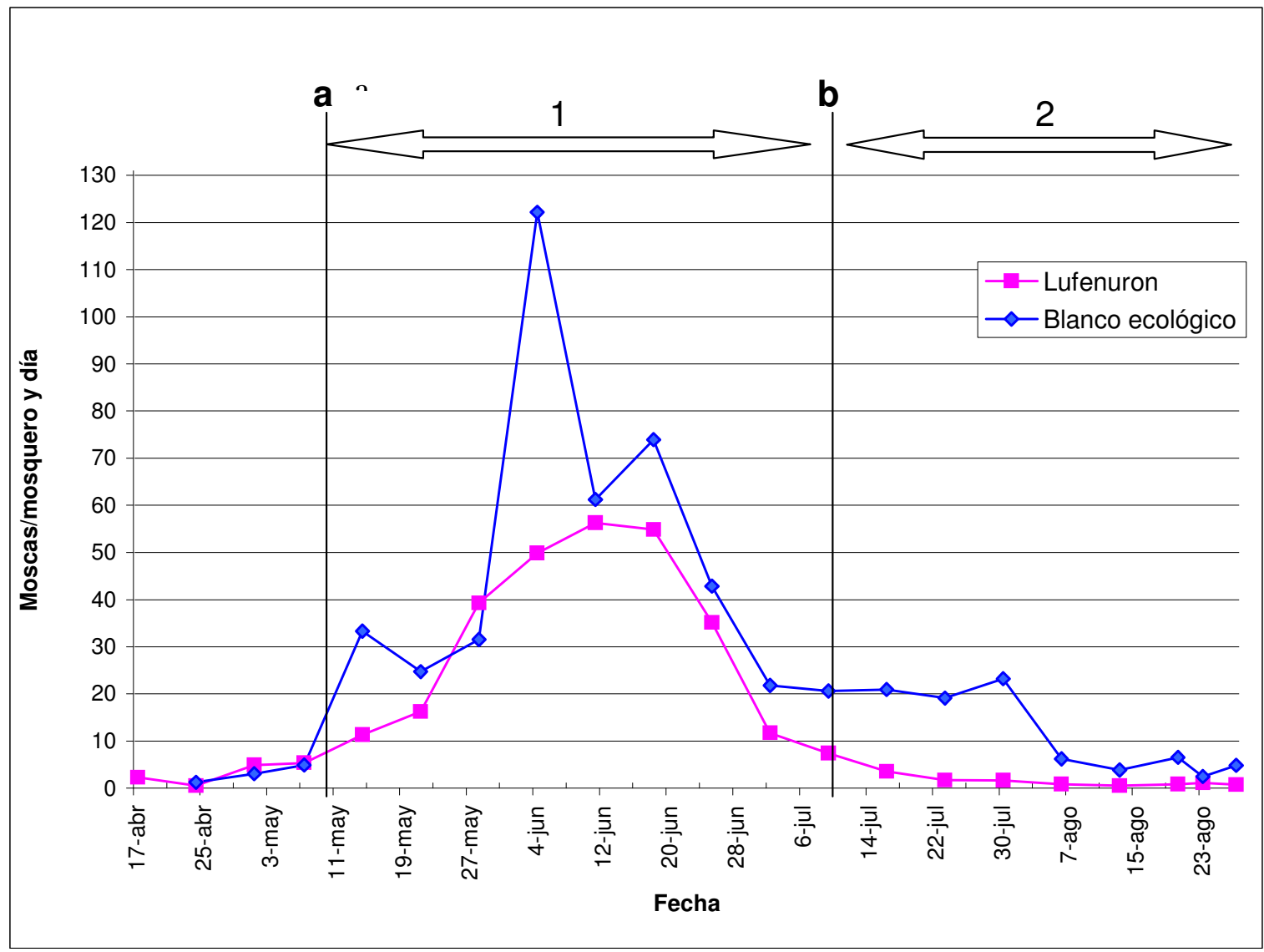

Blanco ecológico: Campo de 8 Ha de superficie en el que no se realiza ningún tratamiento químico. Lufenuron: Campo de $80 \mathrm{Ha}$ en el que se realiza un tratamiento con placas esterilizantes con lufenuron a ) 10 de mayo: colocación de trampas atrayentes quimioesterilizantes.

b ) 10 de julio: primera generación afectada por el tratamiento esterilizante.

Capturas realizadas con mosqueros McPhail y emisor de TML. 
Figura III.2- Comparación de la evolución de las capturas, del 20 de agosto al 10 de octubre, entre el campo tratado con lufenuron y dos blancos: blanco ecológico, blanco tratado con malation.

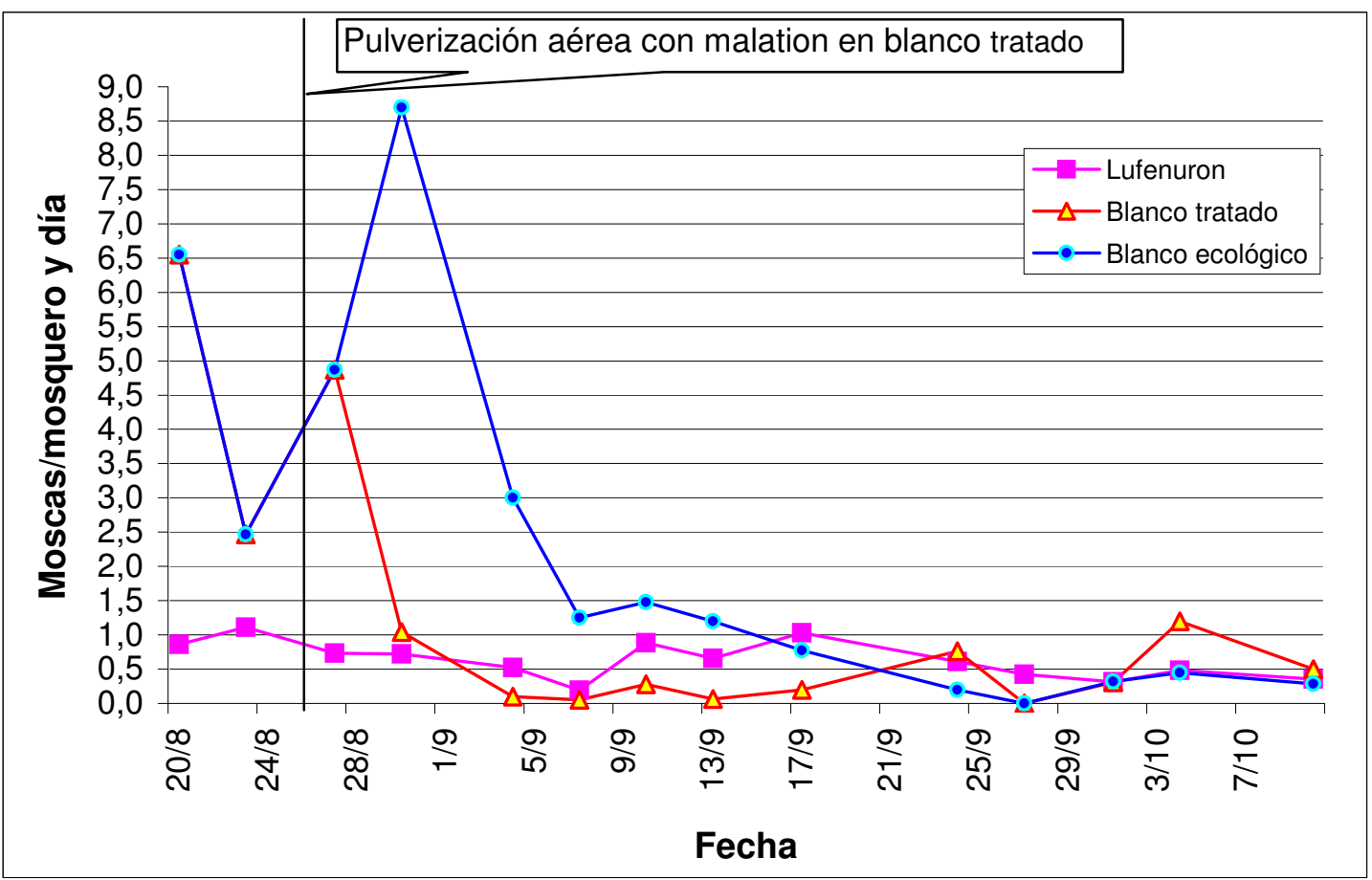

Blanco tratado: Campo de 5 Ha de superficie, situado a 300 metros del campo de ensayo. En este campo se ha realizado un tratamiento aéreo con malation el 28 de agosto y varios tratamientos terrestres posteriores.

Blanco ecológico: Campo de 3 Ha de superficie, situado a $3 \mathrm{~km}$ del campo de ensayo, en el que no se realiza ningún tratamiento químico.

Lufenuron: Campo de 80 Ha en el que se realiza un tratamiento con placas esterilizantes con lufenuron.

Capturas realizadas con mosqueros McPhail y emisor de TML.

Para estudiar la evolución de la población de mosca, el ensayo se ha subdividido en 3 períodos:

El primer período, (Figura III.1) va desde la colocación de las placas de lufenuron hasta el 10 de julio, lo que supone 2 meses de tratamiento esterilizante. Durante este período, a pesar del pico anómalo del blanco el 6 de junio, no se observan diferencias significativas (con $\mathrm{P}<0,1)$ entre las capturas del campo tratado con lufenuron y el campo blanco; hay una emergencia de mosca adulta, gracias a las condiciones climatológicas favorables del principio del verano, que provienen de moscas de principios de temporada y pupas del año pasado que no han sufrido el tratamiento esterilizante. En segundo lugar, la esterilización tiene efecto 
sobre la generación siguiente a la tratada, lo que supone un período de latencia de, como mínimo, 45 días desde el comienzo del tratamiento.

En el segundo período (Figura III.1), que incluye las semanas del 10 de julio al 28 de agosto, se pueden observar grandes diferencias de población entre el campo tratado con lufenuron y el campo blanco. En efecto, en este período, la actividad esterilizante ya debe observarse en gran parte de la población del campo de ensayo, ya que la población está formada mayoritariamente por la siguiente generación a la tratada. De hecho, en este período se aprecian diferencias significativas entre las capturas de los campos sin tratamiento (campo blanco) y el campo tratado con lufenuron. En la Figura III.1 también se puede observar que a final de junio y principios de julio se produce un descenso general de la población de mosca.

El tercer período (Figura III.2), entre el 28 de agosto y el 15 de octubre, coincide la actividad insecticida en el campo blanco tratado con malation y la actividad esterilizante en el campo con lufenuron. La población de mosca en el blanco tratado con malation desciende incluso por debajo del nivel de población obtenido con el tratamiento esterilizante, pero en este período no se observan diferencias significativas entre las poblaciones del campo tratado con malation y el campo tratado con quimioesterilizantes.

Como se puede observar en la Figura III.2, a partir del 28 de agosto, las capturas de la zona blanco se dividen en dos líneas de evolución: la del blanco sin tratamientos químicos (Blanco ecológico "O”) y la del blanco con tratamiento aéreo con malation el 28 de agosto (Blanco tratado " $\boldsymbol{\Delta} ")$.

Con la pulverización aérea se observa un descenso muy acusado de la población de mosca, que hace que, durante las dos primeras semanas de septiembre, la población se mantenga muy cercana a cero. El blanco ecológico, por su parte, sigue una pauta normal con 
un ascenso en las capturas y un posterior descenso hasta niveles muy bajos. Este descenso tan acusado de la población del campo ecológico se corresponde con la ausencia de fruta receptiva en este campo y la existencia de fruta receptiva en los campos vecinos. De hecho, es muy clarificador el acusado descenso de capturas que se produce con el comienzo de maduración de las variedades de cítricos Otiksu y Marisol vecinas.

Los niveles de capturas de los tres períodos se pueden observar en la Tabla III.1.

Tabla III.1. Promedio de capturas en las 3 zonas en estudio durante los 3 períodos.

\begin{tabular}{|c|c|c|c|}
\hline \multirow{2}{*}{} & \multicolumn{3}{|c|}{ Promedio de capturas \pm E.S. } \\
\cline { 2 - 4 } & $\begin{array}{c}\text { Del 10 de mayo } \\
\text { al 10 de julio }\end{array}$ & $\begin{array}{c}\text { Del 10 de julio al } \\
\mathbf{2 8} \text { de agosto }\end{array}$ & $\begin{array}{c}\text { Del 28 de agosto } \\
\text { al 10 de octubre }\end{array}$ \\
\hline Lufenuron & $28,7 \pm 6,49^{\mathrm{a}}$ & $1,4 \pm 0,34^{\mathrm{a}}$ & $0,56 \pm 0,08^{\mathrm{a}}$ \\
\hline Blanco tratado & -- & -- & $0,41 \pm 0,13^{\mathrm{a}}$ \\
\hline Blanco ecológico & $43,7 \pm 10,81^{\mathrm{a}}$ & $10,9 \pm 3,04^{\mathrm{b}}$ & $1,60 \pm 0,75^{\mathrm{a}}$ \\
\hline
\end{tabular}

Blanco tratado: Campo de 5 Ha de superficie, situado a 300 metros del campo de ensayo. En este campo se ha realizado un tratamiento aéreo el 28 de agosto y varios tratamientos terrestres posteriores.

Blanco ecológico: Campo de 3 Ha de superficie, situado a $3 \mathrm{~km}$ del campo de ensayo, en el que no se realiza ningún tratamiento químico.

${ }^{a}$, ${ }^{2}$ Promedios con distinta letra dentro de un mismo período difieren significativamente en el análisis t-student de datos apareados con $\mathrm{P}<0,05$.

Como se puede observar en los datos de la tabla anterior, existen diferencias significativas $(\mathrm{P}<0,05)$ entre las poblaciones de mosca, en el período del 10 de julio al 28 de agosto, como consecuencia del tratamiento con lufenuron iniciado el 10 de mayo. En los demás períodos no hay diferencias, si bien se podrían esperar entre el tratamiento con lufenuron y el blanco tratado respecto al blanco ecológico. En este caso, aunque se puede observar que las medias de capturas son menores en el campo tratado con lufenuron y en el 
campo tratado con malation, respecto al blanco ecológico, las diferencias no son significativas en el análisis estadístico con $\mathrm{P}<0,05$. Las diferencias, en este tercer período, se dan con $\mathrm{P}=0,13$ entre el blanco ecológico respecto al blanco tratado y con $\mathrm{P}=0,19$ de blanco ecológico respecto al tratamiento con lufenuron. Esta baja población de mosca en la zona "ecológica" es debida a la ausencia de variedades tempranas de fruta, lo que provoca la migración de las moscas hacia los campos vecinos y que las capturas sean similares a las de los campos con tratamientos.

Los niveles de población de la mosca son más altos en primavera-verano como es normal en estas zonas, alcanzando un máximo a mediados de junio.

En los datos anteriores, se observa una elevada variabilidad debida a la heterogeneidad de los campos. Estos campos están formados por zonas con distintas variedades cultivadas, técnicas de cultivo, climatología y orografía. Para disminuir dicha variabilidad vamos a subdividir los resultados según la situación de las zonas de estudio.

Estudio de la influencia de la situación y orientación del campo en la evolución de las capturas de mosca. División del campo tratado en dos zonas: solana y umbría.

En los campos tratado y no tratado se distinguen: la zona situada al norte del valle, orientada al sur, en lo que en adelante denominamos solana, y la zona situada al sur del valle, orientada al norte, en lo que en adelante denominaremos umbría. Las poblaciones de solana y umbría difieren significativamente unas de otras, por lo que las analizaremos por separado. La evolución de la población en solana y umbría no es la misma como se puede observar en las Figuras III.3a III.3.b, donde dichas poblaciones son la media de todas las parcelas de cada zona. 
La subida de las capturas está desfasada 13 días entre la solana y la umbría. El desfase va desapareciendo hasta principios del mes de julio en que las dos poblaciones se vuelven a solapar. El retraso inicial de la población de la zona de umbría viene determinado por las menores temperaturas, que demoran la salida de adultos de las pupas enterradas. El descenso conjunto de la población se puede deber a las altas temperaturas y baja humedad del verano o, a la ausencia de fruta donde reproducirse en mayo-junio.

Figura III.3a. Evolución de las capturas en las zonas de solana y umbría.

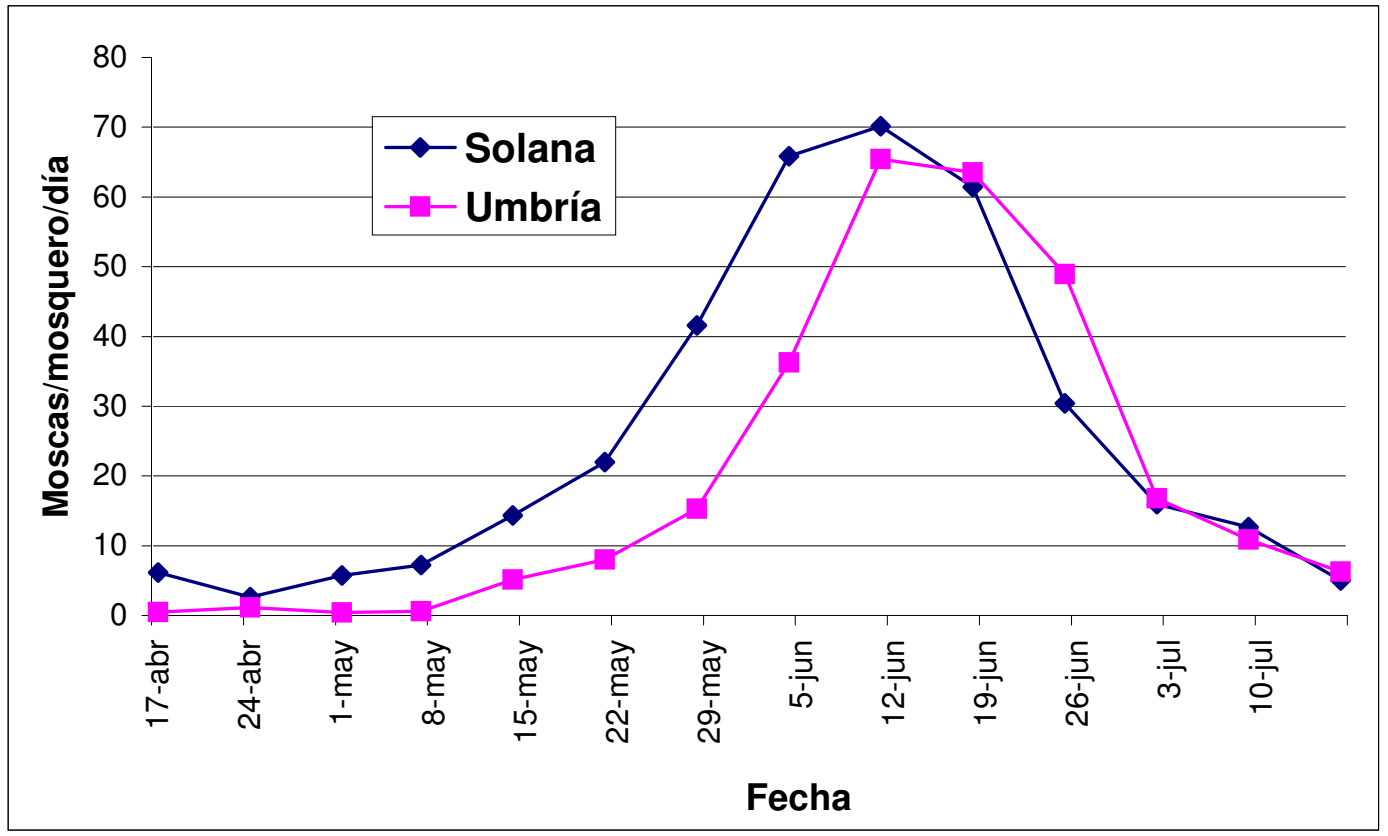

Capturas con mosqueros McPhail y emisores de TML (Econex)

En la Figura III.3.b y la Tabla III.2, aún con el tratamiento con lufenuron, se pueden apreciar diferencias entre las poblaciones de solana y umbría. 
Figura III.3b Detalle de evolución de las capturas a partir del 15 de julio en las zonas de solana y umbría tratadas con lufenuron.

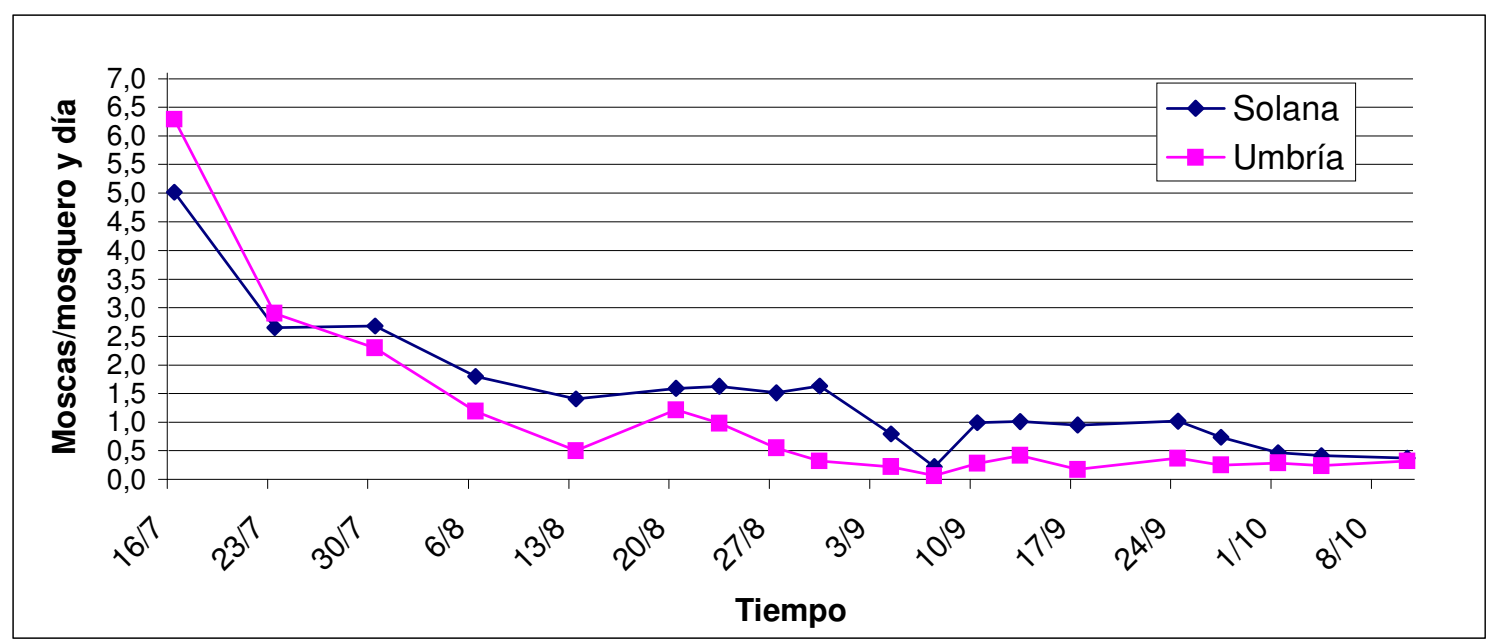

Capturas con mosqueros McPhail y emisores de TML (Econex).

Lufenuron aplicado el 10 de mayo.

16 de julio: primera generación de mosca afectada por el tratamiento esterilizante con lufenuron.

Tabla III.2. Media de capturas en las zonas de solana y umbría, tratadas con lufenuron, del 15 de julio al 10 de octubre.

\begin{tabular}{|l|c|c|}
\hline \multicolumn{3}{|c|}{ Media de capturas con TML \pm E.S. } \\
\hline & Solana & Umbría \\
\hline Promedio capturas & $1,42 \pm 0,26^{\mathrm{a}}$ & $0,99 \pm 0,34^{\mathrm{b}}$ \\
\hline
\end{tabular}

Promedios con distinta letra difieren significativamente en el análisis t-student de datos apareados con $\mathrm{P}<0,05$.

Capturas realizadas con mosqueros McPhail y emisor de TML.

En las Tablas III.3 y III.4, se dan las medias de capturas de las zonas de solana y umbría en dos subzonas: lufenuron, y blanco con tratamiento aéreo con malation el 28 de agosto.

Tabla III.3. Promedio de las capturas en la zona de solana.

\begin{tabular}{|c|c|c|c|}
\hline \multirow{2}{*}{ Lufenuron } & \multicolumn{3}{|c|}{ Promedio de capturas \pm E.S. } \\
\cline { 2 - 4 } & $\begin{array}{c}\text { Del 10 de } \\
\text { mayo al 10 de } \\
\text { julio }\end{array}$ & $\begin{array}{c}\text { Del 10 de julio } \\
\text { al 28 de agosto }\end{array}$ & $\begin{array}{c}\text { Del 28 de } \\
\text { agosto al 10 de } \\
\text { octubre }\end{array}$ \\
\hline solana & $22,8 \pm 4,56^{\mathrm{a}}$ & $1,3 \pm 0,23^{\mathrm{a}}$ & $0,84 \pm 0,13^{\mathrm{a}}$ \\
\hline Blanco solana & $44,2 \pm 8,25^{\mathrm{a}}$ & $17,2 \pm 6,45^{\mathrm{b}}$ & $0,66 \pm 0,17^{\mathrm{a}} *$ \\
\hline
\end{tabular}


Promedios con distinta letra dentro de un mismo período difieren significativamente en el análisis t-student de datos apareados con $\mathrm{P}<0,05$.

* Tratado con malation el 28 de agosto para proteger la cosecha de las variedades tempranas.

Colocación de trampas con lufenuron el 10 de mayo.

10 de julio: primera generación de mosca afectada por el tratamiento esterilizante. 
Tabla III.4. Promedio de las capturas en la zona de umbría.

\begin{tabular}{|l|c|c|c|}
\hline \multirow{1}{*}{} & \multicolumn{3}{|c|}{ Promedio de capturas \pm E.S. } \\
\cline { 2 - 4 } & $\begin{array}{c}\text { Del 10 de } \\
\text { mayo al 10 de } \\
\text { julio }\end{array}$ & $\begin{array}{c}\text { Del 10 de julio } \\
\text { al 28 de agosto }\end{array}$ & $\begin{array}{c}\text { Del 28 de } \\
\text { agosto al 10 de } \\
\text { octubre }\end{array}$ \\
\hline Lufenuron umbría & $21,8 \pm 7,19^{\mathrm{a}}$ & $1,6 \pm 0,66^{\mathrm{a}}$ & $0,23 \pm 0,03^{\mathrm{a}}$ \\
\hline Blanco umbría & $22,9 \pm 5,24^{\mathrm{a}}$ & $4,2 \pm 1,66^{\mathrm{b}}$ & $0,15 \pm 0,04^{\mathrm{a}} *$ \\
\hline
\end{tabular}

Promedios con distinta letra dentro de un mismo período difieren significativamente en el análisis t-student de datos apareados con $\mathrm{P}<0,05$

* Tratado con malation el 28 de agosto para proteger la cosecha de las variedades tempranas

Colocación de trampas con lufenuron el 10 de mayo

10 de julio: primera generación de mosca afectada por el tratamiento esterilizante

Se observa que hasta el 10 de julio no hay diferencias significativas $(\mathrm{P}<0,05)$ entre lufenuron y blanco, debido a que el efecto esterilizante tiene un período de latencia. En el segundo período, esta diferencia es significativa. En el tercer período, no hay diferencias significativas por causa del tratamiento del blanco con malation.

En las Figuras III.4a y III.4b se muestra la evolución de las capturas en las dos subzonas de solana: tratada con lufenuron y blanco tratado con malation el 28 de agosto (en adelante "blanco tratado"), de solana. 
Figura III.4.a Comparación de la evolución de las capturas en la subzona solana tratada con lufenuron y en la subzona solana blanco.

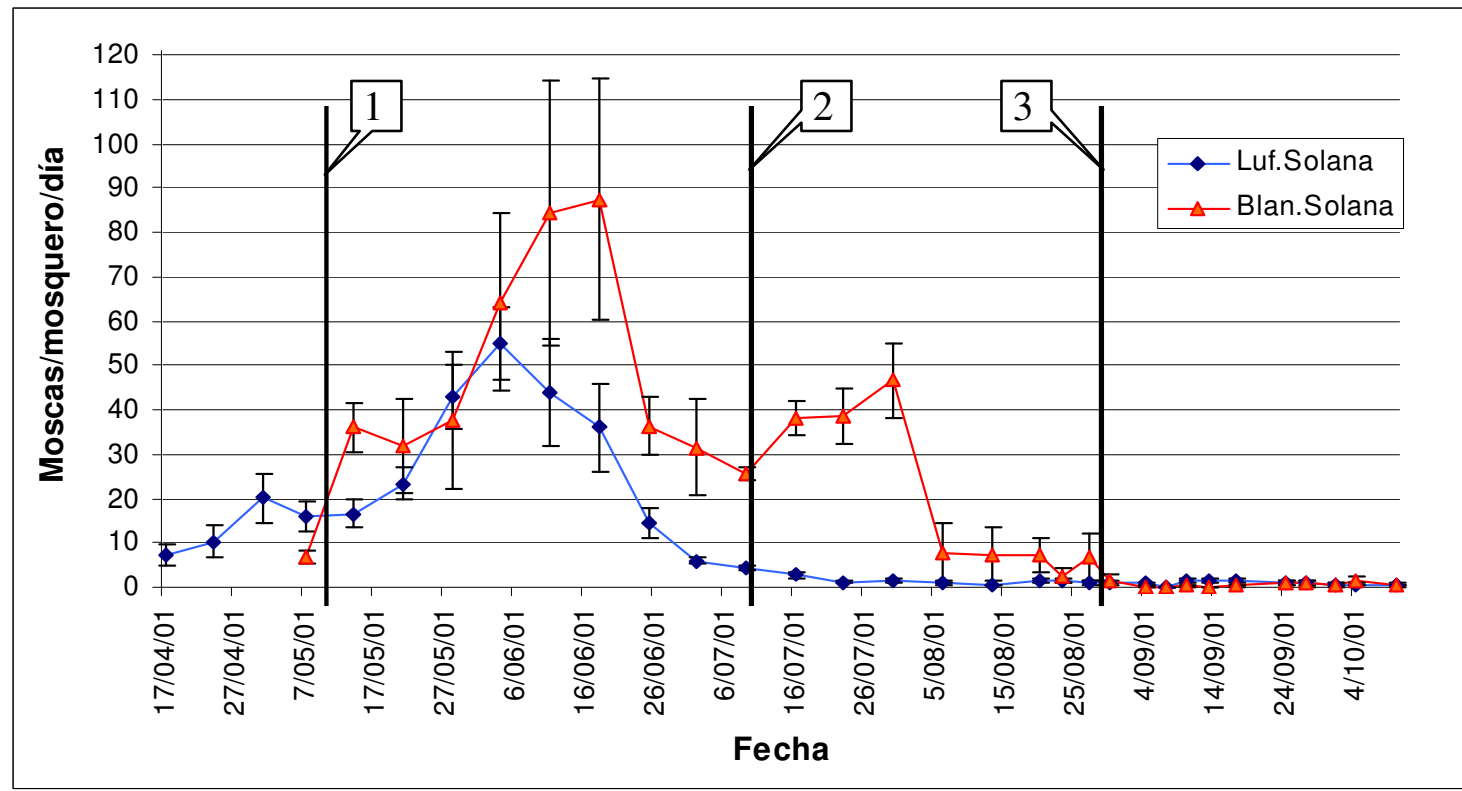

28 de agosto: tratamiento aéreo con malation.

Luf. Solana: subzona de la solana tratada con lufenuron desde 10 de mayo.

Blan. Solana: subzona de la solana sin tratamientos hasta el 28 de agosto.

1.- Colocación de las trampas de lufenuron en el campo tratado.

2.- $1^{a}$ generación de mosca afectada por el lufenuron.

3.- Tratamiento aéreo con malation en el blanco.

Figura III.4.b Detalle de la evolución de las capturas en la subzona solana tratada con lufenuron y en la subzona solana blanco del 27 de agosto al 15 de octubre.

28 de agosto: tratamiento aéreo con malation

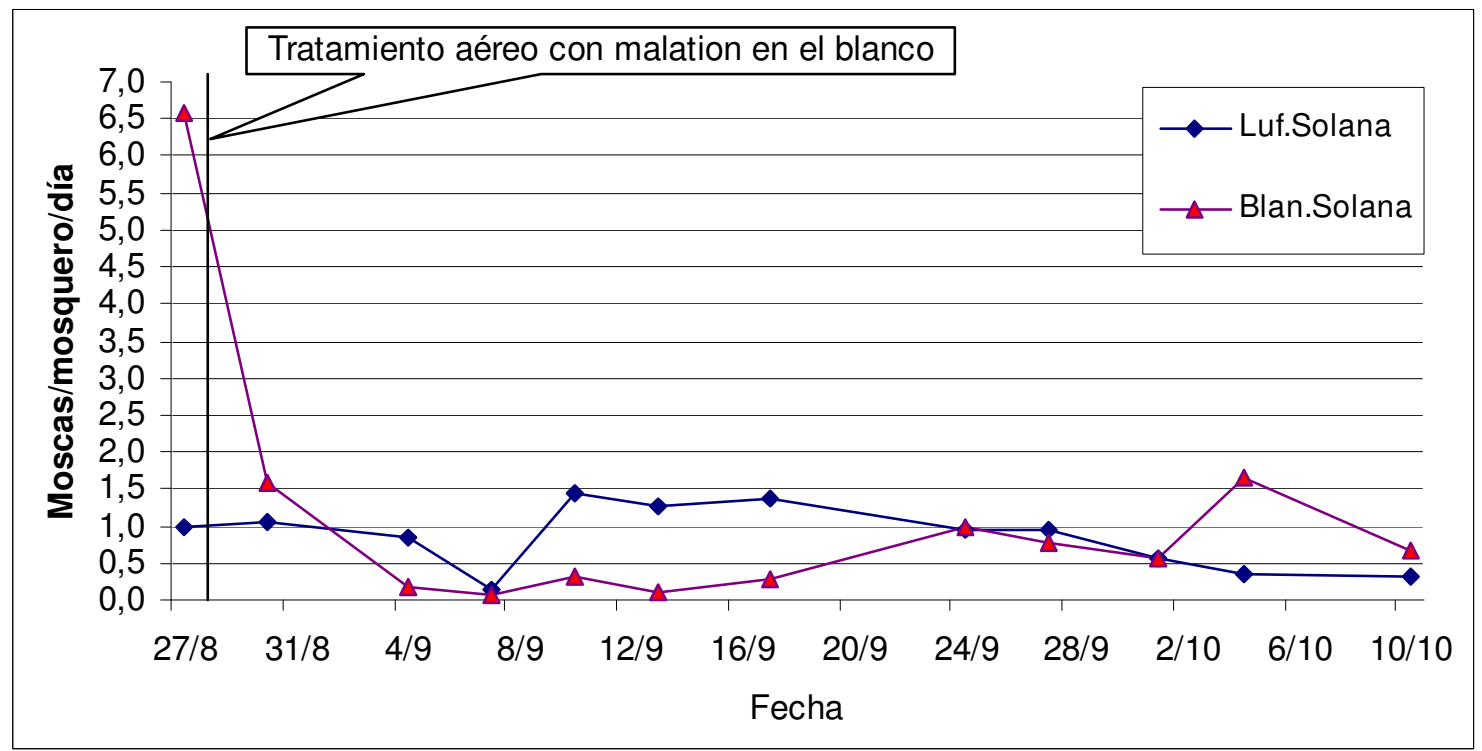

Luf. Solana: subzona de la solana tratada con lufenuron desde el 10 de mayo Blan. Solana: subzona de la solana tratada con malation a partir del 28 de agosto Capturas realizadas con mosqueros McPhail y emisor de TML. 
En la Figura III.4a se puede observar que, hasta principios del mes de junio, la población de mosca es muy similar en las dos subzonas, pero desde esta fechas y hasta el mes de septiembre la población en la zona blanco es mucho mayor. Se puede observar que, a partir del 10 de julio (dos meses desde que se colocaron las trampas de lufenuron), en el blanco se produce una subida de la población que no se produce en la zona tratada con lufenuron.

Si se observan los resultados obtenidos en el ensayo de Gandía de la Parte II de esta Tesis Doctoral, se puede observar que este segundo pico de población, en verano, también se produjo en ese campo, y que, como en este caso, la población tratada con lufenuron no muestra este pico.

En el período que va desde el 10 de julio ( $1^{\mathrm{a}}$ generación de mosca afectada por el tratamiento esterilizante de lufenuron), hasta el comienzo de los tratamientos químicos en el blanco (28 de agosto) la población de mosca difiere significativamente, en el test de datos apareados, entre los campos con tratamiento de lufenuron y blanco. Esta diferencia se puede observar en la Tabla III.3.

En la Figura III.4b se observa que la población de la subzona blanco de la solana desciende rápidamente con la aplicación aérea del 28 de agosto y se mantiene baja durante 20 días. Por su parte, en la subzona de la solana tratada con lufenuron, la población se mantiene en niveles relativamente bajos de forma constante. Únicamente los días del 8 al 18 de septiembre la población supera el índice de $1 \mathrm{mosca} / \mathrm{mosquero} \mathrm{y} \mathrm{día,} \mathrm{y} \mathrm{en} \mathrm{ningún} \mathrm{caso} \mathrm{supera}$ el de 1,5 moscas/mosquero y día, mientras que la subzona tratada con malation el índice supera las 1,5 moscas/mosquero y día después de un mes del tratamiento. Es obvio que el tratamiento aéreo provoca un descenso muy acusado de la población, pero su efecto es menos duradero que el tratamiento esterilizante. 
La zona de la solana está formada por 8 parcelas atendiendo a criterios de orientación, variedad cultivada y situación dentro del valle. En la Figura III.5 se puede observar la evolución de cada una de las parcelas en relación al blanco.

Figura III.5. Evolución de las capturas en las distintas parcelas de la solana. Período del 17 de abril al 10 de julio.

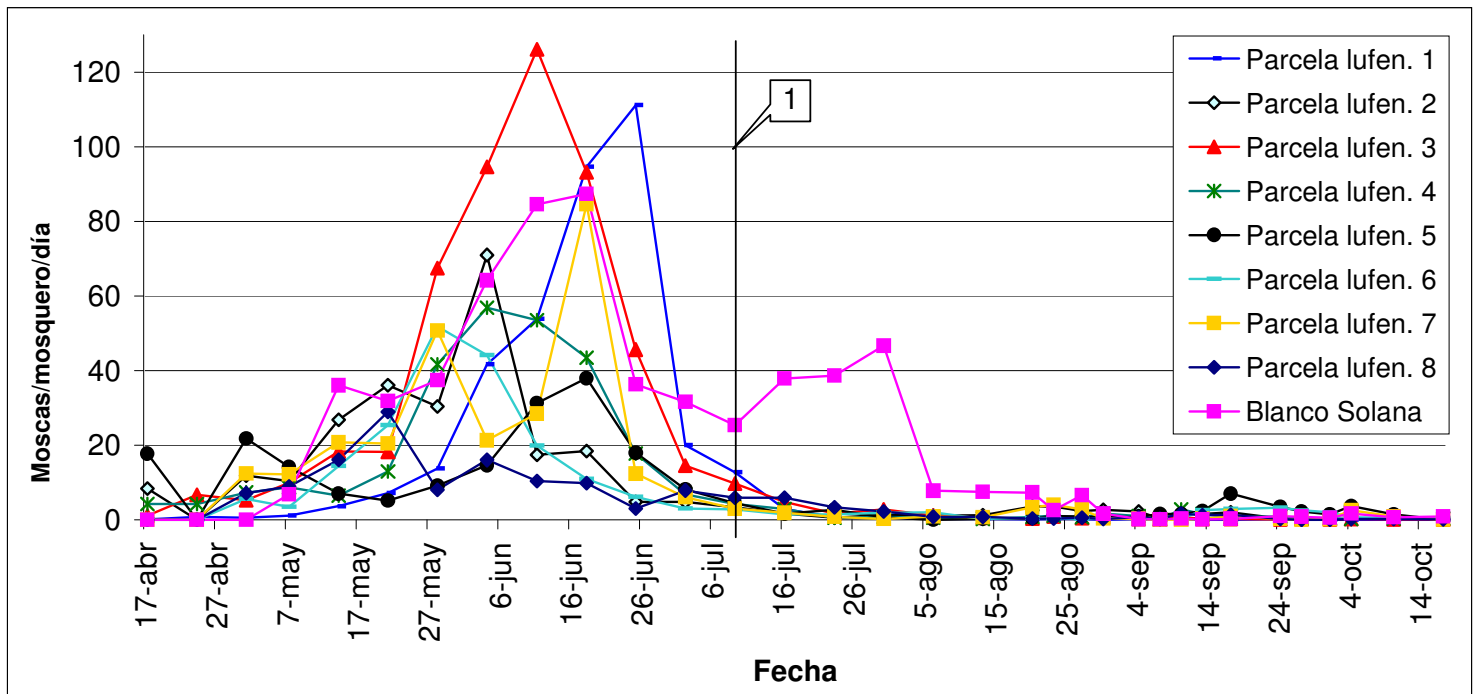

Capturas realizadas con mosqueros McPhail y emisor de TML.

1.- Primera generación afectada por el lufenuron.

Parcela lufen. 1. Variedad Clementina Córcega. Riego a manta.

Parcela lufen. 2. Variedades Marisol y Hernandina. Riego localizado.

Parcela lufen. 3. Variedad Navel. Riego localizado.

Parcela lufen. 4. Variedades Clementina, Córcega y Navelina. Riego localizado.

Parcela lufen. 5. Variedades Marisol, Nova y Beatriz (plantones de 3 años). Riego localizado.

Parcela lufen. 6. Variedades Navelina y Navel. Riego localizado.

Parcela lufen. 7. Variedades Okitsu y Marisol. Riego localizado.

Parcela lufen. 8. Variedades Navelina y Navel Late. Riego localizado.

Blanco solana. Variedades Marisol, ClemenNules, Okitsu y Navel.

En la Figura III.5 se observa que la evolución de las capturas de la subzona blanco

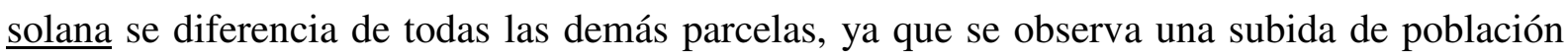
en el mes de julio que no se produce en ninguna de las parcelas tratadas con lufenuron. La población natural es muy distinta en diferentes parcelas, diferenciadas por su situación y orientación dentro del valle; destaca la parcela 3 con más de 120 capturas/mosquero y día en el mes de junio. 
Como se puede observar en la Figura III.6a, si bien en la zona de solana (Fig. III.4) existen diferencias muy marcadas entre la evolución de la población de la zona tratada con lufenuron y la zona blanco, las diferencias en la umbría son menores.

Figura III.6a.- Comparación de la evolución de las capturas en las subzonas umbría tratada con lufenuron y blanco umbria.

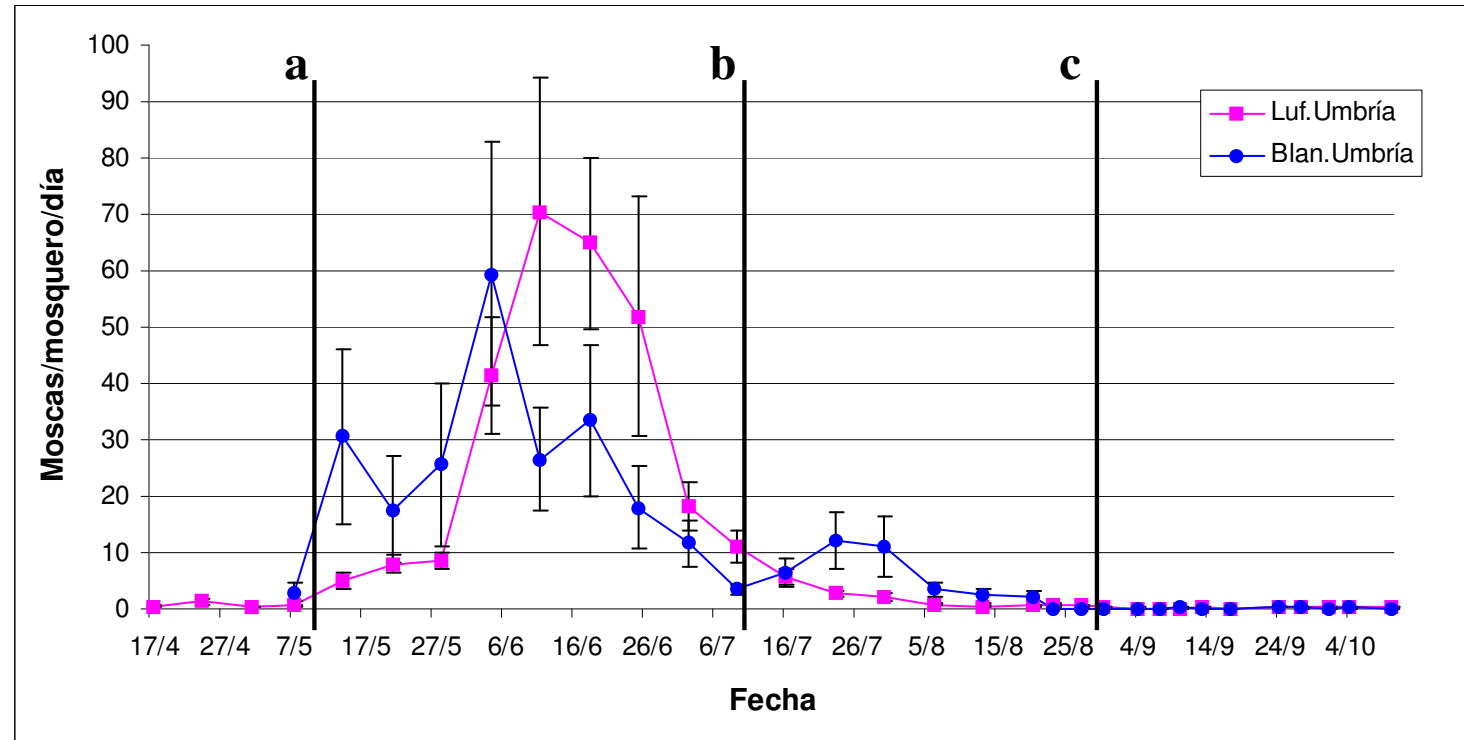

Capturas realizadas con mosqueros McPhail y emisor de TML.

a) 10 de mayo: colocación de las placas esterilizantes de lufenuron.

b) 10 de julio: $1^{\text {a }}$ generación de mosca afectada por el tratamiento con lufenuron.

c) 28 de agosto: tratamiento aéreo con malation del blanco.

Luf. Umbría: Subzona umbría tratada con lufenuron.

Blan. Umbría: Subzona umbría sin tratamientos hasta el 28 de agosto.

Figura III.6b.- Detalle de la evolución de las capturas en las subzonas umbría tratada con lufenuron y blanco umbría del 27 de agosto al 15 de octubre.

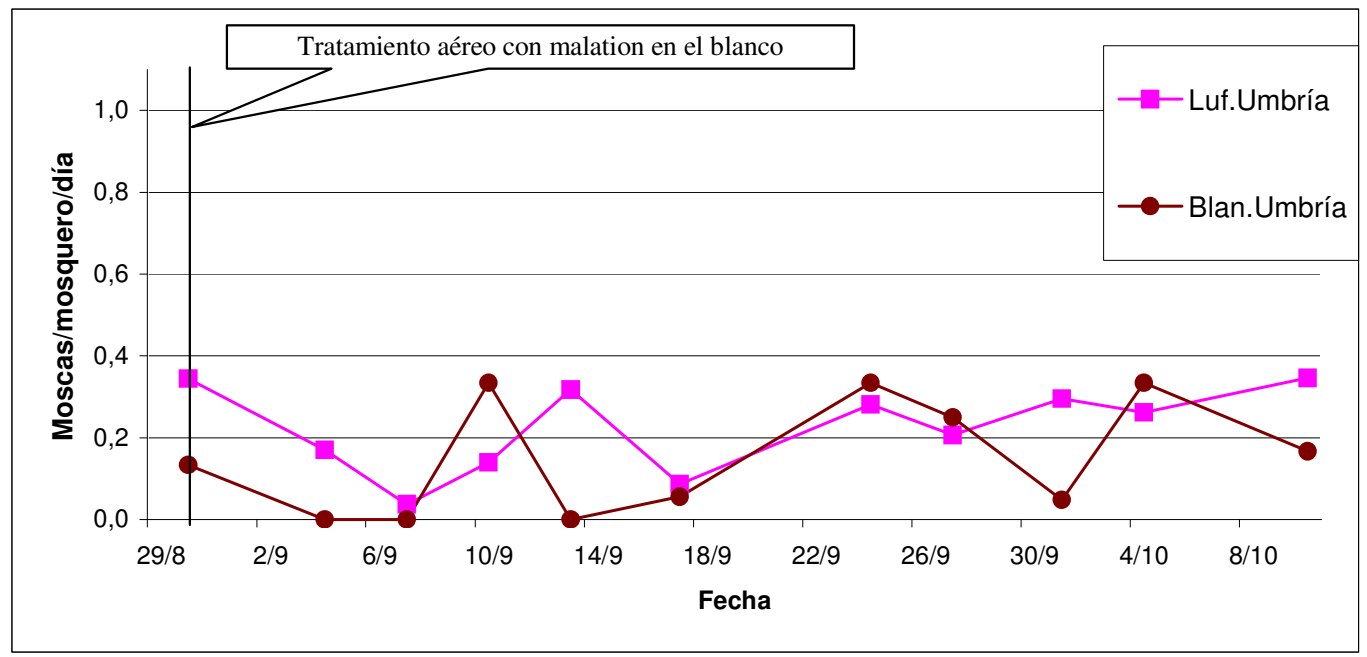

Capturas realizadas con mosqueros McPhail y emisor de TML.

Luf. Umbría: Subzona umbría tratada con lufenuron. 
Blan. Umbría: Subzona umbría sin tratamientos hasta el 28 de agosto, en que se realiza un tratamiento aéreo con malation.

Como se puede observar, en las Figuras II.1, II.3, II.4 y III.6a, se produce una bajada de población en el blanco, hasta niveles cercanos a cero, a mediados de agosto. Sin embargo, el tratamiento con malation es lo que permite reducir las capturas por debajo de 0,5 moscas/mosquero y día en los meses de septiembre y octubre. Sin este tratamiento las capturas hubieran vuelto a ascender en estos meses (Alonso Muñoz et al, 1999) con el consiguiente peligro para la fruta .

En la Figura III.6a podemos observar tres períodos: en mayo y junio, la población de la subzona blanco y la de la tratada se corresponden con su evolución natural. A partir del 10 de julio, la tendencia de población cambia y la subzona blanco tiene un repunte que no se aprecia en el campo tratado con lufenuron. De nuevo se observan diferencias significativas entre las poblaciones de mosca de la subzona umbría-tratada con lufenuron y la subzona umbríablanco, durante el mismo período que en la solana (10 de julio - 28 de agosto) (Tabla III.4).

En la Figura III.6b se observa que la aplicación aérea del 28 de agosto ha reducido drásticamente la población del blanco y que desde esta fecha hasta el 10 de octubre las capturas de la subzona umbría-blanco y umbría-tratada con lufenuron son semejantes.

Para poder aclarar la anomalía que supone el retraso y la menor población en mayojunio, de la subzona umbría-tratada con lufenuron, (Figura III.6a), descomponemos por parcelas los valores de capturas que hemos obtenido, atendiendo a criterios de variedad cultivada y localización dentro del valle. En la Figura III.7 se puede observar la evolución de capturas en las distintas parcelas, dentro del epígrafe "Influencia de los frutales de verano en la población de mosca" 


\section{Influencia de los frutales de verano en la población de mosca.}

Los frutales de verano son el huésped perfecto para la reproducción de la mosca del Mediterráneo por sus características de piel y pulpa. Además, en esta estación, Ceratitis capitata disfruta de las mejores condiciones climáticas para su reproducción. La población de C. capitata presenta en España un máximo en los meses de junio, julio o agosto; la ausencia de fruta receptiva, en los campos de cítricos, no favorece su multiplicación, pero, la presencia de melocotones, higos, albaricoques y otros frutos en las cercanías suponen un substrato ideal para la mosca, ofreciéndole una continuidad de huéspedes para su desarrollo.

En este apartado se estudia la influencia de dichos frutales sobre la población de mosca. Para ello se compara la población de mosca en parcelas sin frutales de verano con la de una parcela en que se combina este cultivo con el de cítricos. 
Figura III.7.- Comparación de la evolución de las capturas en distintas parcelas de la umbría.

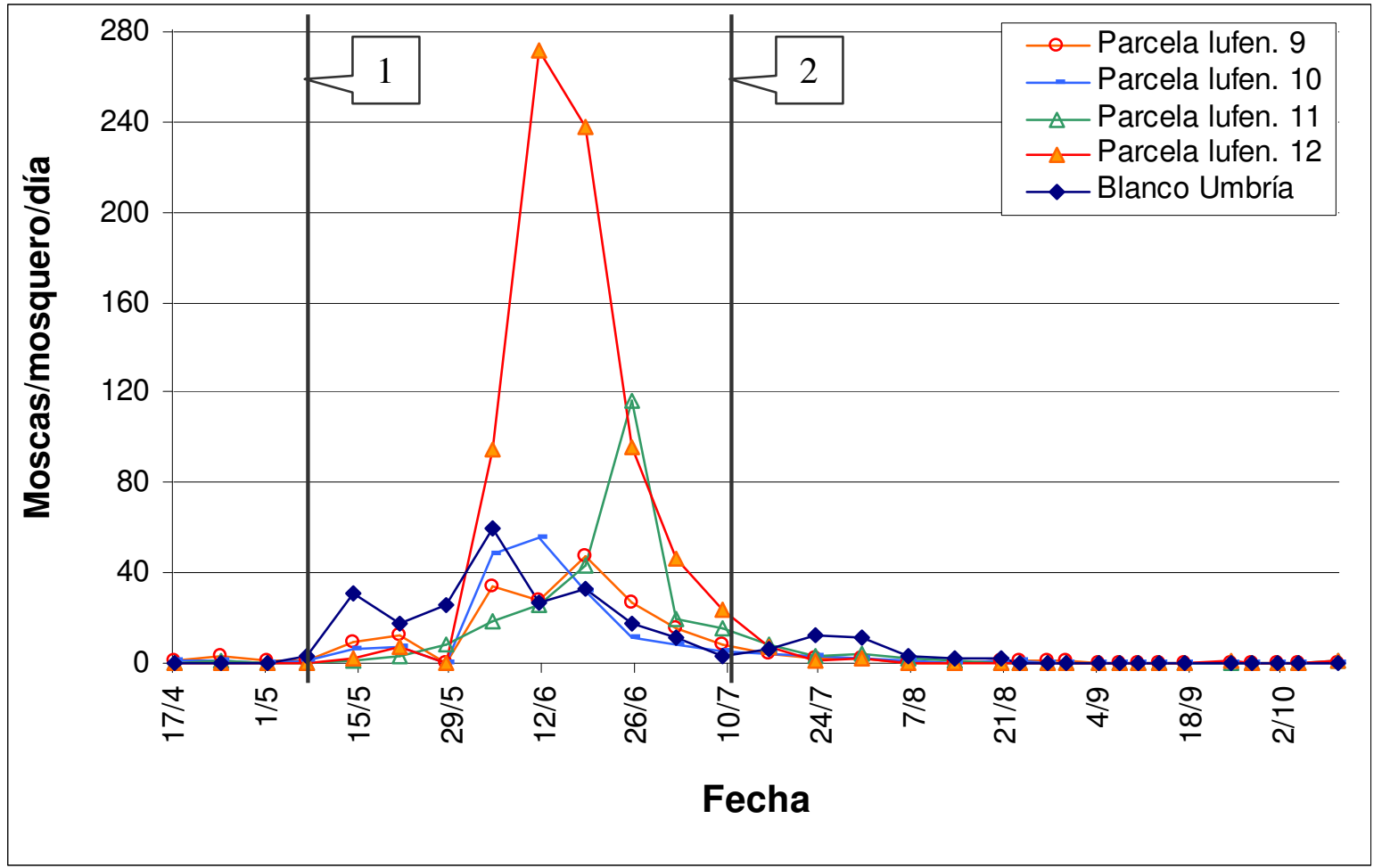

Capturas realizadas con mosqueros McPhail y emisor de TML.

1.- Colocación de las placas esterilizantes con lufenuron.

2.- Primera generación de mosca afectada por el tratamiento esterilizante con lufenuron. Parcela lufen. 9. Variedad Clementina fina y salustiana. Riego a manta.

Parcela lufen. 10. Variedades Okitsu. Riego a manta.

Parcela lufen. 11. Variedad Navelina. Riego a manta.

Parcela lufen. 12. Variedad de cítricos Marisol doblada de melocotoneros y Salustiana doblada de Ciruelos. Riego a manta.

Blanco umbría. Variedades Marisol, Clemen-Nules y Navelina. Riego mixto.

En la Figura III.7 se observa que la "parcela lufenuron 12" que alberga cítricos de variedad Marisol doblados de melocotoneros y variedad Sanguinelli doblada de ciruelos, tiene una subida de población desmesurada que altera la población normal. Ante una población tan elevada de mosca, y la presencia de fruta madura donde poder reproducirse, cabría esperar un aumento elevado de la población de mosca a los 30-45 días de esta subida tan espectacular (Mavrikakis et al, 2000). Pero, en esta gráfica, podemos observar que no hay ningún repunte 
significativo de la población en la "parcela lufenuron 12", lo que índica que el tratamiento con lufenuron ha actuado sobre la siguiente generación reduciendo su normal desarrollo.

La evolución de la población, en los campos de cítricos de la umbría, eliminando de la gráfica las capturas de la "parcela lufenuron 12", se ve en la Figura III.8.

Figura III.8. Comparación de la evolución de las capturas de mosca en la subzona umbríalufenuron y umbría-blanco tras eliminar las capturas de la parcela con frutales.

Capturas realizadas con mosqueros McPhail y emisor de TML.

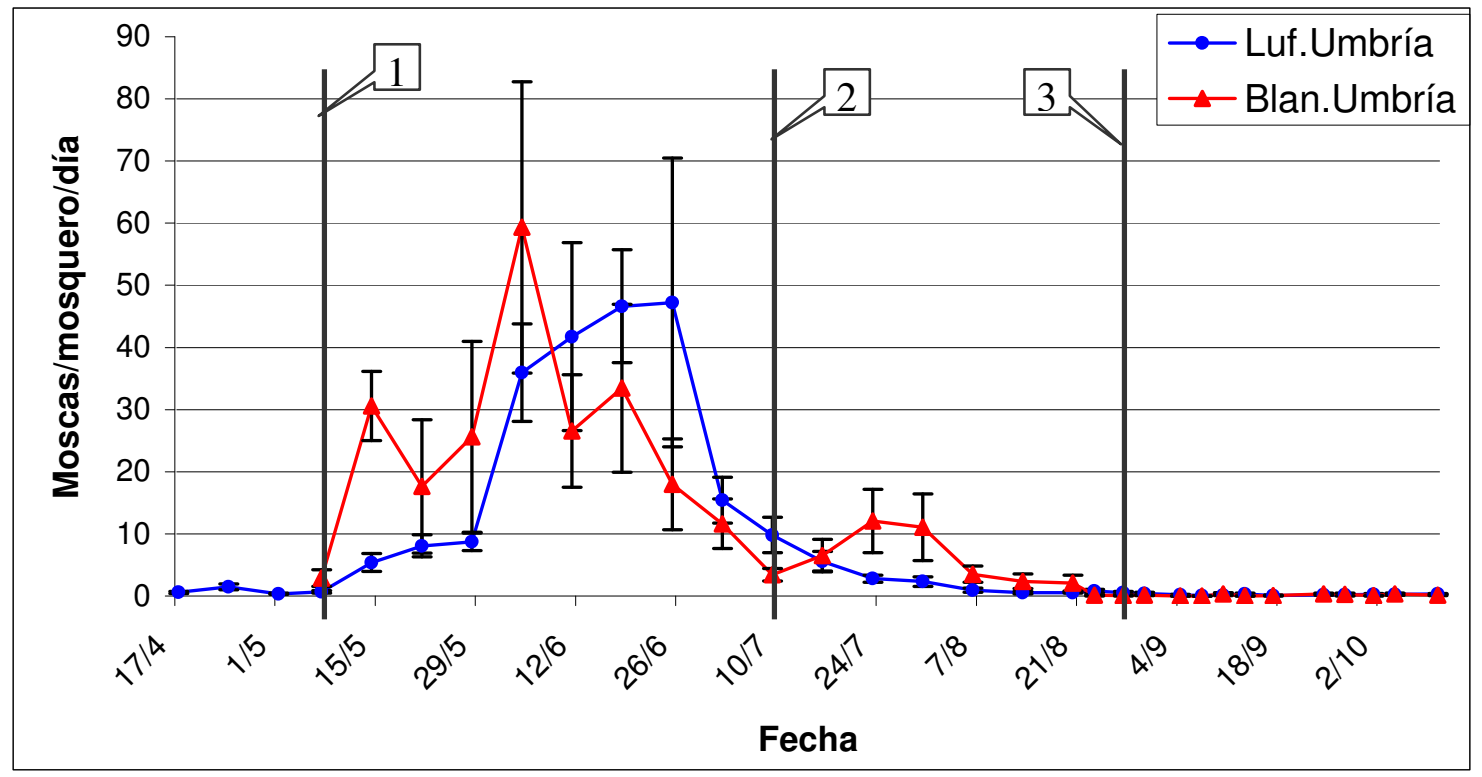

1.- 10 de mayo- Colocación de las placas esterilizantes con lufenuron.

2.- 10 de julio - Primera generación de mosca afectada por el tratamiento esterilizante con lufenuron.

3.- 28 de agosto - Tratamiento aéreo con malation en la subzona blanco-umbría.

Entre las Figuras III.6a y III.8 no hay diferencias en la evolución a partir del 10 de julio, pero sí las hay durante el mes de junio. Cabe señalar que los frutales, en este caso melocotones y ciruelos, maduraron en el mes de junio, lo que explica el gran aumento en la población de mosca en este mes (Figura III.6a). Sin embargo, al comparar las dos figuras, vemos que no hay diferencias en los meses de julio y agosto, lo que es atribuible al efecto esterilizante del lufenuron.

En la Figura III.9 vemos las capturas que se obtienen, en septiembre-octubre, en distintas parcelas. 
Figura III.9. Evolución de las capturas, cuando la fruta comienza a estar receptiva, en la zona umbría del ensayo.

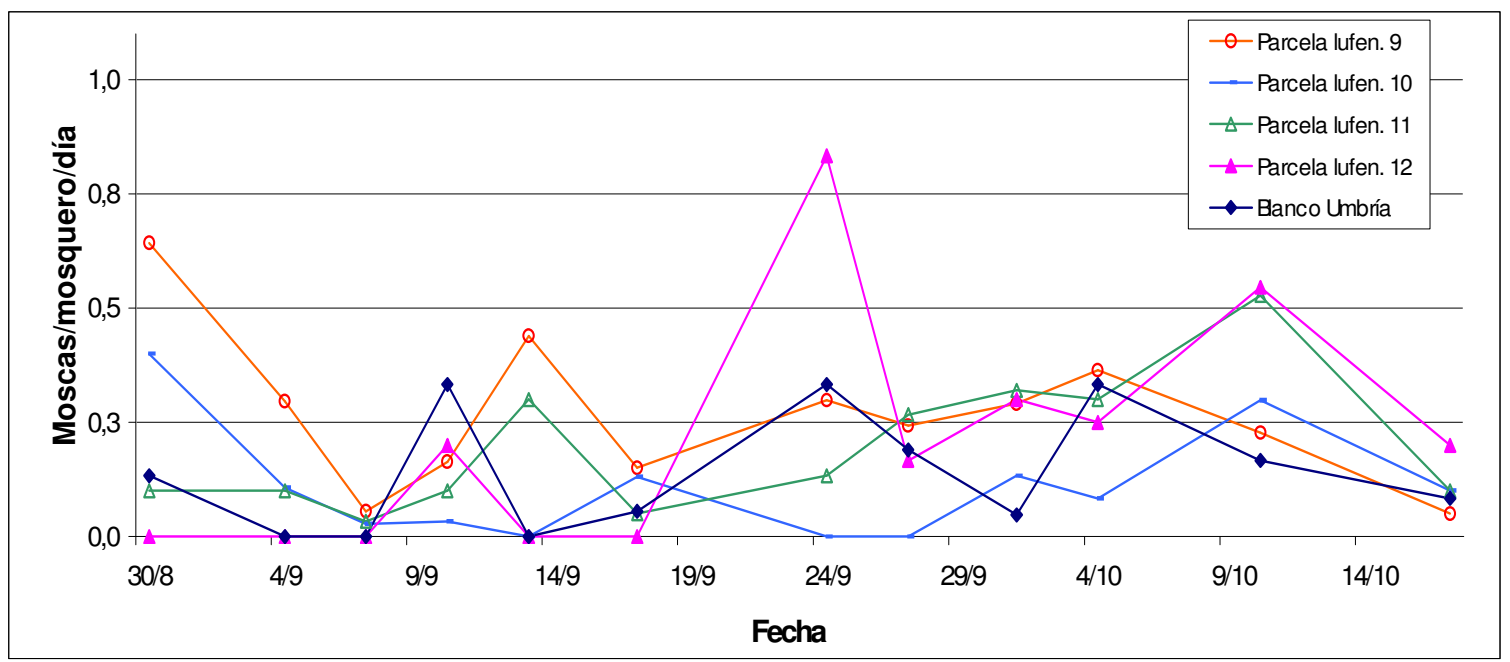

Capturas realizadas con mosqueros McPhail y emisor de TML.

10 de mayo.- Colocación de las placas esterilizantes con lufenuron.

10 de julio.- Primera generación de mosca afectada por el tratamiento esterilizante con lufenuron.

28 de agosto.- Tratamiento aéreo con malation en el blanco.

Parcela lufen. 9. Variedad Clementina fina y salustiana. Riego a manta.

Parcela lufen. 10. Variedades Okitsu. Riego a manta.

Parcela lufen. 11. Variedad Navelina. Riego a manta.

Parcela lufen. 12. Variedad de cítricos Marisol doblada de melocotoneros y Salustiana doblada de Ciruelos. Riego a manta.

Blanco umbría. Variedades Marisol, Clemen-Nules y Navelina. Riego mixto.

En la Figura III.9, se puede observar que las capturas no han sobrepasado el límite de 0,5 moscas/mosquero y día, en toda la temporada de recolección de fruta, salvo en las parcelas dobladas de frutales de verano "parcela lufenuron 12 ".

Con este análisis se muestra la gran influencia que tienen los frutales de verano en la evolución de la mosca (Ros, J.P., 1988), ya que suponen un sustento para su población, en una época en que no hay ninguna variedad de cítricos receptiva donde reproducirse. 
Evolución de las capturas con atrayentes Tri-pack tras el tratamiento con lufenuron.

En el campo de ensayo, tratado con lufenuron, también se colocaron mosqueros TephriTrap que contenían atrayente Tri-pack (trimetilamina, acetato amónico y putrescina) para observar la evolución de la población de hembras y poder relacionarla con el aumento de picadas.

En la Figura III.10a y III.10b se observa la evolución de las capturas, en estas trampas, en el campo tratado con lufenuron:

Figura III.10a.- Evolución de las capturas de machos y hembras, utilizando Tri-pack como atrayente, en el campo tratado con lufenuron.

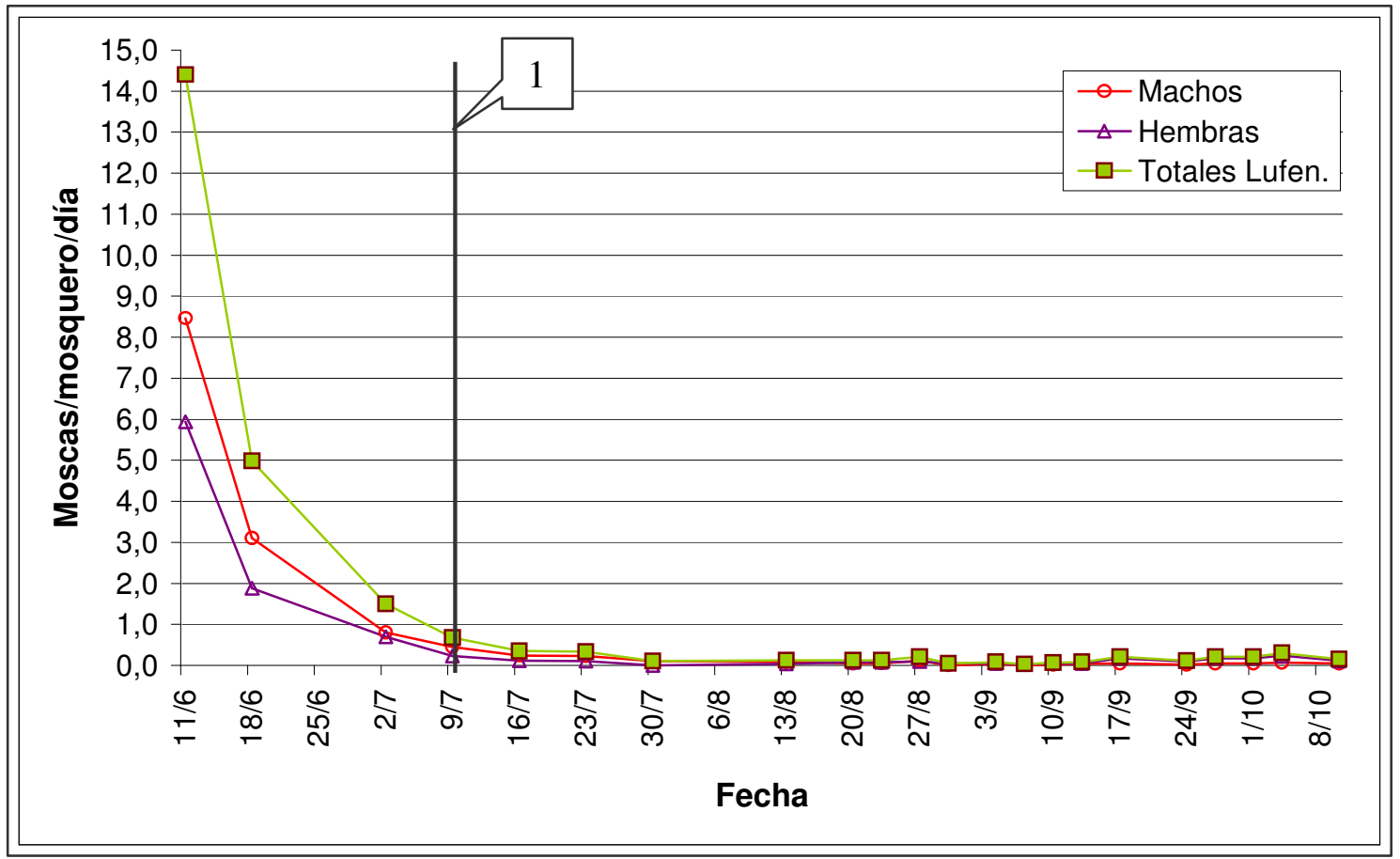

Capturas realizadas con mosqueros Tephri-trap y emisor Tri-pack de Consep.

10 de mayo.- Colocación de las placas esterilizantes con lufenuron.

1.- 10 de julio.- Primera generación de mosca afectada por el tratamiento esterilizante con lufenuron. 
Figura III.10b.- Detalle de la evolución de las capturas de machos y hembras, a partir del 10 de julio, utilizando Tri-pack como atrayente, en el campo tratado con lufenuron. 10 de julio: primera generación de mosca afectada por el lufenuron.

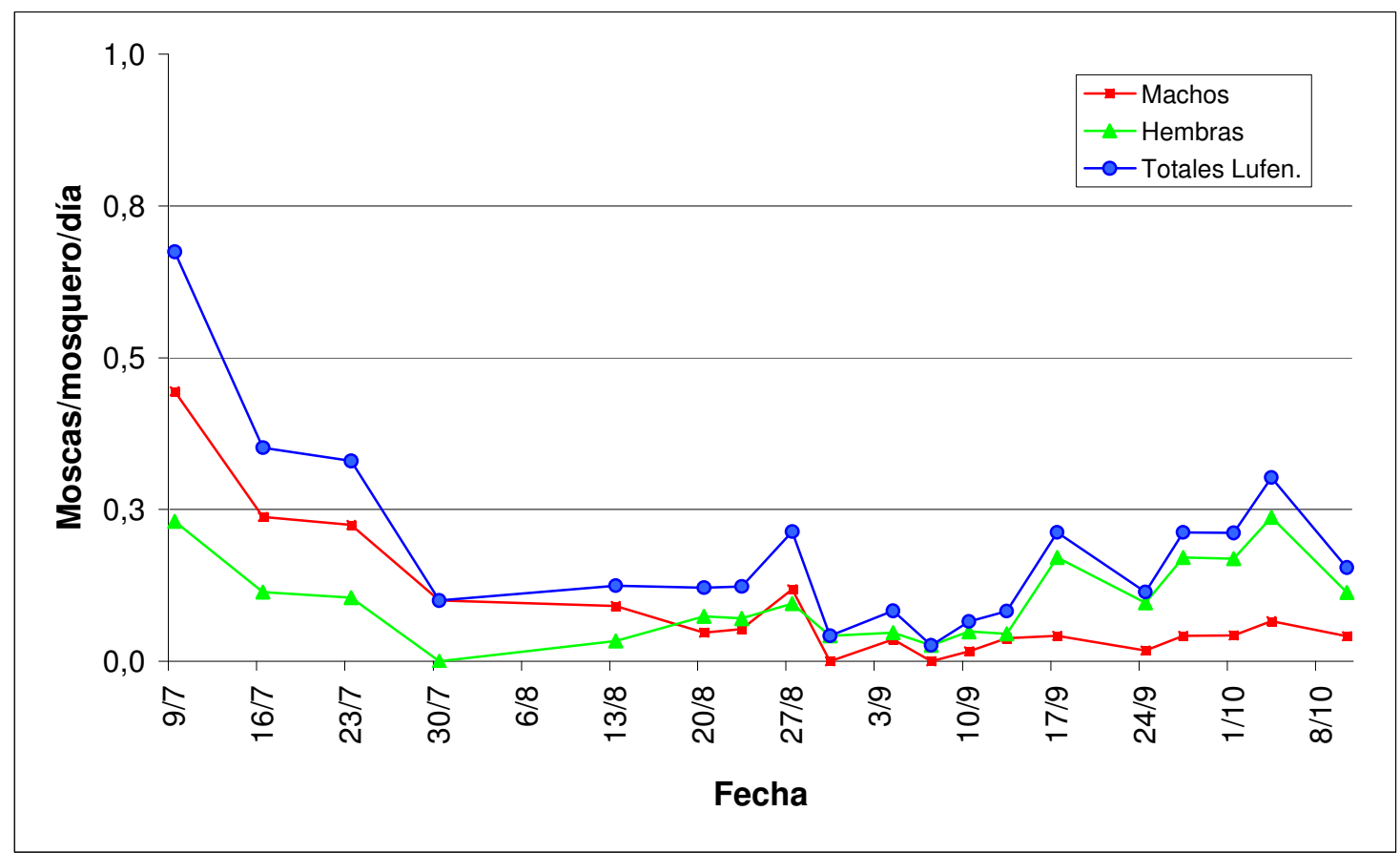

Capturas en mosqueros Tephri-Trap con atrayentes Tri-pack.

En la Figura III.10a se ve como las capturas que se obtienen con las trampas TephriTrap con emisores Tri-pack descienden en la segunda quincena de junio, como sucedía con las trampas McPhail y emisores de TML. Sin embargo, con los atrayentes Tri-pack se observa que las capturas, a partir de la segunda quincena de julio (Figura III.10b), quedan por debajo de 0,5 moscas/mosquero y día, mientras que, con las de TML, el nivel de capturas era mayor. Por tanto las trampas con Tri-pack capturan menos moscas y son menos sensibles a la hora de seguir la evolución de la población.

Además, con estos atrayentes no se han observado diferencias significativas (Tabla III.5) de capturas entre el campo situado en la solana y el campo de la umbría (Figuras III.11a y III.11b). Esto confirma que si bien los mosqueros Tephri-Trap con emisores Tri-pack tienen la ventaja de capturar hembras de $C$. capitata, no son tan sensibles como los mosqueros con TML para el seguimiento de la población de mosca. 
Figura III.11a. Evolución de las capturas de las subzonas lufenuron-solana y lufenuron-umbría con atrayentes Tri-pack.

Campo tratado con placas esterilizantes desde el 10 de mayo.

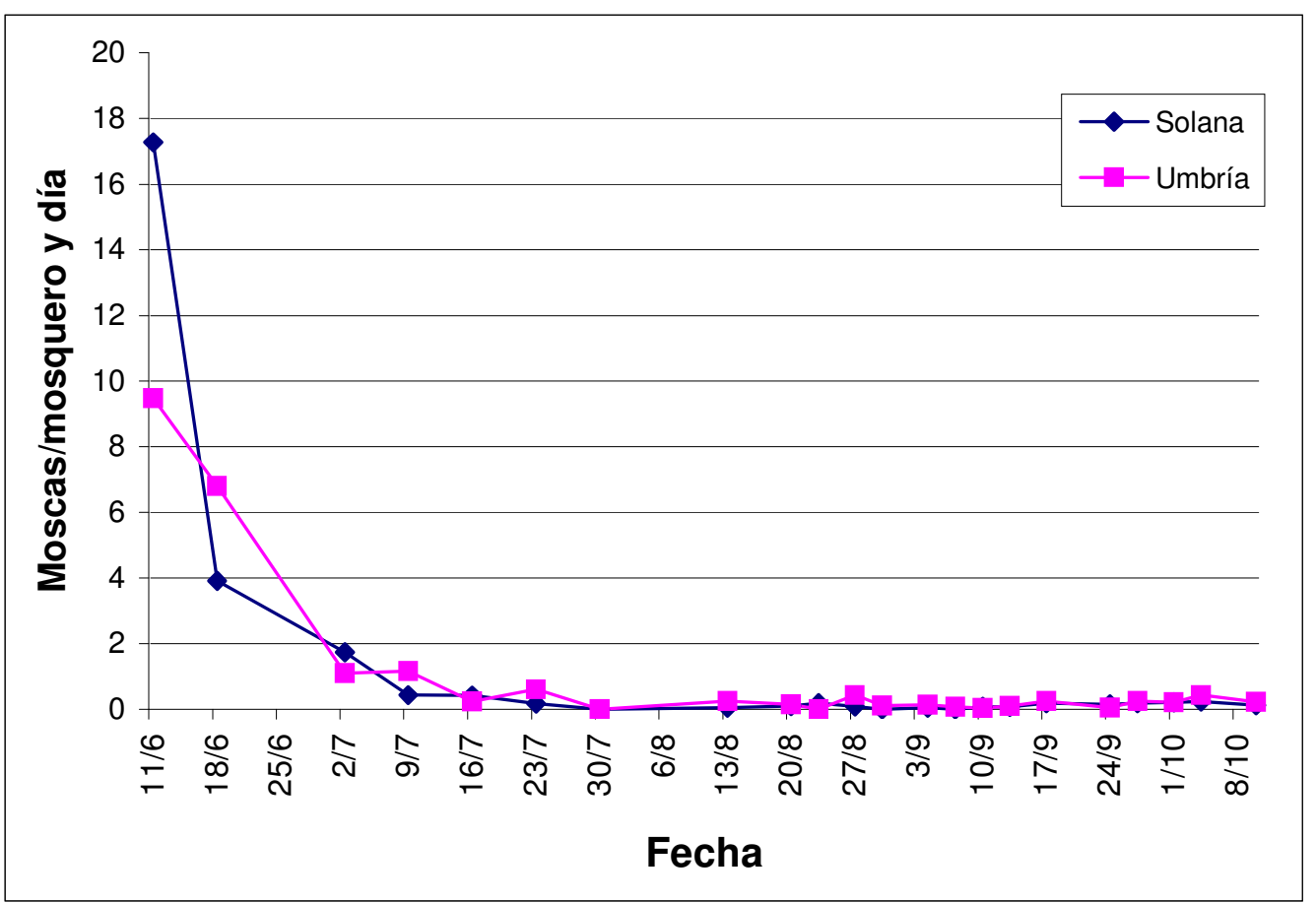

10 de julio: $1^{\text {a }}$ generación afectada por el tratamiento esterilizante con lufenuron.

Figura III.11b. Detalle de la evolución de las capturas de las subzonas lufenuron-solana y lufenuron-umbría con atrayentes Tri-pack.

Campo tratado con placas esterilizantes desde el 10 de mayo.

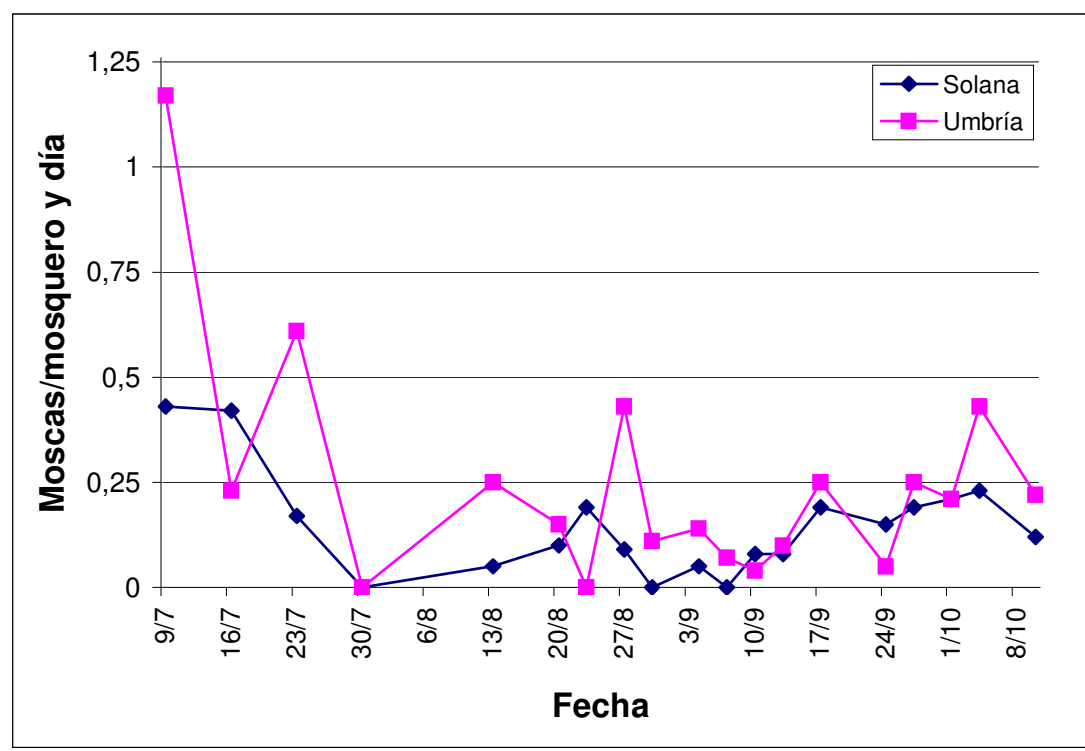

10 de julio: $1^{\text {a }}$ generación afectada por el tratamiento esterilizante con lufenuron. 
Tabla III.5. Media de capturas en las zonas de solana y umbría con mosqueros con Tripack, a partir del 15 de julio, en el campo tratado con lufenuron.

\begin{tabular}{|l|c|c|}
\hline \multicolumn{3}{|c|}{ Media de capturas con Tri-pack \pm ES } \\
\hline & Solana & Umbría \\
\hline Promedio capturas & $0,129 \pm 0,024^{\mathrm{a}}$ & $0,197 \pm 0,038^{\mathrm{a}}$ \\
\hline
\end{tabular}

Promedios con igual letra no difieren significativamente en el análisis t-student de datos apareados con $\mathrm{P}<0,05$.

Dentro del este apartado de atrayentes Tri-pack cabe señalar que éstos capturan muchas más hembras que el TML, pero la proporción de hembras respecto al total de capturas no es constante. En las Figuras III.10a y III.10b se observa que esta proporción varía a lo largo del año. En el mes de junio y julio la proporción de machos capturados respecto al total de capturas ha sido alta; en el mes de septiembre y octubre la proporción de hembras capturadas aumentó mucho. Esta circunstancia se puede observar en la Figura III.12.

Figura III.12.- Evolución de la proporción de hembras capturadas con atrayentes Tri-pack en el campo tratado con lufenuron.

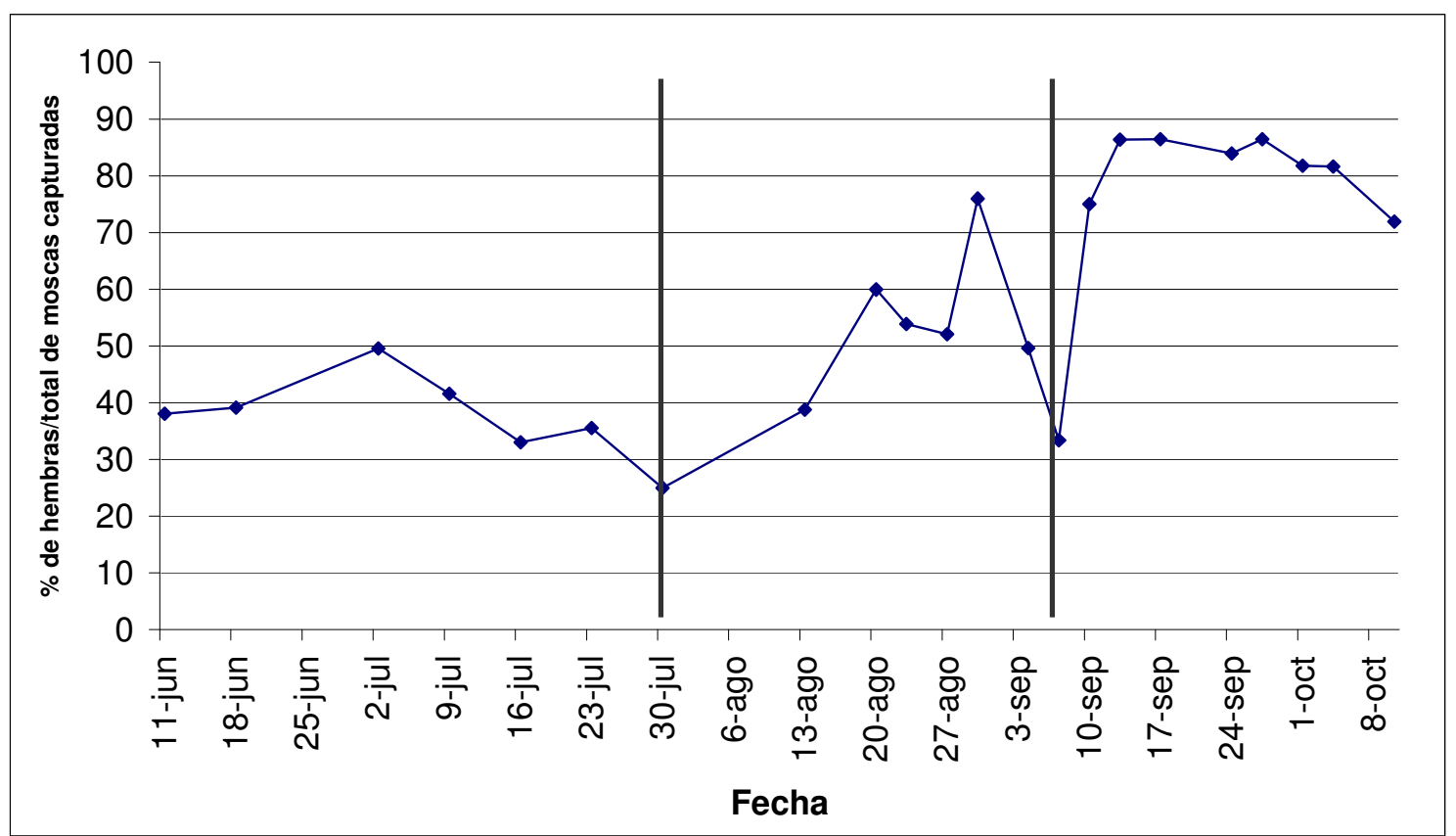

Las líneas verticales indican fecha de renovación de los atrayentes.

En la Figura III.12 se observa una bajada súbita de la proporción de hembras capturadas, a principios de septiembre, que debe atribuirse al envejecimiento de los atrayentes 
Tri-pack. De hecho, el descenso de la proporción coincide con el mínimo de capturas totales (Figura III.10b).

En la gráfica se puede observar que, a principios de temporada, la proporción de hembras capturadas, respecto al total de capturas, no llega al 50\%, mientras que a partir de mediados del mes de septiembre y principios del mes de octubre esta proporción se acerca al $90 \%$.

Esta figura muestra una clara variación en la proporción de capturas a lo largo del año que pueden responder a dos motivos:

- que la relación de machos/hembras de la población de mosca varía a lo largo del año (Alonso Muñoz, D. y García-Marí, F., 2000).

- que la selectividad de atracción varíe según la época.

En cualquiera de los dos casos, se confirma que hay un máximo en el porcentaje de hembras capturadas, respecto al total de capturas, que se produce durante el mes de septiembre, tal y como se mostraba en el trabajo de Alonso Muñoz y García Marí citado. 


\section{Datos sobre fruta picada.}

Otra medida de eficacia del tratamiento con quimioesterilizantes es la revisión de fruta picada.

El recuento de picadas no ha podido cumplirse totalmente porque, cuando éste alcanzaba el $2 \%$, teníamos que realizar un tratamiento total con malation para evitar pérdidas de cosecha en los huertos cedidos. De todos modos, puede servir como dato que, de las 4 parcelas tratadas con lufenuron, que tenían variedades tempranas, en dos fue conveniente la aplicación preventiva con malation, y en dos se mantuvieron las picadas por debajo del $2 \%$ sin ninguna aplicación de malation.

En este apartado también se puede destacar que hemos observado una relación entre el número de capturas y el de picadas.

Salvo en la "parcela lufenuron 12" (cítricos de variedad Marisol y Sanguinelli doblados de melocotones y ciruelos) la población de mosca se ha mantenido baja. Sin embargo, la "parcela lufenuron 2" tiene un mosquero donde las capturas se han disparado por encima de las 20 moscas/mosquero y día, durante el mes de agosto. Este mosquero se sitúa en una subparcela de variedad Marisol, a escasos 25 metros de una higuera que ha servido de huésped, durante el mes de agosto, para la reproducción de la mosca.

Con excepción de estas dos parcelas, los muestreos han dado un porcentaje de picadas por debajo del $2 \%$. Sin embargo, en fecha 17 de octubre, en la "parcela lufenuron 12 " el porcentaje de fruta picada es del 4,5\%, y la subparcela de Marisol de la "parcela lufenuron 2" un porcentaje del 10\%. Estas dos parcelas son las únicas que han superado el umbral de 0,5 moscas mosqueros y día. 


\section{III.4.- CONCLUSIONES.}

El control de la mosca de la fruta necesita nuevos métodos que reduzcan la población hasta niveles tolerables. En la actualidad, en la Comunidad Valenciana, cuando la población de mosca es elevada, se precisan para proteger la fruta 1 ó 2 tratamientos semanales terrestres, lo que en algunas variedades significa la realización de 8 a 10 tratamientos antes de la recolección. Por otra parte, cuando las variedades de cítricos cultivadas son tempranas los tratamientos químicos no son suficientes para el control de la mosca.

El método de esterilización es una alternativa al control químico, que puede disminuir las poblaciones, a medio plazo, hasta límites tolerables, y reducir o eliminar los tratamientos químicos. El descenso de la población mediante la esterilización disminuye la necesidad de dichos tratamientos, siendo posible incluso la supresión de los mismos.

De los ensayos de esterilización realizados, se puede concluir que la población de mosca es muy dinámica y es capaz de desplazarse cientos de metros en busca de huéspedes receptivos, lo que supone la necesidad de una estrategia global. Si esta premisa es necesaria en tratamientos químicos, en los tratamientos con quimioesterilizantes es más exigible. También se ha observado que la presencia de frutales de verano es un factor muy influyente en la dinámica de población, ya que ofrecen a la mosca un substrato donde reproducirse, en una época en la que la población de mosca es máxima y donde la ausencia de fruta receptiva es un factor limitante en su reproducción.

No se conoce un valor umbral de densidad de plaga, a partir del cual se deban realizar los tratamientos. El establecimiento de un umbral de tratamiento en Ceratitis capitata ha de tener en cuenta el estado de maduración del fruto, el porcentaje aceptable de fruta dañada y el nivel de población de la mosca. En cítricos, el envero es el punto a partir del cual la mosca realiza las puestas y, por lo tanto, en él comienza el período crítico de vigilancia de la 
población de mosca. El porcentaje de fruta dañada aceptable con esta plaga es prácticamente cero, ya que es una plaga que requiere cuarentena en algunos países importadores y, por lo tanto, un solo fruto dañado puede significar el rechazo de todo un envío.

El seguimiento de los niveles de población de mosca se realiza con mosqueros y atrayentes de distintos tipos. En la actualidad se utiliza, como atrayente, el TML que es más potente y responde mejor ante pequeñas variaciones de la población. El inconveniente de este atrayente es que sólo atrae machos y que, por lo tanto, no estamos valorando la población que realmente causa el daño en los frutos. No obstante, estas capturas se consideran como un índice representativo de la población. En este ensayo se observa que el TML ha sido más eficaz, para el seguimiento de la población, que el Tri-pack (que sí atrae hembras), ya que diferencia niveles de población, donde el Tri-pack no es capaz de diferenciarlos.

Con el TML hemos observado que niveles de población por encima de 0,5 moscas/mosquero y día pueden provocar daños superiores al $4 \%$ de la cosecha. Sin embargo, en ninguna de las parcelas donde las capturas han sido inferiores a 0,5 moscas/mosquero y día, se han observado daños por encima del $2 \%$.

La utilización de quimioesterilizantes trata de disminuir la población de mosca paulatinamente, generación tras generación, con lo que se pretende llegar un nivel de población por debajo del umbral de tolerancia. En el primer año de ensayo a gran escala de este método, se ha observado que una sola aplicación de placas protege durante toda la campaña. Si bien la verdadera potencia del método se observará en los próximos años, los resultados de este año muestran que la utilización de quimioesterilizantes, combinada con alguna aplicación de malation, ya resulta eficaz en el control de la mosca.

También es destacable el efecto que tiene el lufenuron sobre los huevos de la mosca. Si bien la picada de una mosca provoca un punto de discontinuidad de la corteza de los cítricos, y por lo tanto, en algunos casos, una pudrición del fruto, las larvas no llegan a eclosionar. 
Este método también puede resultar muy útil como apoyo de la técnica de machos estériles (SIT) que se está introduciendo en la actualidad en la cuenca mediterránea. El SIT requiere la suelta de al menos 50 machos estériles, por cada macho fértil, para asegurar el éxito de la suelta. Si, gracias a los quimioesterilizantes en campo, esterilizásemos una parte significativa de la población salvaje (lo cual resulta obviamente factible con los resultados de estos ensayos), la necesidad de machos esterilizados disminuiría enormemente, con el consiguiente ahorro en este costoso método de control.

Con los resultados de este ensayo no se pueden obtener conclusiones definitivas ya que la esterilización es un método de lucha cuyos resultados se observan tras varias generaciones tratadas. Sin embargo, los resultados de este primer año son esperanzadores, en cuanto al nivel de capturas observado tras varios meses de tratamiento.

En las zonas en que, por su orografía u orientación, la población de mosca es más elevada, los tratamientos de un año han producido un descenso importante de población, respecto a los blancos, aunque insuficiente para reducir la picada de mosca a niveles comercialmente tolerables. En los momentos en que la fruta está receptiva la aplicación de malation tampoco ha suprimido las picadas, lo que demuestra que sólo manteniendo la población en niveles bajos, las aplicaciones químicas son totalmente efectivas.

Como apunte final cabe señalar que este método de lucha contra Ceratitis capitata puede aplicarse en combinación con otros métodos de lucha además del SIT. La utilización de parásitos y depredadores, o la realización de pulverizaciones tradicionales de insecticidas en los períodos de máxima eficacia, pueden, al combinarse con esta técnica, conseguir un control más eficaz de la plaga. 


\begin{abstract}
ANEXO.
Los métodos quimioesterilizantes tienen una doble cara: suponen un arma de lucha muy potente para llegar a erradicar una determinada plaga, pero obtienen sus mejores resultados a medio-largo plazo.

La utilización del lufenuron como esterilizante no es una excepción a este hecho, lo que quiere decir que, si bien los resultados descritos en esta Tesis Doctoral han sido satisfactorios, el máximo rendimiento de esta forma de lucha se obtendrá tras su utilización en años sucesivos.

En las experiencias realizadas se ha obtenido un resultado significativo: la reducción importante de la población de mosca por métodos de esterilización. En los años sucesivos este descenso debe traducirse en una progresiva menor emergencia de adultos y por lo tanto en una disminución paulatina de la población.
\end{abstract}

Además, se han obtenido datos sobre evolución de la población, daño en fruta y datos climatológicos relacionados, que nos ayudarán en los ensayos de los próximos años.

La continuación de los ensayos, en gran escala, aportará nuevas luces a la quimioesterilización, ya que además de observar el efecto progresivo año a año, se irán perfilando las condiciones técnicas de los tratamientos. 


\section{BIBLIOGRAFÍA}




\section{BIBLIOGRAFIA}

Abbott W.S. 1925. "A method of computing the effectiveness of an insecticide". Journal of Economic Entomology. (18): 265-267.

Alonso Muñoz, D.; Soler Feliu J. M.; García Marí, F.; Blas Carreras M. 1999. "Control de la mosca de la fruta Ceratitis capitata (Wiedemann) en el cultivo de los cítricos". Levante Agrícola. $2^{\circ}$ Trimestre.204-211.

[D] Alonso Muñoz, D. y García-Marí, F.. 2000. "Evolución de la población de la mosca de la fruta Ceratitis capitata y su relación con el daño al fruto en cítricos". Trabajo de Investigación de Doctorado de la UPV. Código 1779/8.

DD Beroza, M.; Green, N.; Gertler, S.I.; Steiner, L.F.; Miyashita, D.H. 1961. "Insect attractants: new attractants for the Mediterranean fruit fly". Journal of Agricultural Food Chemistry. 9: 361-365.

Borkovec A. B. 1966. "Insect chemosterilants". Advances in pest control research. 71-143.

Budia, F. and Viñuela, E. 1996. "Effects of cyromazine on adult Ceratitis capitata (Diptera: Tephritidae) on mortality and reproduction". Journal Economic Entomology. 86: 826-831.

Cangussu, J.A. and Zucoloto, F.S. 1995. "Self-selection and perception threshold in adult females of Ceratitis capitata (Diptera, Tephritidae)". Journal of insect physiology. Vol. 41 (3): 223-227.

(1] Casana-Giner,-V.; Gandia-Balaguer,-A.; Mengod-Puerta,-C.; Primo-Millo,-J.; Primo-Yufera,-E. 1998. "Insect growth regulators as chemosterilants for Ceratitis capitata (Diptera: Tephritidae)". Journal Economic Entomology. Vol.92 (2). 303308. 
[C] Chinery, M. 1988. En "Guia de campo de los insectos de España y Europa"; Omega S.A. (ed.). Barcelona.

[D] Cangussu,J.A. and Zucoloto,F.S., 1995. "Self-selection and perception threshold in adult females of Ceratitis capitata (Diptera, Tephritidae)". Journal of Insect Physiology. Vol. 41 (3) p. 223-227.

[D] Duan,-J.J.; Prokopy,-R.J.; Yin,-C.M.; Bergweiler,-C.; Oouchi,-H. 1995. "Effects of pyriproxyfen on ovarian development and fecundity of Rhagoletis pomonella flies". Entomologia Experimentalis et Applicata. Vol.77 (1). 17-21.

Féron, M. 1959. "Attraction chimique du male de Ceratitis capitata Wied. (Dipt. Trypetidae) pour la femelle". C.R. Seances Acad. Sci. Ser. D., Sci. Nat (Paris). 248: $2403-2404$.

Déron, M. 1962. "L'instinct de reproduction chez la mouche Mediterranéenne des fruits Ceratitis capitata Wied. (Dipt. Trypetidae). Comportement de ponte”. Revue Pathol. Veget. et d'Entom. Agric. de France. 41: 1-129.

D] Fytizas, E. 1976. "Effect of TH6040 on Dacus Oleae Gmel (Diptera: Trypetidae) metamorphosis". Z.Angew.Entomol. 81: 440-444.

Gothilf, S. and Levin G, 1987. "Attraction of the Mediterranean fruit fly to ammonium and protein bait traps". Symposium of fruit flies of Economic importance. Pp.387-391.

[L] Jiménez-Peydro, R.; Gimeno-Martos, C.; López-Ferrer, J.; Serrano-Delgado, C. and Moreno-Marí, J. 1995. "Effects of the insect growth regulator cyromazine on the fecundity, fertility ans offspring development of Mediterranean fruit fly Ceratitis capitata Wiedemann (Diptera: Tephritidae)". Journal of Applied Entomology. 119, 135-138.

Katsoyannos,B.I.; Papadopoulos, N.T.; Heath, R.R.; Hendrichs, J.; Kouloussis, N.A. 1999. "Evaluation of synthetic food-based attractants for female 
Mediterranean fruit flies (Dipt., Tephritidae) in McPhail type traps". Journal of Applied Entomology. Vol. 123 (10): 607-612.

[D] Katsoyannos, B.I.; Papadopoulos, N.T.; Kouloussis, N.A.; Heath, R.; Hendrichs, J.. 1999b. "Method of assessing the fertility of wild Ceratitis capitata (Diptera: Tephritidae) females for use in sterile insect technique programs". Journal of Economic Entomology. Vol. 92 (3): 590-597.

Langley, P.A. and Hall, M.J.R.. 1986. "TseTse control by autosterilization". Parasit, Today, 2: 125-126

Martelli, G. 1910. “Alcune note intorno ai costumi ed ai della mosca dele arance Ceratitis capitata". Boll. Lab. Zool. Sci. Agric. Portici. 4, 120-127.

Mavrikakis, P.G.; Economopoulos A.P. and Carey J.R. 2000. "Continuous winter reproduction and growth of the Mediterranean fruit fly (Diptera: Tephritidae) in Heraklion, Crete, Southern Greece". Environmental entomology. Vol 29 (6): 1180-1187.

Del McLeay, W.S. 1829: "Notice of Ceratitis citriperda, an insect very destructive to oranges". Zool. Journ. IV, 475-482.

Moner, J.P.; Petit, V.R. y Bernat J.M. 1988. "Control de Ceratitis capitata (Wiedemann) en los cítricos españoles”. Phytoma España. 88: 35-39.

[D] Miranda MA; Alonso R. y Alemany A.. 2001. "Field evaluation of Medfly (Dipt., Tephritidae) female attractants in a Mediterranean agrosystem (Balearic Islands, Spain)" Journal of Applied Entomology. Vol. 125(6):333-339.

[Dd Prokopy, R.J. and Hendrichs, J. 1979. "Mating behaviour of Ceratitis capitata on a field-caged host tree". Annals of the Entomological Society of America. Vol 75, 642-648. 
[D] Robacker,D.C. 1995. "Attractiveness of a mixture of ammonia, methylamine and putrescine to Mexican fruit flies (Diptera: Tephritidae) in a citrus orchard". Florida Entomologist. Vol. 78 (4): 571-578.

[D] Ros, J.P. 1988. "La mosca mediterránea de la fruta, Ceratitis capitata (Wiedemann). Biología y métodos de control". Hojas divulgadoras del Ministerio de Agricultura, Pesca y Alimentación. 8/88 HD.

Sarasua, M.J. and Santiago-Alvarez, C.. 1983 "Effect of diflubenzuron on the fecundity of Ceratitis capitata". Entomologia Experimentalis et Applicata. Vol. 33: $223-225$.

Wharton R.A. 1987. "Biological control of fruit-infesting Tephritidae". Symposium of fruit flies of Economic importance. 323-332.

[d] Wiedemann C.R.W. 1824 "Analecta entomologica ex Museo regio Hafniae maxime congesta". Kiliae, Vol.124, 55.

[D] Wiedemann C.R.W. 1830. “Aussereuropaeische zweifluegelige Insekten, zweiter Theil. Hamm, in der Schulzischen Buchhandlung. Pp: 496-497.

Wong, T.T.Y.; Ramadan, M.M.; Herr, J.C.; McInnis, D.O.. 1992. "Suppression of a Mediterranean fruit fly (Diptera: Tephritidae) population with concurrent parasitoid and sterile fly releases in Kula, Maui, Hawaii". Journal of Economic Entomology. Vol. 85 (5). 1671-1681. 